Leibniz-Institut für Katalyse e.V.

an der Universität Rostock

\title{
Non-Noble Metal-Catalysed Carbonylative Transformations
}

\author{
Dissertation \\ In Kumulativer Form \\ zur Erlangung des akademischen Grades \\ Doctor rerum naturalium (Dr. rer. nat.) \\ der Mathematisch-Naturwissenschaftlichen Fakultät \\ der Universität Rostock
}

vorgelegt von

Yahui Li

geb. am 20. 05. 1989 in P. R. China

Rostock, 15.12.2017 
Die vorliegende Arbeit entstand in der Zeit von October 2015 bis January 2018 am Leibniz-Institut für Katalyse e.V. an der Universität Rostock.

The thesis has been performed at Lebniz Institute for Catalysis at the University of Rostock in the period from October 2015 to May 2018 and was supervised by Prof. Dr. Matthias Beller, Prof. Dr. Armin Börner, and Dr. Xiao-Feng Wu

\section{Gutachter:}

\section{Professor Dr. Matthias Beller}

leibniz-institut für katalyse ev. an der universität rostock

Albert-Einstein-Straße 29A, 18059 Rostock, Deutschland

\section{Gutachter:}

Prof. Dr. Troels Skrydstrup

Interdisciplinary Nanoscience Center, Department of Chemistry, Aarhus University

Gustav Wieds Vej 14, 8000 Aarhus C, Denmark

Tag der Einreichung: 30. 01. 2018

Tag der Verteidigung: 12. 06. 2018 
The scourge is often filled with ignorance, and talent is more trapped in the place.

-- Ouyang Xiu

袺患常积于忽微，而智勇多困于所溺。-- 欧阳修 


\section{Acknowledgement}

How time flies! I am going to finish my PhD study in a twinkling of an eye.

First of all, I would like to express my deepest appreciation to my supervisor Prof. Dr. Matthias Beller for accepting me as a PhD student in LIKAT. His commitment and unique insight towards scientific research, also his kind and patient guidance and encouragement inspire me to be a responsible and earnest researcher.

Secondly, I am truly grateful to my group leader Dr. Xiao-Feng Wu for his outstanding cooperation and numerous scientific discussions. I was deeply impressed by his optimistic attitude towards life and work.

My sincere thanks also go to Dr. Haijun Jiao, Dr. Kaiwu Dong, Dr. Weiping Liu, Dr. Wu Li, Chaoren Shen, Zechao Wang, Fengxiang Zhu, Zhiping Yin and Jianxing $\mathrm{Xu}$ for the excellent collaboration and the obliging discussions.

I would also like to thank my dear colleagues, Jiawang Liu, Shaoke Zhang, Tian Xia, Delong Han, Jiadong Xiao, Lin Wang, Wei Zhou, Yaoyuan Zhang, Zhihong Wei, Teng Li, Bernhard Stadler, Florian Weniger for sharing a comfortable and pleasant working atmosphere, friendship, and unforgettable moments.

In addition, I am greatly indebted to the teams of the analytic department and technical department in LIKAT. I'm grateful for their performance and assistance throughout this work. Special thanks go to Dr. Christine Fischer, Mr. Andreas Koch, Mrs. Susanne Schareina and Mrs. Susann Buchholz for taking care of my GC-MS and NMR samples and Mr. Andreas Hutter for his excellent repairing techniques.

I would like to thank all my friends and colleagues for the happy time I spent in LIKAT.

I appreciate China Scholarship Council for the financial support during my three years' PhD study.

Last but not the least; I would like to thank my parents for their patience, love and the constant encouragements, which are essential for me during my PhD study. 


\title{
Abstract
}

\section{Non-Noble Metal-Catalysed Carbonylative Transformations}

Yahui Li

\author{
Leibniz-Institut für Katalyse e.V. an der Universität Rostock
}

The dissertation is mainly concerned with non-noble metal-catalyzed carbonylative reactions. More specifically, copper, iron and manganese catalysed carbonylation reactions are presented. The resulting aliphatic imides, amides and esters constitute important intermediates for both organic synthesis and chemical industries. Regarding methodology developments, firstly a copper-catalyzed carbonylation of alkanes and amides is presented. Additionally, different nucleophiles including amine, alcohols were also used. Furthermore, an unexpected copper-catalysed carbonylative acetylation of amines is also presented. Also, a practical and general manganese-catalyzed carbonylative coupling of alkyl lodides with amides allows producing synthetically useful imides in good yields. At last, a coppercatalyzed carbonylative four components reaction of ethene and aliphatic olefins. In all the above mentioned areas systematic catalyst optimization studies were performed and the scope and limitations of the respective protocol were presented.

\section{Nicht-Edel metallkatalysierte carbonylierende Transformationen}

Yahui Li

Leibniz-Institut für Katalyse e.V. an der Universität Rostock

Die vorliegende Dissertation befasst sich hauptsächlich mit Nicht-Edelmetall-katalysierten Carbonylierungen. Insbesondere werden Kupfer-, Eisen- und Mangan-katalysierte Carbonylierungsreaktionen vorgestellt. Die resultierenden aliphatischen Imide, Amide und Ester sind wichtige Zwischenprodukte sowohl für die organische Synthese als auch für die chemische Industrie. Bezüglich methodischer Entwicklungen wird zunächst eine kupferkatalysierte Carbonylierung von Alkanen und Amiden vorgestellt. Zusätzlich wurden verschiedene Nucleophile, einschließlich Amine und Alkohole eingesetzt. Darüber hinaus wird eine unerwartete kupferkatalysierte carbonylierende Acetylierung von Aminen vorgestellt. Eine effiziente und allgemeingültige Mangan-katalysierte carbonylierende Kupplung von Alkyliodiden mit Amiden ermöglicht die Herstellung synthetisch nützlicher Imide in guten Ausbeuten. Abschließend wird eine kupferkatalysierte carbonylierende Vierkomponentenreaktion von Ethen und aliphatischen Olefinen beschrieben. In allen oben genannten Bereichen wurden systematische Katalysatoroptimierungsstudien durchgeführt und der Umfang und die Limitierungen des jeweiligen Protokolls vorgestellt. 


\section{List of abbreviations}

\begin{tabular}{|c|c|}
\hline acac & Acetylacetone \\
\hline Ac & Acetyl \\
\hline Ad & Adamantyl \\
\hline$B u$ & Butyl \\
\hline cat. & Catalyst \\
\hline $\mathrm{CO}$ & Carbon monoxide \\
\hline$C p$ & Cyclopentadienyl \\
\hline CTAB & Cetyltrimethylammonium bromide \\
\hline$C y$ & Cyclohexyl \\
\hline$D A B C O$ & 1,4-Diazabicyclo[2.2.2]octane \\
\hline$D B U$ & 1,8-Diazabicyclo[5.4.0]undec-7-ene \\
\hline$D C P$ & Dicumyl peroxide \\
\hline DiPEA & Diisopropylethylamine \\
\hline DMAC & $\mathrm{N}, \mathrm{N}$-dimethylacetamide \\
\hline DME & Dimethoxyethane \\
\hline DMEDA & 1,2-Dimethylethylenediamine \\
\hline$D M F$ & Dimethylformamide \\
\hline DMPA & $N, N^{\prime}$-Dimethyl-1,3-propanediamine \\
\hline DMSO & Dimethyl sulfoxide \\
\hline DMPO & 5,5-Dimethyl-1-pyrroline- $N$-oxide \\
\hline DTBP & Di-tert-butyl peroxide \\
\hline DPEPhos & (Oxydi-2,1-phenylene)bis(diphenylphosphine) \\
\hline DPPE & 1,2-Bis(diphenylphosphino)ethane \\
\hline$d p p b z$ & 1,2-Bis(diphenylphosphino)benzene \\
\hline EtOH & Ethanol \\
\hline $\boldsymbol{h}$ & Hour \\
\hline iso or $i$ & Sum of branched products \\
\hline$L$ & Ligand \\
\hline $\mathrm{MeCN}$ & Acetonitrile \\
\hline NHCs & $N$-heterocyclic carbenes \\
\hline $\mathrm{MeOH}$ & Methanol \\
\hline NMI & $N$-methylimidazole \\
\hline $\mathrm{NuH}$ & Nucleophile \\
\hline $\mathrm{NuH}$ & Nucleophile \\
\hline
\end{tabular}




\begin{tabular}{|c|c|}
\hline OTf & Trifluoromethanesulfonyl \\
\hline PEG-400 & Polyethylene glycol 400 \\
\hline$P h$ & Phenyl \\
\hline PPN & Bis(triphenylphosphine)iminium \\
\hline TAED & Tetraacetylethylenediamine \\
\hline$T B D$ & 1,5,7-Triazabicyclo- [4.4.0]dec-5-ene \\
\hline TBHP & Tertbutyl hydroperoxide solution \\
\hline TDA-1 & Tris[2-(2-methoxyethoxy)ethyl]amine \\
\hline TEMPO & 2,2,6,6-Tetramethylpiperidine-1-oxyl \\
\hline TFA & Trifluoroacetic acid \\
\hline THF & Tetrahydrofuran \\
\hline TMEDA & Tetramethylethylenediamine \\
\hline TMHD & 2,2,6,6-Tetramethyl-3,5- heptanedionate \\
\hline$T M U$ & 1,1,3,3-Tetramethylurea \\
\hline$T P P$ & Tetraphenylporphyrin \\
\hline$x$ & Leaving group \\
\hline
\end{tabular}




\section{Table of Contents}

Acknowledgement

Abstract

1. Introduction .1

1.1 Mn-catalysed carbonylation reactions

1.2 Fe-catalysed carbonylation reactions

1.3 Cu-catalysed carbonylation reactions

1.4 Co-catalysed carbonylation reactions

1.5 Ni-catalysed carbonylation reactions

2. Objectives of this work

3. Summary of works

3.1 Copper-catalysed carbonylative coupling of cycloalkanes and amides

3.2 Copper-catalysed carbonylative synthesis of aliphatic amides from alkanes and primary amines via $\mathrm{C}\left({ }_{\mathrm{sp} 3}\right)-\mathrm{H}$ bond activation.

3.3 Copper-catalysed alkoxycarbonylation of alkanes with alcohols. .48

3.4 An unexpected copper-catalysed carbonylative acetylation of amines. .54

3.5 Practical and general manganese-catalysed carbonylative coupling of alkyl iodides with amides. .58

3.6 Copper-catalysed carbonylative four components reaction of ethene and aliphatic olefins. .64

4. References... .69 


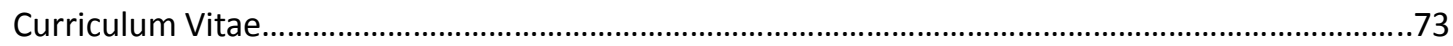

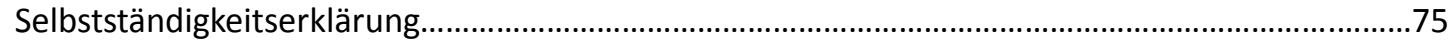




\section{Introduction}

Since the discovery and identification of carbon monoxide by de Lassone and W. C. Crukshank in 18th century, the exploration of the utilizations of this small molecular in organic chemistry have become one of the core topics since then. And terms 'carbonylation' and 'carbonylative' are given specially for carbon monoxide related organic transformations. Due to the interests of carbon monoxide related transformations, continues efforts have been attracted from generations of organic chemists and many novel procedures have been developed. ${ }^{[1]}$ In nowadays, carbonylation reactions have already become one of the most straightforward choices for the synthesis of carbonyl-containing compounds, and many related procedures have been industrialized. ${ }^{[2]}$ In addition to the importance of carbonyl-containing chemicals, through carbonylative transformations, the carbon chain of the parent compounds can be easily increased by introducing one or several molecules of CO which represents one of the cheapest C1 source. However, concerning the transition metal catalysts applied, most of the efforts have been put on noble metal catalysts. ${ }^{[1-6]}$ Although these catalyst systems have advantages in reactivity and efficiency, their high costs and toxicity, and the demand of even more expensive but non-reusable phosphine ligands still limits their applications in large scale.

On the other hand, especially in nowadays, the developments of economic and environmental benign synthetic methods become an important but challenging goal in organic chemistry. And the exploration of non-noble catalysts in organic synthesis proved to be one of the ideal choices, due to their advantages such as abundance, low price, low toxicity and etc. ${ }^{[7]}$ Nevertheless, to the best of our knowledge, there is no summery work on non-noble metal catalysed carbonylative reactions has been published so far. Considering the importance of both topics and also based on our ongoing research interests, we become interested to fill this gap. We also hope that this introduction can intrigue and promote the further developments on this interesting area.

The present dissertation highlights recent achievements in the main achievements on non-noble metal ( $\mathrm{Mn}, \mathrm{Fe}, \mathrm{Cu}, \mathrm{Co}, \mathrm{Ni}$ ) catalysed carbonylative reactions. It is also presented as a cumulative collection of publications which have been already released in international journals. 
1.1 Mn-catalysed carbonylation reactions

Manganese, as the twelfth abundant element and the third most abundant transition metal in the earth, have properties such as low costs and relative low toxicity. Many novel manganese-catalysed organic reactions have been reported during the past decades. ${ }^{[8 a-8 b]}$ As early as in 1965, F. Calderazzo reported the pioneer work on manganese-catalysed carbonylation of amines. Using decacarbonyldimanganese and pentacarbonylmethylmanganese as the catalyst, primary aliphatic amines can be transformed to the corresponding 1,3-dialkylureas in good yields (Scheme 1). ${ }^{[8 c]}$

$$
2 \mathrm{R}-\mathrm{NH}_{2}+\mathrm{CO} \frac{\mathrm{Mn}_{2}(\mathrm{CO})_{10} / \mathrm{CH}_{3} \mathrm{Mn}(\mathrm{CO})_{5}}{\text { Heptane or } \mathrm{THF}, 180-200^{\circ} \mathrm{C}} \mathrm{R}_{\mathrm{H}_{\mathrm{H}}}
$$

Scheme 1. Manganese-catalysed carbonylation of amines.

Later on, Watanabe and co-workers studied the application of manganese catalyst in the carbonylative coupling of alkyl iodides with different nucleophiles. ${ }^{[9 a, 9 b]}$ Alkyl esters and amides can be effectively produced by using alcohols and amines as the reaction partners. Additionally, thiols, azide and hydride can be used as nucleophiles as well (Scheme 2, a). Additionally, alkyl bromides can also be applied as the substrates by adding $\mathrm{Nal}$ as the additive. Here, high pressure of carbon monoxide and high temperature or irritation is required. In 1998, Kang and co-workers reported a $\mathrm{MnCl}_{2} \cdot 4 \mathrm{H}_{2} \mathrm{O}$ (5 mol\%)-catalysed carbonylative cross-coupling of organostannanes with hypervalent iodonium salts. ${ }^{[10]}$ Under CO atmosphere (1 bar), good yields of the desired biaryl ketones can be produced (Scheme 2, b). Interestingly, biaryls can be formed in good yields with the same substrates under the same conditions just in the absence of CO.

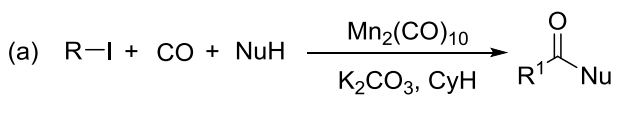
$\mathrm{Nu}=\mathrm{OH}, \mathrm{NR} '$, OR', SR', H

(b) $\mathrm{ArSnBu}_{3}+\mathrm{CO}+\mathrm{Ar}^{\prime} \mathrm{I}^{+} \mathrm{PhBF}_{4}^{-} \frac{\mathrm{MnCl}_{2} \cdot 4 \mathrm{H}_{2} \mathrm{O}}{\mathrm{NMP} / \mathrm{THF}, 60^{\circ} \mathrm{C}} \mathrm{Ar}_{\mathrm{Ar}^{\prime}}$

Scheme 2. Mn-catalysed carbonylative coupling of iodides.

More recently, Alexanian and co-workers reported a manganese-catalysed intramolecular carbonylative cyclization of alkenes with alkyl iodides. ${ }^{[11]}$ In the presence of $2.5 \mathrm{~mol} \% \mathrm{Mn}_{2}(\mathrm{CO})_{10}$ and $\mathrm{KHCO}_{3}$ (1 equiv.) under $\mathrm{CO}$ (10 bar) pressure in $\mathrm{EtOH}$, five-, six- and seven-membered carbocycles and heterocycles were synthesised in good yields with good diastereoselectivity (Scheme 3). A possible 
reaction mechanism based on radical nature was provided as well. The reaction started with the homolysis of $\mathrm{Mn}-\mathrm{Mn}$ bond in $\mathrm{Mn}_{2}(\mathrm{CO})_{10}$ dimer to generate the corresponding $\bullet \mathrm{Mn}(\mathrm{CO})_{5}$ radical. Then the $\bullet \mathrm{Mn}(\mathrm{CO})_{5}$ radical abstract iodine atom from the substrates and give rise to the carbon-centered radical, which undergoes an alkene addition and generates a new carbon radical. The newly formed carbon radical will be trapped by manganese to produce the corresponding acylmanganese intermediate which will be provide the final products after reacted with alcohols.

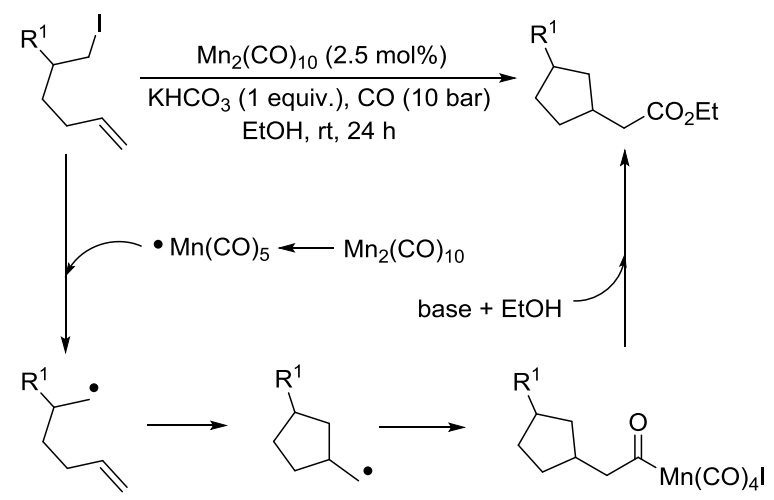

Scheme 3. Mn-catalysed intramolecular carbonylative cyclization of alkenes with alkyl iodides.

\subsection{Fe-catalysed carbonylation reactions}

The exploring of iron salts as catalysts in organic synthesis has become an attractive topic due to its abundance, low price, high biological compatibility, and also rich oxidation states from -2 to +6 .

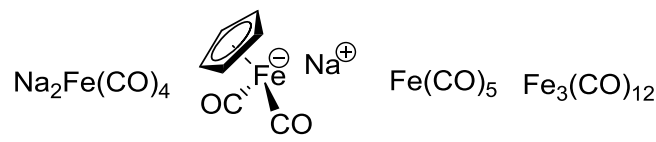

Figure 1. Iron catalysts for carbonylation reactions.

Since the middle of 20th century, chemists have started to explore iron-promoted carbonylation reactions and the most often used reagents are shown in Figure 1. $\mathrm{Na}_{2} \mathrm{Fe}(\mathrm{CO})_{4}$ which also known as Collman reagent was commonly applied as a stiometric carbonylation reagent, with several different preparation procedures have been developed. ${ }^{[12]}$ The original method needs expensive sodium-mercury amalgam (Scheme 4, formula 1) and this factor limited its scale-up, but a more practical procedure was developed later on (Scheme 4, formula 2). The latest process makes the preparation conditions milder, but the needs of bubbling with CO gas make the manufacture more risk (Scheme 4, formula 3). 


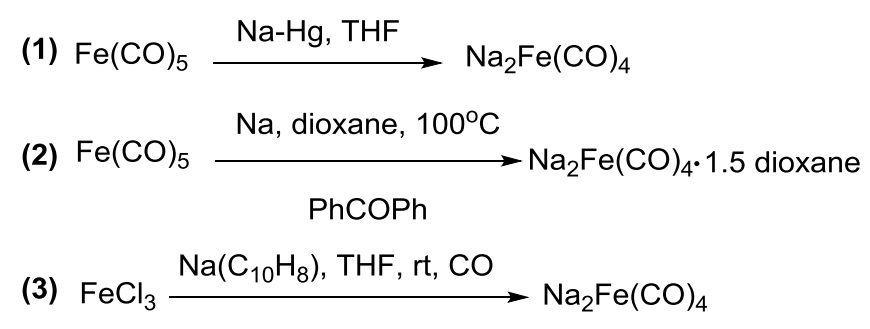

Scheme 4. The synthesis of $\mathrm{Na}_{2} \mathrm{Fe}(\mathrm{CO})_{4}$.

In 1975, Collman found disodium tetracarbonylferrate can be used in a wide range of useful synthetic reactions (Scheme 5). ${ }^{[13]} \mathrm{Na}_{2} \mathrm{Fe}(\mathrm{CO})_{4}$ can be considered as a kind of a Grignard reagent. Reactions that use $\mathrm{Na}_{2} \mathrm{Fe}(\mathrm{CO})_{4}$ as the catalyst has advantages of high yields and good tolerance of different functional groups. But it also has some limitations, such as tertiary aliphatic halides cannot be used due to its satirical and allylic halides cannot be employed due to the stable 1,3-diene $\cdot \mathrm{Fe}(\mathrm{CO})_{3}$ Intermediate.

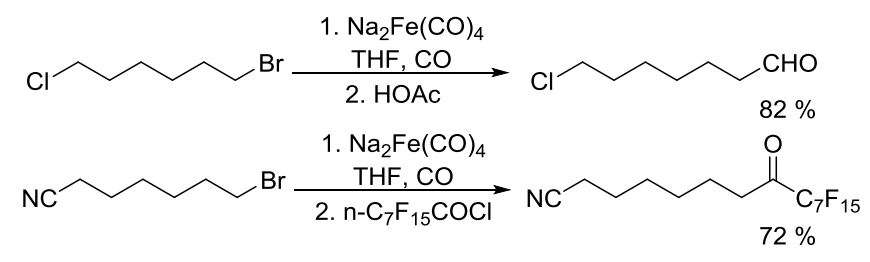

Scheme 5. $\mathrm{Na}_{2} \mathrm{Fe}(\mathrm{CO})_{4}$-mediated carbonylation reactions.

After that, he also found $\mathrm{Na}_{2} \mathrm{Fe}(\mathrm{CO})_{4}$ can be used for the synthesis of carboxylic acids, esters and amides (Scheme 6). The reaction begin with an $\mathrm{S}_{\mathrm{N}} 2$ displacement at carbon or an oxidative addition of the alkyl bromides to the $\mathrm{Na}_{2} \mathrm{Fe}(\mathrm{CO})_{4}$ and affords intermediate 2. In the presence of $\mathrm{CO}$, acyl complexes 3 can be generated. Various carboxylic acids, ${ }^{[14]}$ esters, ${ }^{[14]}$ amides, $^{[14]}$ ketones ${ }^{[15]}$ and hemifluorinated ketones ${ }^{[16]}$ can be produced by reacting the complex with proper nucleophiles.

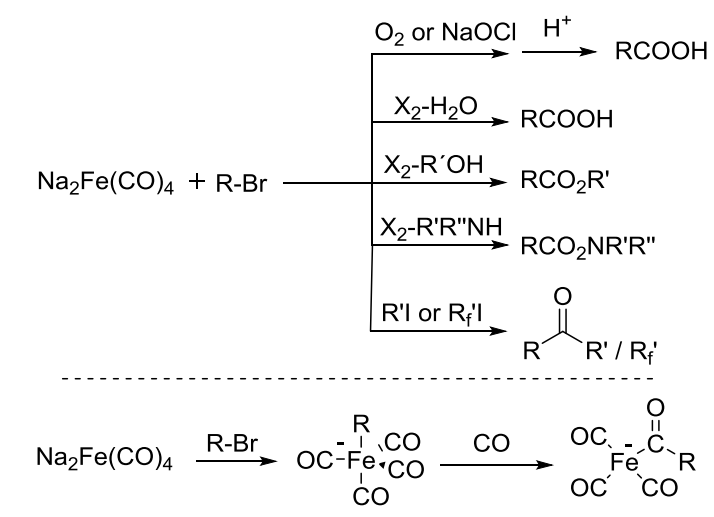

Scheme 6. $\mathrm{Na}_{2} \mathrm{Fe}(\mathrm{CO})_{4}$-mediated carbonylative transformations.

In 1970, Cooke found using sodium tetracarbonylferrate as the catalyst, alkyl bromides can be 
transformed into the corresponding aldehydes (Table 2). ${ }^{[17]}$ The reaction begin with the oxidative addition of the alkyl bromides to the $\mathrm{Na}_{2} \mathrm{Fe}(\mathrm{CO})_{4}$ and affords intermediate 2 or 3 . Then triphenylphosphine been add to the intermediate and give the intermediate 4. Finally, intermediate 4 will be protonated by acetic acid to give the acyl iron hydride intermediate 5 which undergoes reductive elimination to yield the desired aldehyde (Scheme 7).

Table 2. $\mathrm{Fe}(\mathrm{CO})_{5}$-mediated alkyl bromides to aldehydes.

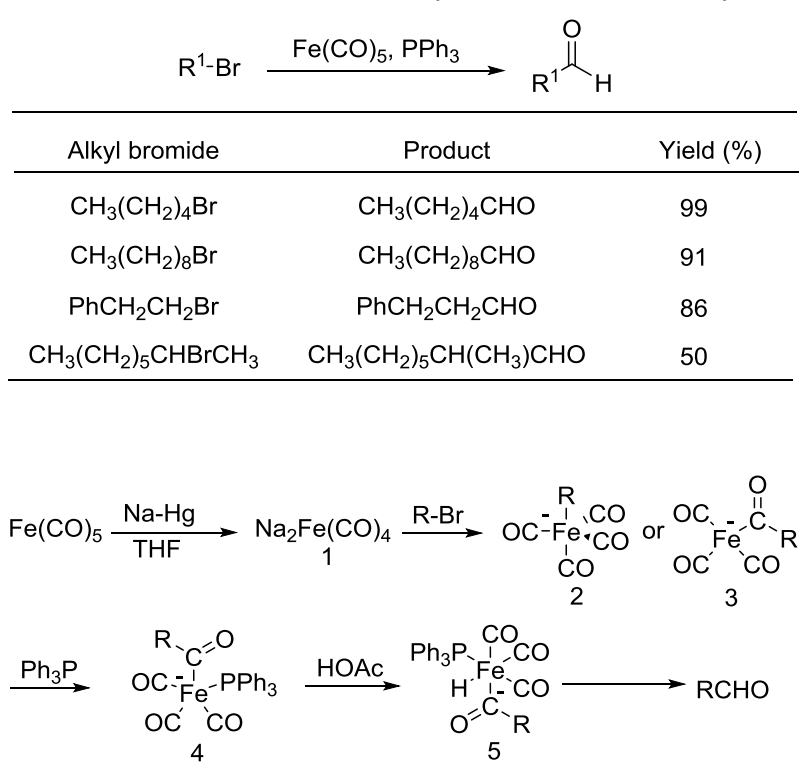

Scheme 7. Mechanism of Fe(CO) $)_{5}$-mediated aldehydes synthesis.

Nitro-containing compounds hold an important role in organic chemistry. In 1981, a procedure for converting nitro compounds to the corresponding formamides and carbamate esters by using iron and ruthenium carbonyl as catalyst system was reported by Alper and Hashem. ${ }^{[18]}$ These reactions have features of mild conditions $\left(60^{\circ} \mathrm{C}\right.$, atmospheric pressure of $\mathrm{CO} / \mathrm{H}_{2}$; Table 3).

Table 3. $\mathrm{Fe}_{3}(\mathrm{CO})_{12} / \mathrm{Ru}_{3}(\mathrm{CO})_{12}$-catalysed transformation of nitro compounds to the formamides and carbamate esters.

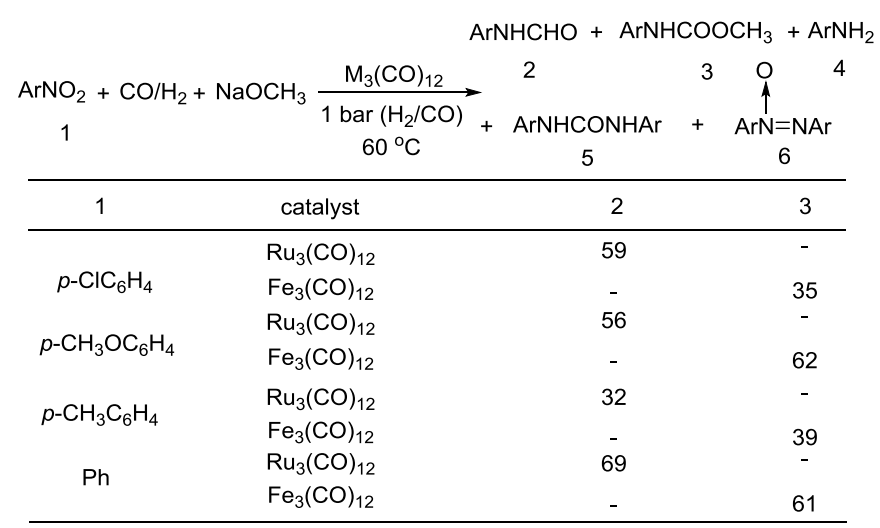


In 1992, Eaton and co-workers reported an interesting iron-catalysed carbonylative [4+1] cycloaddition reaction. ${ }^{[19]}$ In the presence of $\mathrm{Fe}(\mathrm{CO})_{5}(10 \mathrm{~mol} \%)$ as the catalyst and $\mathrm{CO}$, conjugated diallenes were transformed into the desired 2,5-diakylidenecyclo-3-pentenones in good yields (Table 4).

Table 4. $\mathrm{Fe}(\mathrm{CO})_{5}$-catalysed $[4+1]$ cycloaddition reaction.

\begin{tabular}{|c|c|c|c|c|}
\hline $\mathrm{R}^{1}$ & $R^{2}$ & $R^{3}$ & $R^{4}$ & Yield \% \\
\hline $\mathrm{C}\left(\mathrm{CH}_{3}\right)_{3}$ & $\mathrm{CH}_{3}$ & $\mathrm{C}\left(\mathrm{CH}_{3}\right)_{3}$ & $\mathrm{CH}_{3}$ & $72 \%$ \\
\hline $\mathrm{C}_{6} \mathrm{H}_{5}$ & $\mathrm{CH}_{3}$ & $\mathrm{C}_{6} \mathrm{H}_{5}$ & $\mathrm{CH}_{3}$ & $81 \%$ \\
\hline
\end{tabular}

Soon later, the same group also succeeded to extend their substrates to allenyl ketones ${ }^{[20 a]}$ and allenyl imines. ${ }^{[20 \mathrm{~b}]}$ With iron as the catalyst via carbonylative [4+1] cycloaddition involving both $\mathrm{C}-\mathrm{O}$ and $\mathrm{C}-\mathrm{N}$ bond formation, the desired five-membered heterocycles were formed in good yields (Scheme 8, a). In their proposed reaction mechanism, irradiation of $\mathrm{Fe}(\mathrm{CO})_{5}$ was necessary to give the active species and then reacted with the starting substrates to form the complex A. Metallocycle B was be formed through insertion and followed by $\mathrm{CO}$ insertion to give the complex $\mathrm{C}$ which will give the final product after reductive elimination.

The group of Rueck-Braun developed a series of $\left[\mathrm{Cp}(\mathrm{CO}){ }_{2} \mathrm{Fe}\right] \mathrm{Na}$-mediated cyclocarbonylations of $\beta$-bromo enals to $\gamma$-lactams and $\gamma$-lactones (Scheme $8, \mathrm{~b}) .{ }^{[21]}$ Iron substituted $(Z)$-enals were formed as the key intermediates, after reacted with Grignard reagents or organolithiums the corresponding 5 -substituted lactams or $y$-lactones were formed in moderate to good yields. These methodologies provide alternative procedures for the five-membered lactones preparation under mild conditions and some reaction mechanism was also studied, but the necessary of equivalent amount of iron complex still leave space for further improvement.

a)
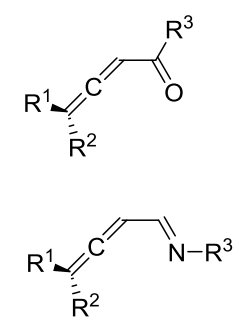

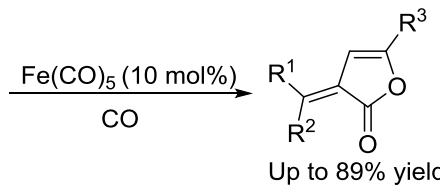

$\underset{\mathrm{CO}}{\stackrel{\mathrm{Fe}(\mathrm{CO})_{5}(10 \mathrm{~mol} \%)}{\longrightarrow}}$
Up to $89 \%$ yield

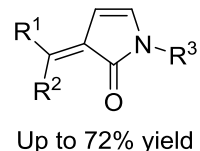


b)<smiles>[R]C(=O)C([R])=C([R])Br</smiles>

Scheme 8. Iron-catalysed [4+1] cycloaddition reactions.

In 1989, Brunet and Taillefer developed a $\mathrm{Fe}(\mathrm{CO})_{5}-\mathrm{CO}_{2}(\mathrm{CO})_{8}$ bimetallic system for the carbonylative transformation of aryl iodides (Scheme 9). Using this bimetallic system, iodobenzene can be transformed into benzoic acid ${ }^{[22]}$ or benzophenone under 1 bar of carbon monoxide at $60{ }^{\circ} \mathrm{C} .{ }^{[23]}$ The combination of $\mathrm{Bu}_{4} \mathrm{NBr}$ and $\mathrm{EtOH}$ was found critical. And the function of ethanol was to extract salt $\left[\mathrm{NBu}_{4}\right]^{+} \cdot\left[\mathrm{HFe}(\mathrm{CO})_{4}\right]^{-}$from water to the organic layer. In the absence of ethanol, iodobenzene can be transformed into benzophenone in fair yield.

(1) $\mathrm{Phl} \frac{\mathrm{Fe}(\mathrm{CO})_{5}-\mathrm{Co}_{2}(\mathrm{CO})_{8}, \mathrm{NaOH} / \mathrm{PhH} / \mathrm{EtOH}}{\mathrm{NBu}_{4} \mathrm{Br}, \mathrm{CO}(1 \mathrm{bar}), 60^{\circ} \mathrm{C}} \mathrm{PhCOONa}$
(2) $\mathrm{Phl} \frac{\mathrm{Fe}(\mathrm{CO})_{5}-\mathrm{Co}_{2}(\mathrm{CO})_{8}, \mathrm{NaOH} / \mathrm{PhH}}{\mathrm{NBu}_{4} \mathrm{Br}, \mathrm{CO}(1 \mathrm{bar}), 60^{\circ} \mathrm{C}} \underset{\mathrm{Ph}}{\mathrm{Ph}}+\mathrm{PhCOONa}$

Scheme 9. $\mathrm{Fe}(\mathrm{CO})_{5}-\mathrm{CO}_{2}(\mathrm{CO})_{8}$ bimetallic-catalysed carbonylation

Periasamy and co-workers developed a carbonylative transformation of $\mathrm{R}_{2}{ }_{2} \mathrm{BI}$ in 1991 . In the presence of $\mathrm{NaCo}(\mathrm{CO})_{4}$ or $\mathrm{Na}_{2} \mathrm{Fe}(\mathrm{CO})_{4}$, symmetric dialkyl ketones can be formed after $\mathrm{H}_{2} \mathrm{O}_{2} / \mathrm{OH}$ oxidation (Table 5). ${ }^{[24]}$ Here the $\mathrm{R}_{2}{ }_{2} \mathrm{BI}$ applied was prepared in situ by reacting of alkene with $\mathrm{IH}_{2} \mathrm{~B}: \mathrm{N}(\mathrm{Et})_{2} \mathrm{Ph}$ at room temperature in benzene. This method provides a straightforward pathway for the synthesis of symmetric dialkyl ketones from alkenes.

Table 5. Carbonylation of $\mathrm{R}_{2} \mathrm{BI}$ in the presence of $\mathrm{NaCo}(\mathrm{CO})_{4}$ or $\mathrm{Na}_{2} \mathrm{Fe}(\mathrm{CO})_{4}$.

\begin{tabular}{|c|c|c|c|}
\hline Entry & Alkene & Product & Yield \\
\hline 1 & $\mathrm{C}_{4} \mathrm{H}_{9} \mathrm{CH}=\mathrm{CH}_{2}$ & $\left(\mathrm{C}_{4} \mathrm{H}_{9} \mathrm{CH}_{2}-\mathrm{CH}_{2}\right)_{2} \mathrm{C}=\mathrm{O}$ & 76 \\
\hline 2 & $\mathrm{C}_{6} \mathrm{H}_{13} \mathrm{CH}=\mathrm{CH}_{2}$ & $\left(\mathrm{C}_{6} \mathrm{H}_{13} \mathrm{CH}_{2}-\mathrm{CH}_{2}\right)_{2} \mathrm{CO}$ & 72 \\
\hline 3 & & & 85 \\
\hline 4 & & & 75 \\
\hline
\end{tabular}

Later on, Periasamy and co-workers reported a homo-coupling reaction of $\mathrm{Na}(\mathrm{RCO}) \mathrm{Fe}(\mathrm{CO})_{4}$ with 
$\mathrm{CuCl}$ or $\mathrm{I}_{2}$ as the oxidant to produce 1,2-diketones (Scheme 10 ). ${ }^{[25]}$ In this transformation, $\mathrm{Na}(\mathrm{RCO}) \mathrm{Fe}(\mathrm{CO})_{4}$ reacted with $\mathrm{CuCl}$ at $25{ }^{\circ} \mathrm{C}$ in THF to form the desired 1,2-diketones in 70-90\% yields. In their mechanistic investigations they found the formation of 1,2-diketone takes place through the decomposition of $\mathrm{Cu}(\mathrm{RCO}) \mathrm{Fe}(\mathrm{CO})_{4}$ or I(RCO)Fe $(\mathrm{CO})_{4}$ to $\mathrm{RCOFe}(\mathrm{CO})_{4}$ followed by the formation of $\eta^{2}$ complexes of 1,2-diketones intermediates. However, single-electron reduction pathway cannot be excluded.

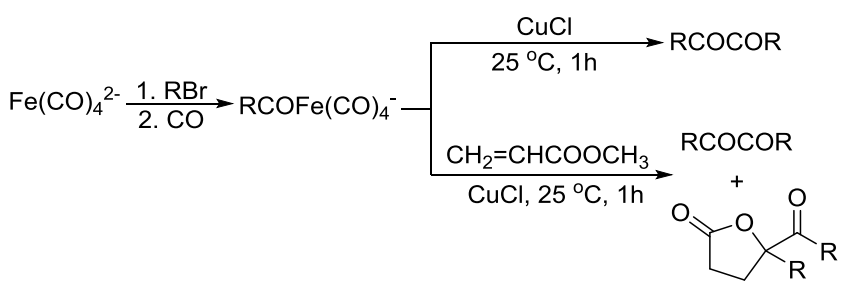

Scheme 10. $\mathrm{Fe}(\mathrm{CO})_{4}{ }^{2-}-\mathrm{CuCl}$ mediated carbonylation

In 1996, Brunet, Periasarny and their co-workers developed an novel method for double carbonylation transformation of alkynes using $\mathrm{NaHFe}(\mathrm{CO})_{4}$ as the catalyst (Table 6). ${ }^{[26]}$ This method contains three steps: i) $\mathrm{NaHFe}(\mathrm{CO})_{4}$ react with $\mathrm{Mel}$ to generate the active reagent; ii) the formed reagent reacted with alkynes to form the key intermediate and iii) subsequently oxidized by $\mathrm{CuCl}_{2}$ to give the corresponding cyclobutenediones in $27-42 \%$ yields and together with the formation of $\alpha, 8$-unsaturated carboxylic acids.

Table 6. Double carbonylation of alkynes using $\mathrm{NaHFe}(\mathrm{CO})_{4}$.

Entry


After that, they found $\mathrm{NaH},{ }^{[27]} \mathrm{NaBH}_{4},{ }^{[28]}$ amines, ${ }^{[29]} \mathrm{Me}_{3} \mathrm{NO}^{[30]}$ and $t-\mathrm{BuOK}^{[31]}$ can also be used to enhance the reactivity of $\mathrm{Fe}(\mathrm{CO})_{5}$ and $\mathrm{Fe}_{3}(\mathrm{CO})_{12}$ (Scheme 11). Compared with the previous method, the reaction become more selective and give cyclobutenediones as the only product. In the presence of excess amount of amine oxide, cyclic anhydrides can be observed.

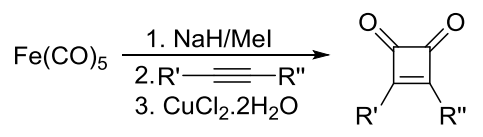

$$
\begin{aligned}
& \mathrm{Fe}(\mathrm{CO})_{5} \frac{1 . \mathrm{NaBH}_{4} / \mathrm{AcOH}^{\prime}}{2 \cdot \mathrm{R}^{\prime} \overline{\overline{\bar{m}}} \mathrm{R}^{\prime \prime}}{ }_{\mathrm{R}^{\prime}}^{\text {3. } \mathrm{CuCl}_{2} \cdot 2 \mathrm{H}_{2} \mathrm{O}} \\
& \mathrm{Fe}_{3}(\mathrm{CO})_{12} \frac{\substack{\text { 2. } \mathrm{R}-\mathrm{C} \equiv \mathrm{C}_{3} \mathrm{~N}-\mathrm{O} \\
\text { 3. } \mathrm{CuCl}_{2} \cdot 2 \mathrm{H}_{2} \mathrm{O}}}{\mathrm{R}}
\end{aligned}
$$

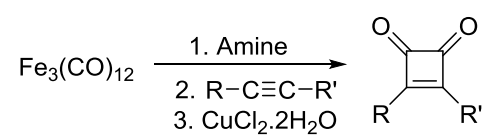

$$
\begin{aligned}
& \mathrm{Fe}_{3}(\mathrm{CO})_{12} \frac{\begin{array}{l}
1 . t-\mathrm{BuOK} \\
\text { 2. } \mathrm{R}-\mathrm{C} \equiv \mathrm{C}-\mathrm{R}^{\prime} \\
\text { 3. } \mathrm{CuCl}_{2} \cdot 2 \mathrm{H}_{2} \mathrm{O}
\end{array}}{\mathrm{R}}
\end{aligned}
$$

Scheme 11. $\mathrm{Fe}(\mathrm{CO})_{5}$ mediated cyclocarbonylation.

Recently, Beller and co-workers reported an iron-catalysed carbonylation for the synthesis of succinimides in 2009 (Table 7). ${ }^{[32]}$ With 10 mol\% of $\mathrm{Fe}(\mathrm{CO})_{5}$ as the catalyst under CO pressure (20 bar) at $120{ }^{\circ} \mathrm{C}$, excellent yields of the desired products can be isolated. This synthetic procedure has also been applied in the synthesis of biologically interesting 3,4-diaryl-substituted maleimides ${ }^{[33]}$ and himanimide ${ }^{[34]}$ as well.

Table 7. Iron-catalysed carbonylative synthesis of succinimides.

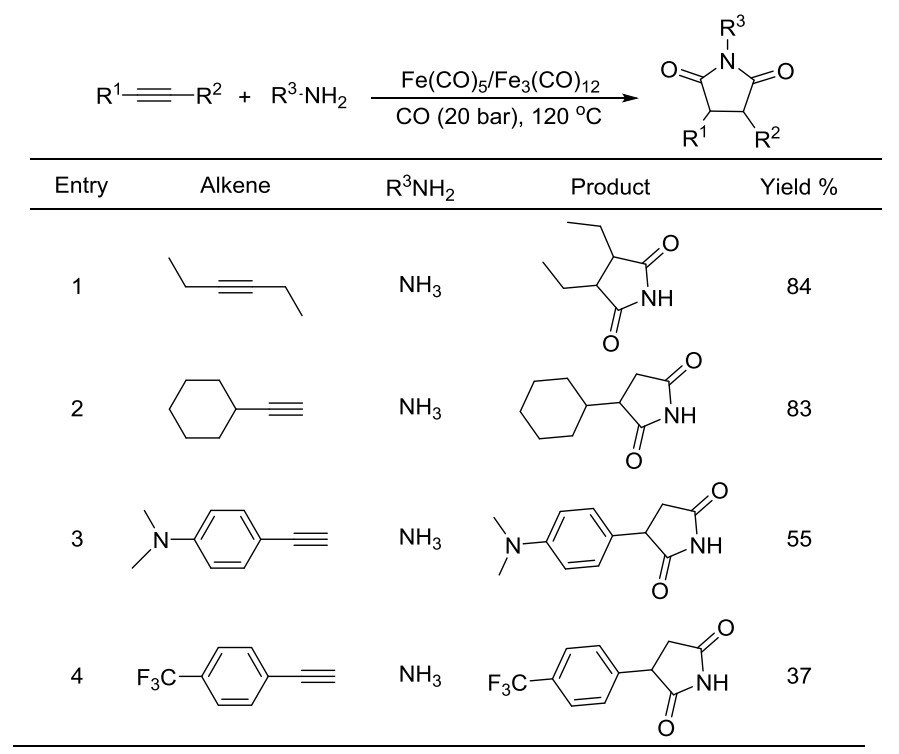


In 2011, Beller and co-workers found that the selectivity can be tuned by the addition of nitrogen ligand (Table 8). ${ }^{[35 a]} \alpha, 6$-Unsaturated amides can be selectivity produced from the same alkynes and amines in the presence of $5 \mathrm{~mol} \%$ of $\mathrm{Fe}_{3}(\mathrm{CO})_{12}$ and ligand. With 5 equivalents of $\mathrm{NEt}_{3}$ as the base under CO pressure (10 bar) in THF at $120^{\circ} \mathrm{C}, 20$ different $\alpha, 6$-unsaturated amides were formed in $47-95 \%$ yields. Meanwhile, a microwave-assisted aminocarbonylation of ynamides with amines at low pressures of CO (1.3 bar) was reported by Petricci and co-workers. ${ }^{[35 b]}(E)$-Acrylamides can been regioselectively synthesized after microwave irradiation with $\mathrm{Fe}_{3}(\mathrm{CO})_{12}$ as the catalyst precursor and triethylamine (TEA) as the ligand.

Table 8. Iron-catalysed aminocarbonylation of alkynes.

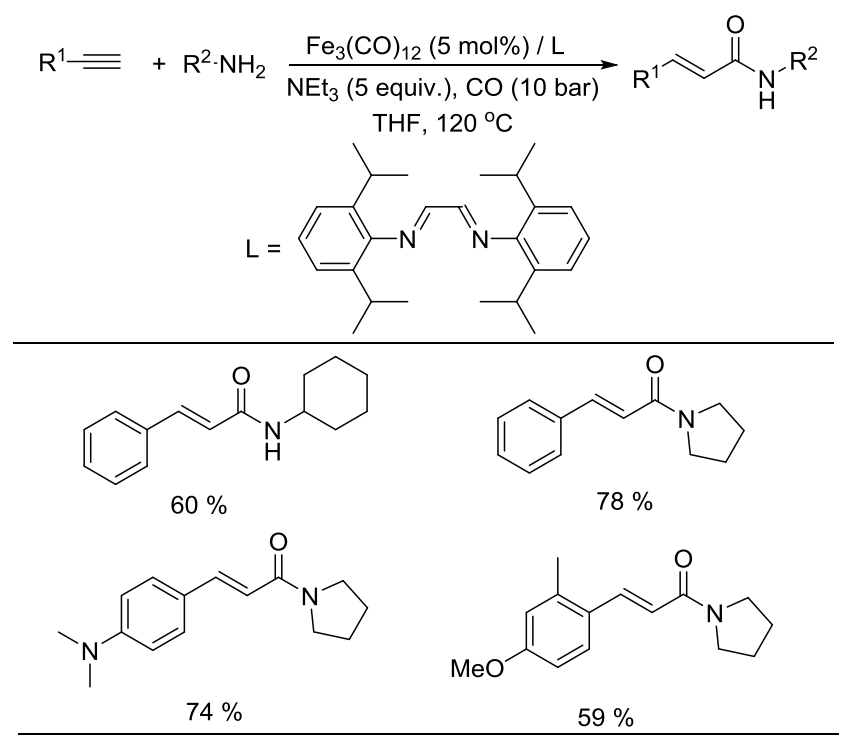

Mathur and co-workers developed a $\mathrm{Fe}(\mathrm{CO})_{5}$-catalysed carbonylative procedure for the synthesis of maleimides and hydantoins in 2012 (Table 9). ${ }^{[36]}$ With terminal alkynes and isocyanate as the substrates in presence of $\mathrm{CO}$, the maleimides can be obtained as the major products. Interestingly, hydantoins can be formed in up to $87 \%$ yield in absence of $\mathrm{CO}$.

Table 9. Iron-catalysed one-pot synthesis of maleimide and hydantoin.

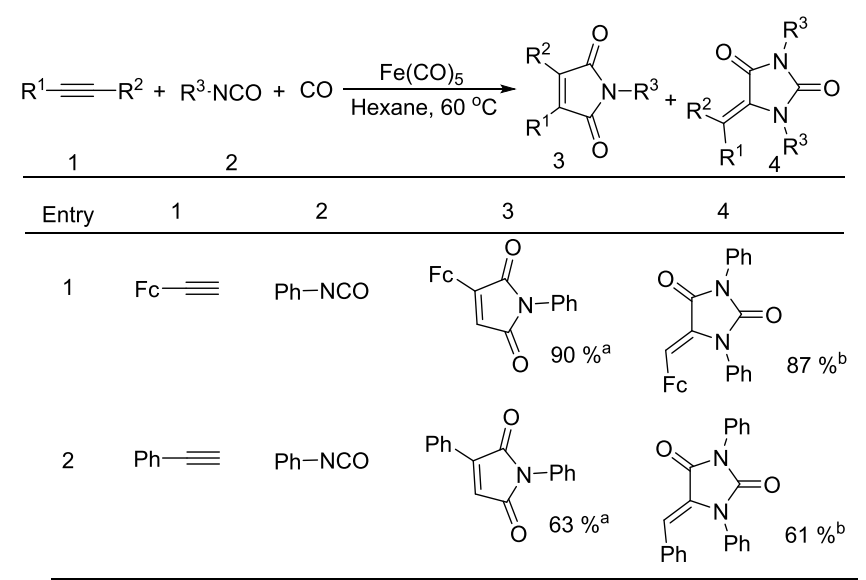

a With $\mathrm{CO}$ budding. ${ }^{\mathrm{b}}$ With $\mathrm{N}_{2}$ or $\mathrm{Ar}$ atmosphere. 
More recently, Iranpoor, Firouzabadi and their co-workers reported a $\mathrm{Fe}(\mathrm{CO})_{5}$ or $\mathrm{Mo}(\mathrm{CO})_{6}$ mediated hydrocarbonylation of phenylacetylene to give $\alpha, b$-unsaturated esters and thioesters (Table $10, a) .{ }^{[37 a]}$ In presence of 1 equiv. of $\mathrm{Fe}(\mathrm{CO})_{5}$ and 2 equiv. of DABCO in DMF at $100{ }^{\circ} \mathrm{C}$, phenylacetylene reacted with different alcohols and thiols to give the desired products in $87-98 \%$. Notably, a $\mathrm{Fe}(\mathrm{CO})_{5} / \mathrm{hv}$ catalyst system for the producing of vinylesters and lactones from alkynes and alcohols was established by Mathur and co-workers in $2010 .{ }^{[37 \mathrm{~b}]}$ The reactions were carried out at $0{ }^{\circ} \mathrm{C}$, and the selectivity of the products were depends on the time of photolysis of the reaction as well as the solvent applied. A stable reaction intermediate ferrole was isolated which produce $\alpha, b$-vinylester after further photolysis with alcohols.

Table 10. Fe $(\mathrm{CO})_{5}$ mediated hydrocarbonylation of alkynes.
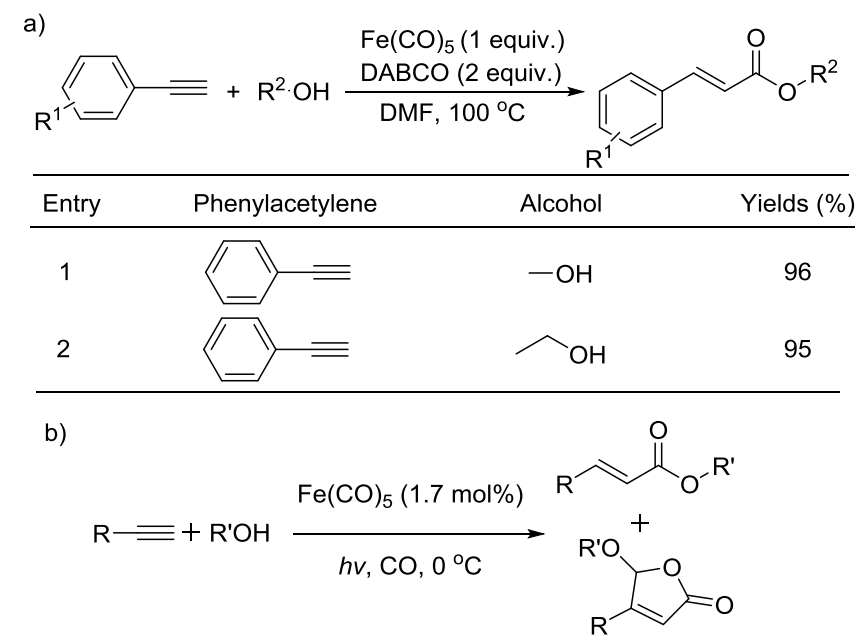

Notably, Han and Zhong developed an iron-catalysed carbonylative Suzuki reaction with PEG-400 as the solvent in 2014 (Table 11). ${ }^{[38]}$ In presence of $4 \mathrm{~mol} \%$ of $\mathrm{FeCl}_{2}$ and $6 \mathrm{~mol} \% \mathrm{FeCl}_{3}$ as the catalyst combination with 2 equivalents of $\mathrm{NaHCO}_{3}$ as the base in PEG-400, the desired ketone products can be obtained in $79-94 \%$ yields. Good functional groups tolerance can be observed, even nitro group. The reactions were performed under atmospheric pressure of carbon monoxide. In their mechanism studies, they found iron carbonyl species was formed as the intermediate and then acting as $\mathrm{CO}$ source to form the product. However, due the properties of PEG solvents, in situ formed nanoparticles cannot be excluded as the real catalyst.

Table 11. Iron-catalysed carbonylative Suzuki reactions.

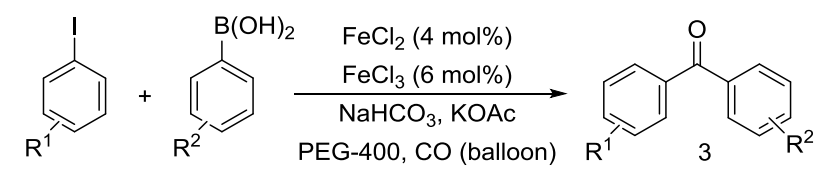

\begin{tabular}{lllll}
\hline Entry & 1 & 2 & 3 & Yields \% \\
\hline
\end{tabular}


1<smiles>O=[N+]([O-])c1ccc(I)cc1</smiles><smiles>O[Se]c1ccccc1</smiles>
2<smiles>Clc1ccc(I)cc1</smiles><smiles>CO[Se]c1ccccc1</smiles>
3<smiles>O=C(c1ccccc1)c1ccc([N+](=O)[O-])cc1</smiles><smiles>[10BH2]</smiles>

$$
\mathrm{Cl}^{-}
$$<smiles>O=C(c1ccccc1)c1ccc(I)cc1</smiles><smiles>N#Cc1ccc(C(=O)c2ccc([N+](=O)[O-])cc2)cc1</smiles>

1.3 Cu-catalysed carbonylation reactions

Copper catalysts have been extensively exported in oxidation reactions and cross-coupling reactions. The applications in carbon monoxide insertion related reactions are still very limited. In 1996, Kang and co-workers developed a copper-catalysed cross-coupling and carbonylative coupling reaction of organostannanes (Table 12) and organoboranes (Table 13) with hypervalent iodine compounds. ${ }^{[39]}$ These reactions can be achieved under extremely mild conditions (room temperature, 10-120 min).

Table 12. Copper-catalysed carbonylative reaction of organostannanes with hypervalent iodine compounds.

\begin{tabular}{llll}
\multicolumn{2}{c}{$\mathrm{R}^{1} \mathrm{SnBu}_{3}+\mathrm{CO}+\mathrm{Phl}^{+} \mathrm{ArX}-\frac{\mathrm{Cul}(2.5 \mathrm{~mol} \%)}{\mathrm{DMF}, \mathrm{rt}, 10-120 \mathrm{~min}}$} & $\mathrm{PhCOR}^{1}$ \\
\hline Entry & $\mathrm{R}^{1} \mathrm{SnBu}_{3}$ & Product & Yields \% \\
\hline & \\
\hline
\end{tabular}

Table 13. Copper-catalysed carbonylative coupling reaction of organoboranes with hypervalent iodine compounds.

$$
\begin{aligned}
& \mathrm{R}^{1} \mathrm{~B}\left(\mathrm{OR}^{2}\right)_{2}+\mathrm{CO}+\mathrm{Ph}_{2} \mathrm{I}^{+} \mathrm{BF}_{4}-\frac{\mathrm{Cul}(2 \mathrm{~mol} \%)}{\mathrm{NaOH}, \mathrm{DME} / \mathrm{H}_{2} \mathrm{O}} \mathrm{PhCOR}^{1} \\
& 35^{\circ} \mathrm{C}, 30 \mathrm{~min}
\end{aligned}
$$

\begin{tabular}{lllll}
\hline Entry & $\mathrm{R}^{1}$ & $\mathrm{R}^{2}$ & Product & Yields \% \\
\hline 1 & &
\end{tabular}




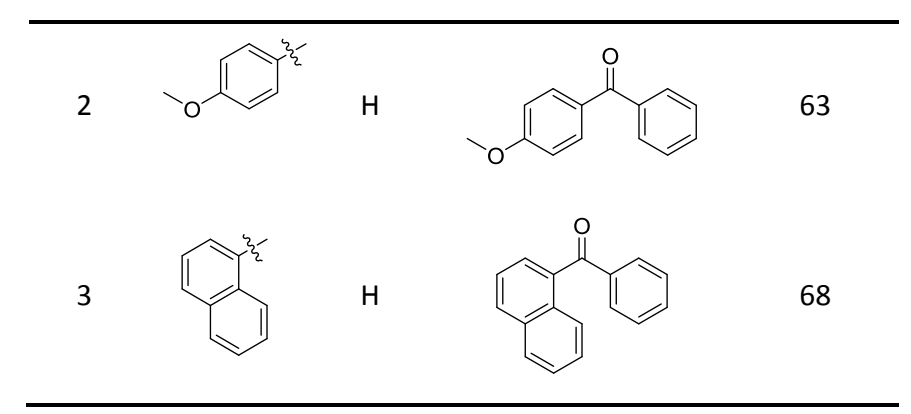

Fujiwara and co-workers developed a transition metal catalysed carboxylation of alkanes and arenes in 1995 (Scheme 12). ${ }^{[40]}$ Using palladium and/or copper as the catalysts, with TFA (trifluoroacetic acid) as the solvent, different alkanes can reacted with CO in TFA to give the corresponding carboxylic acid products. Additionally, $\mathrm{Pd}$ and $\mathrm{Cu}$ combined catalyst (1:1) gives better activity for this transformation.

$$
\mathrm{C}_{n} \mathrm{H}_{2 \mathrm{n}+2}+\mathrm{CO} \frac{\mathrm{Pd}(\mathrm{OAc})_{2} \text { and/or } \mathrm{Cu}(\mathrm{OAc})_{2}}{\mathrm{~K}_{2} \mathrm{~S}_{2} \mathrm{O}_{4}, \mathrm{TFA}, 80^{\circ} \mathrm{C}} \mathrm{C}_{\mathrm{n}} \mathrm{H}_{2 \mathrm{n}+1} \mathrm{CO}_{2} \mathrm{H}
$$

Scheme 12. Palladium and/or copper-catalysed carboxylation of alkanes and arenes.

Sundermeyer and co-workers developed a copper-catalysed oxidative carbonylation of methanol to produce dimethyl carbonate with $N$-methylimidazole (NMI) as the ligand in 2001 (Scheme 13). ${ }^{[41]}$ After various catalysts testing, $(\mathrm{NMI})_{4} \mathrm{CuCl}_{2},(\mathrm{NMI})_{3} \mathrm{CuBr}_{2}$, and $(\mathrm{NMI})_{4} \mathrm{Cul}$ all gives activity and selectivity with DMC (dimethyl carbonate) as the solvent. In 2013, Monopoli, Nacci and their co-workers reported a copper catalysed oxidative carbonylation of glycerol to produce glycerol carbonate (Scheme 14). ${ }^{[42]}$ With $\mathrm{CuCl}_{2}$ and pyridine as the catalyst system, using DMAc $\left(\mathrm{N}, \mathrm{N}\right.$-dimethylacetamide) as the solvent under pressure of $\mathrm{CO} / \mathrm{O}_{2}\left(\mathrm{PCO}=3.3 \mathrm{MPa} ; \mathrm{PO}_{2}=0.7 \mathrm{MPa}\right)$ at $130{ }^{\circ} \mathrm{C}$, excellent conversions (>92\%) and selectivities (>93\%) can be obtained in relatively short reaction time (3-4 h).

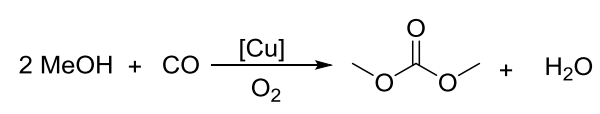

Scheme 13. Copper-catalysed synthesis of carbonate.

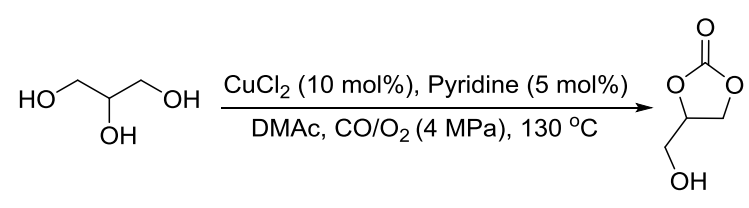

Scheme 14. Copper-catalysed oxidative carbonylation.

Alternative procedures for the synthesis of carbonyl-containing compounds have been developed 
as well. Gao and co-workers reported a copper-catalysed dicarbonylation of imidazo[1,2- $\alpha$ ]pyridines with acetamides and acetone using molecular oxygen as the terminal oxidant (Scheme 15, formula 1 and 2$)^{\left[{ }^{[43]}\right.}$ The reactions were carried out in the presence of $5 \mathrm{~mol} \%$ of $\mathrm{Cu}(\mathrm{OAc})_{2}$ in $\mathrm{AcOH} / \mathrm{t}-\mathrm{AmOH}$ under $\mathrm{O}_{2}$ at $120^{\circ} \mathrm{C}$, the desired 1,2-dicarbonyl imidazo[1,2- $\alpha$ ]pyridines were formed regioselectively in good yields. In their ${ }^{18} \mathrm{O}$-labeling experiments, they proved that the oxygen source of products originated from $\mathrm{O}_{2}$ rather than $\mathrm{H}_{2} \mathrm{O}$. Later on, they successfully extended their methodology to 2-methylpyridines (Scheme 15, formula 3). ${ }^{[44]}$

(1)

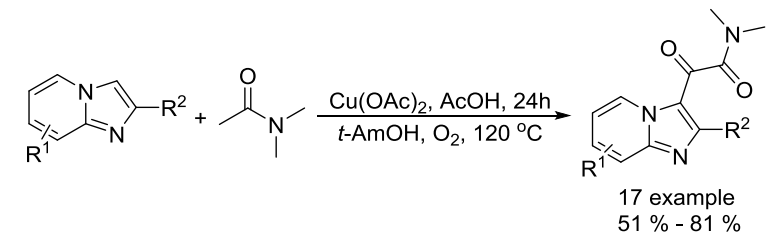

(2)

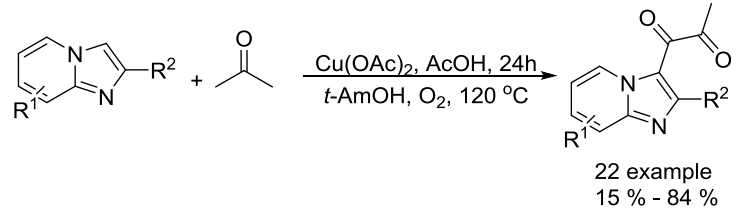

(3)

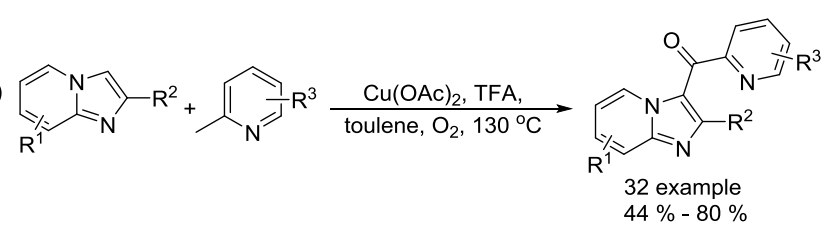

Scheme 15. Copper-catalysed acylation of imidazo[1,2- $\alpha]$ pyridines.

The group of Ye and Ke reported a copper-catalysed acylation of terminal alkynes with formamides using TBHP (tert-butyl hydroperoxide) as the oxidant (Scheme 16). ${ }^{[45]}$ Terminal alkynes undergo cross-dehydrogenative coupling in formamides at $60{ }^{\circ} \mathrm{C}$ and in the presence of catalytic amounts of $\mathrm{CuCl}_{2}$ to give the desired propiolamides in good yields. A competing reaction, the reaction of DMF with phenylacetylene was performed in the presence of excess diethylamine and no diethylamine product was detected, indicating that the mechanism involving the generation of $\mathrm{CO}$ and amine in situ could be ruled out.

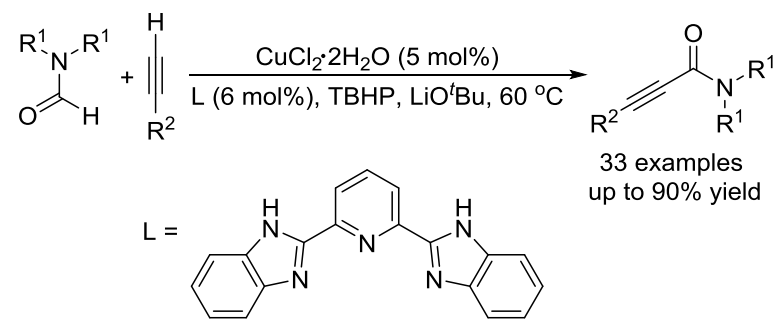

Scheme 16. Copper-catalysed acylation of terminal alkynes. 
In 2016, a general methodology for copper-catalysed oxidative amidation of terminal alkynes to construct $\alpha$-ketoamides was reported by Shen, Zhang and their co-workers (Table 14). ${ }^{[46]}$ In the presence of $10 \mathrm{~mol} \%$ of $\mathrm{Cu}(\mathrm{OTf})_{2}$ as the catalyst with 2 equivalents of DBU as the base, terminal alkynes can reacted with $O$-benzoyl hydroxylamines in THF and the desired products were obtained in good to excellent yields. It is worthy to point out that $O$-benzoyl hydroxylamines act as both amination reagent and oxidant here.

Table 14. Copper-catalysed oxidative $\alpha$-ketoamides synthesis.

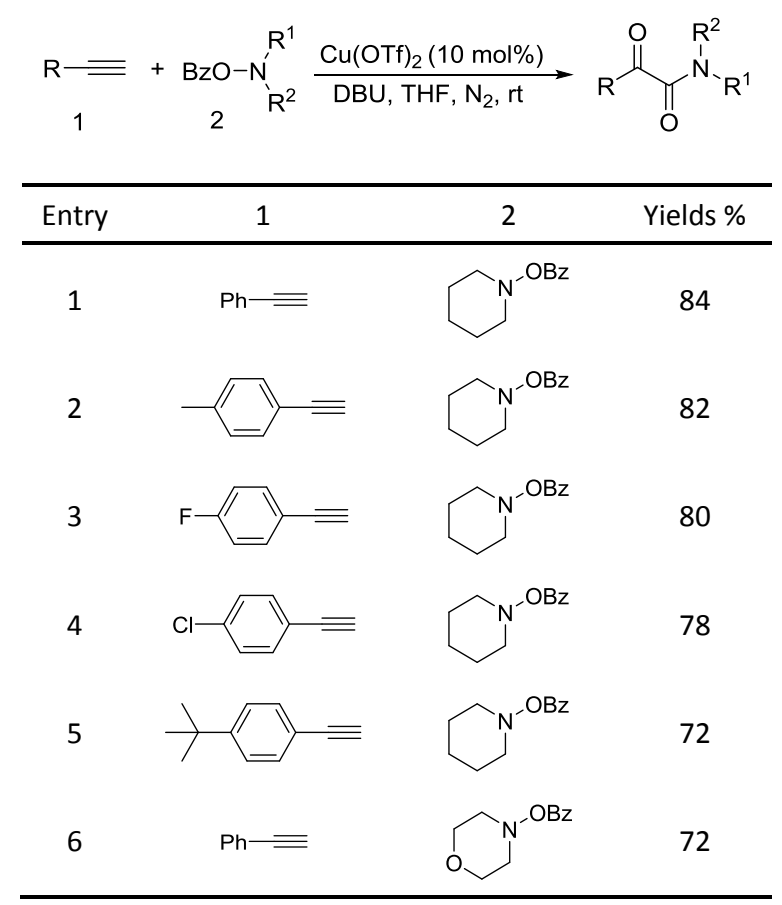

Organic carbamates are important intermediates for the synthesis of pesticides, herbicides and pharmaceutical drugs. An interesting copper-catalysed cross-coupling of anilines with diisopropyl azodicarboxylate was developed by Guan and co-workers in $2016 .{ }^{[47]}$ The desired carbamates were isolated in moderate to good yields (Scheme 17). Interestingly, this catalyst protocol was carried out under solvent-free conditions.

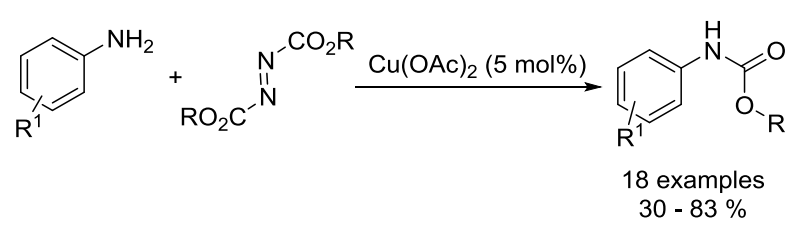

Scheme 17. Copper-catalysed carbamates synthesis.

The report from Yu's group in 2005 demonstrated a copper-catalysed carbonylation of alkynyliodonium salts with boronic acids to the corresponding alkynones (Table 15$).{ }^{[48]}$ In the 
presence of 10 mol\% of $\mathrm{Cul}$ and 1.2 equivalent of $\mathrm{K}_{2} \mathrm{CO}_{3}$, alkynyliodonium salts can reacted with organoboronic acids to form the corresponding $\alpha, 6$-ynone in good yields under $\mathrm{CO}$ atmosphere in $\mathrm{DME} / \mathrm{H}_{2} \mathrm{O}$.

Table 15. Copper-catalysed carbonylation of alkynyliodonium salts.

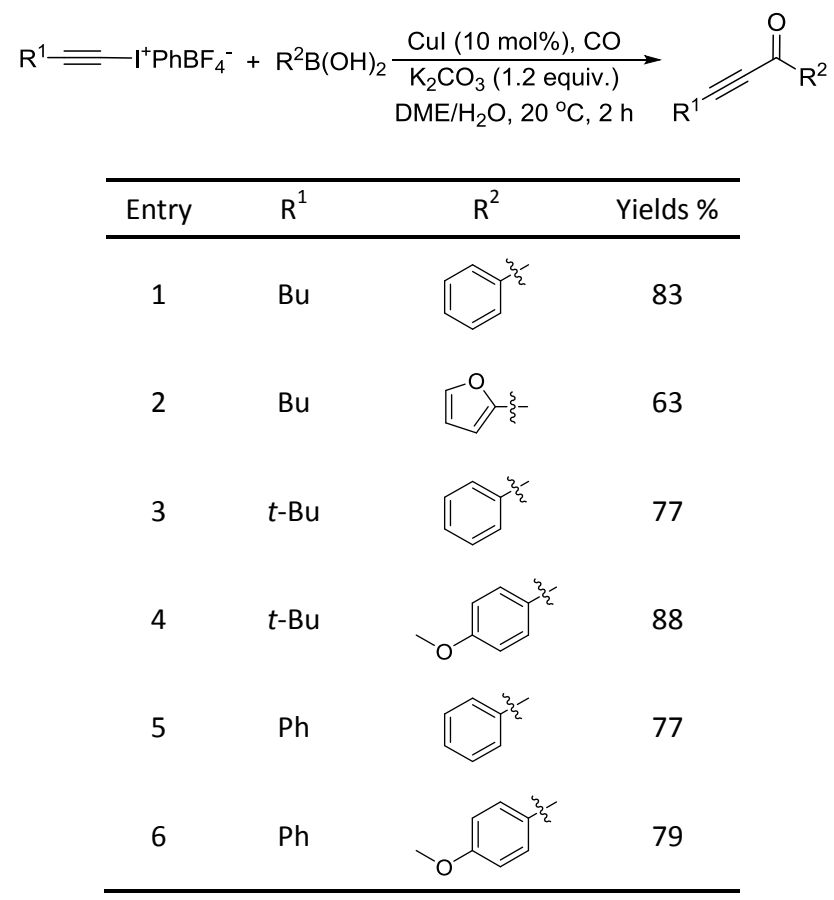

More recently, an efficient method for the synthesis of succinimides via $\mathrm{C}-\mathrm{H}$ activation was developed by Li, Ge and their co-workers (Scheme 18). ${ }^{[49]}$ This protocol is based on the sequential $\mathrm{sp}^{3}$ and $\mathrm{sp}^{2} \mathrm{C}-\mathrm{H}$ bonds activation with nitromethane as the carbonyl source. Using 2-ethyl-2-methylpentanamide bearing a bidentate 8-aminoquinoline directing group as the starting material at $165{ }^{\circ} \mathrm{C}$, with $\mathrm{Cu}(\mathrm{OAC})_{2}$ as the catalyst and $\mathrm{K}_{2} \mathrm{~S}_{2} \mathrm{O}_{8}$ as the oxidant using $\mathrm{PhCO}_{2} \mathrm{Na}$ as the base, good yields of the desired products can be isolated.

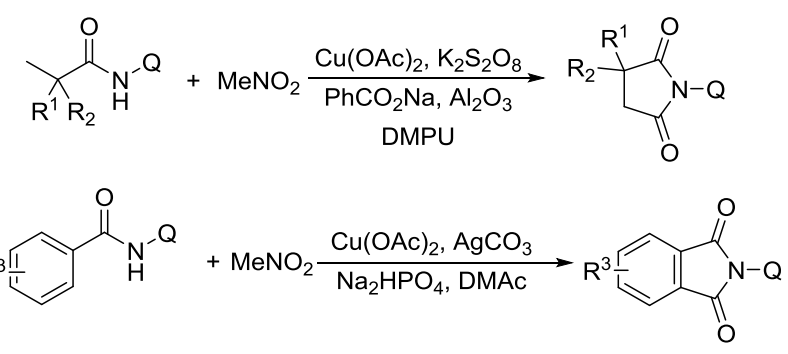

Scheme 18. Copper-catalysed synthesis of succinimides. 


\subsection{Co-catalysed carbonylation reactions}

As early as in 1977, Alper's group reported a procedure and demonstrated that carboxylic acids can be synthesized in good to excellent yields by using catalytic amount of $\mathrm{CO}_{2}(\mathrm{CO})_{8}$ under mild reaction conditions in phase-transfer system. ${ }^{[50]}$ In this procedure, double carbon monoxide insertion reaction was also described. Then, in 1978, Abbayes and co-worker reported a systematic study on the double carbonylation of substituted benzyl chlorides with cobalt carbonylanion by phase transfer catalysis to give arylpyruvic acids. ${ }^{[51]}$ Among their study, it was found that substitution on the aromatic ring played an important role in the double carbonylation by phase transfer catalysis: with $\mathrm{R}=\mathrm{H}$ or $m-\mathrm{CF}_{3}$, which was strongly electron-withdrawing, no keto-acid appeared; while, with $\mathrm{R}=\mathrm{Me}$, double carbonylation occurred, wherever the position of the substituent, suggesting that the electron donating effect of the methyl group was more important than its position. Moreover, further alkylation occurred, giving the substituted arylpyruvic acid. When the aromatic ring bore three methyl groups (in $o, o^{\prime}$, and $p$ positions) double carbonylation became an important pathway, giving only the simple arylpyruvic acid (3). In all these cases, the expected arylacetic acid (2) was produced besides the keto-acid (Scheme 20).

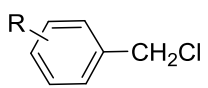

(1)

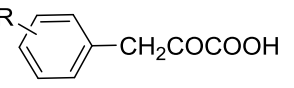

(3)

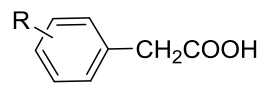

(2)

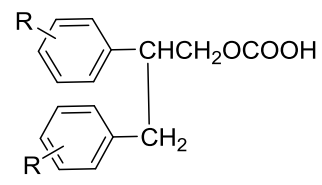

(4)

Scheme 20. Double carbonylation of benzyl chlorides.

In 1982, Imamoto and co-workers reported a facile method for the conversion of benzyl alcohols into one carbon-homologated amides or esters by cobalt carbonyl catalysed carbonylation under mild reaction conditions (Scheme 21). ${ }^{[52]}$ In the same year, Foa and Francalanci found that in the phase-transfer catalysis in cobalt catalyzed carbonylation of secondary benzyl halides, the results were highly depending on the experimental conditions. Alcohols or ethers mainly gave carboxylic acid salts and the use of higher pressure of $\mathrm{CO}$ association with a hydrocarbon organic phase favored the other selectivity. ${ }^{[53]}$ Soon later, Foa and co-workers reported acobalt-catalyzed carbonylation of optically active and $\alpha$-deuterated phenylethyl halides under phase transfer conditions. ${ }^{[54]}$ The stereochemistry of catalytic monocarbonylation of optically active $\alpha$-deuterated phenylethyl halides, as well as the deuterium-exchange experiments to clarify the origin of the double carbonylation were devised. 


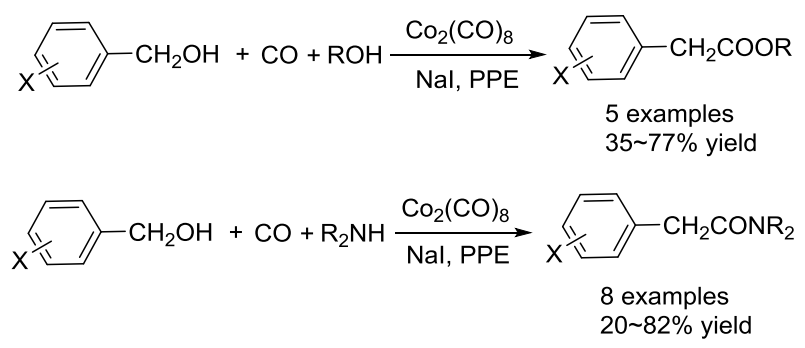

Scheme 21. Cobalt-catalysed carbonylation of benzyl alcohols.

In 1985 , Alper's group reported the double carbonylation of styrene oxides. ${ }^{[55]}$ With $\mathrm{Co}_{2}(\mathrm{CO})_{8}$ as the catalyst, and treatment of substrates with carbon monoxide, $\mathrm{NaOH}$, methyl iodide in benzene, and using cetyltrimethylammonium bromide (CTAB) as the phase transfer agent, good yields of the corresponding products can be obtained (Scheme 22).

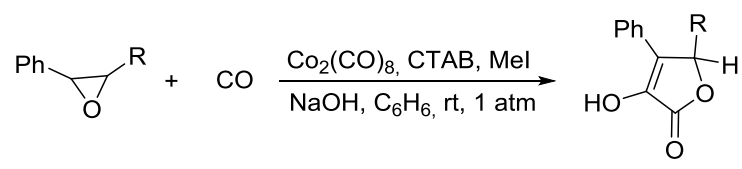

Scheme 22. Co-catalysed double carbonylation of epoxides.

In 1986, a methodology on cobalt-catalysed reductive carbonylation of methyl esters was reported by Wegman and Busby. Acetaldehyde and a carboxylic acid were obtained in high yields via the $\mathrm{Col}_{2}$-Lil-catalysed reaction of a methyl ester with synthesis gas (Scheme 23). ${ }^{[56]}$

$$
\mathrm{MeCO}_{2} \mathrm{Me}+\mathrm{CO}+\mathrm{H}_{2} \stackrel{\mathrm{Col}_{2}, \mathrm{Lil}}{\longrightarrow} \mathrm{MeCHO}+\mathrm{MeCOOH}
$$

Scheme 23. Co-catalysed carbonylation of methyl ester

In 1986, Kshimura et.al. reported a procedure on cobalt carbonyl catalysed carbonylative transformation of $o$-halogenated benzoic acids under photo-stimulation (Scheme 24). ${ }^{[57]}$ Double carbonylation products can be observed as well under these reaction conditions.

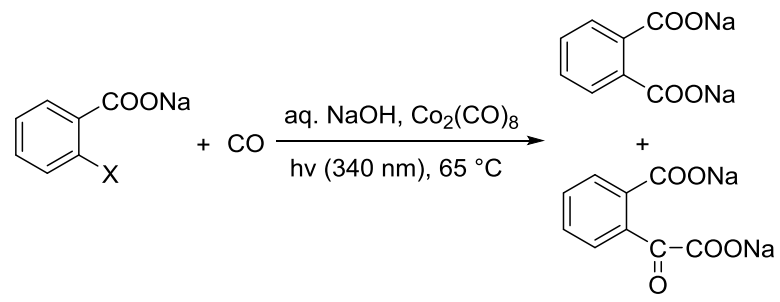

Scheme 24. Co-catalysed carbonylation of o-halogenated benzoic acids. 
In 1985, a method for carbonylative transformation of aromatic and heteroaromatic halides was reported by Foa and co-workers (Scheme 25 , formula 1 ). ${ }^{[58]}$ In this mild catalytic system, the anionic cobalt complexes were formed and showed great activity towards aromatic halides. One year later, they presented a novel procedure on the double carbonylation of aryl and secondary benzylic halides with $\mathrm{CO}_{2}(\mathrm{CO})_{8}$ as the catalyst. ${ }^{[59]}$ The corresponding $\alpha$-keto acids were generated in moderate to good yields (Scheme 25, formula 2). In this process, a methyl source (dimethyl sulfate or methyl iodide) was necessary for the carbonylation of aryl halides.

$$
\begin{aligned}
& \mathrm{ArX}+\mathrm{CO}+\mathrm{ROH} \frac{\mathrm{ECH}_{2} \mathrm{Co}(\mathrm{CO})_{4}}{\mathrm{CO}(1 \mathrm{bar}), 25^{\circ} \mathrm{C}} \mathrm{ArCOOR}+\mathrm{HX} \\
& \mathrm{R}=\mathrm{CH}_{3}, \mathrm{C}_{2} \mathrm{H}_{5}, \mathrm{i}-\mathrm{C}_{3} \mathrm{H}_{7} \\
& \mathrm{E}=\text { electron-withdrawing groups }
\end{aligned}
$$

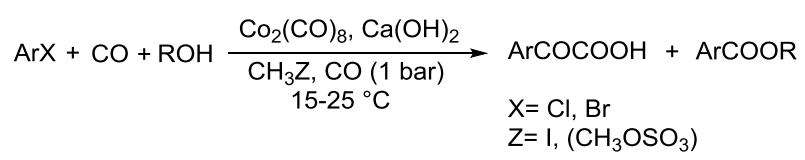

Scheme 25. Co-catalysed carbonylation of organo halides.

An interesting cobalt carbonyl-catalysed carbonylative synthesis of unsaturated carboxylic acids in aqua solutions was developed by Alper and Calet in $1988 .{ }^{[60]}$ Under the assistant of phase transfer catalyst and methyl iodide, carbonylation of vinyl epoxides occurred and gave the desired products in good yields and high regioselectivity (Scheme 26).
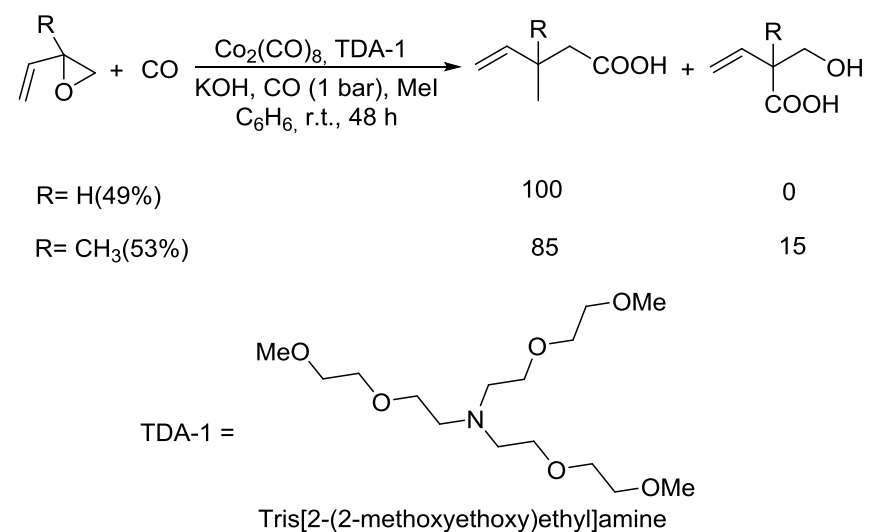

Scheme 26. Co-catalysed carbonylation of vinyl epoxides.

In 1989, Alper and Roberto reported the synthesis of pyrrolidinones by cobalt carbonyl catalysed carbonylation of azetidines. That was the first example on metal catalysed ring-expansion-carbonylation reaction of azetidines to tetrahydroazepinones (Scheme 27). ${ }^{[61]}$ Various pyrrolidinones could be synthesized in high yields and regioselectivity from the parent azetidines. The position for carbonyl insertion on 2-substituted azetidines (alkyl, aryl, $\mathrm{CHOH}, \mathrm{CH}_{2} \mathrm{OR}, \mathrm{CHOCOR}$, and 
COOR), the outcome depends on the properties of the substituent groups and also on the reaction temperature. The reaction displays high regio- and stereo-selective, and also tolerated functional groups such as esters, ethers, and alcohols.

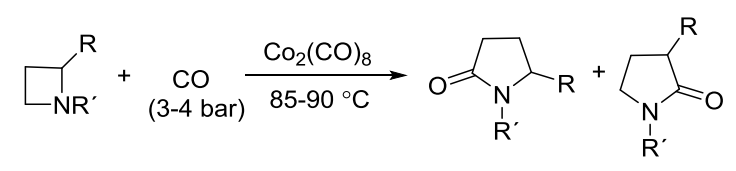

Scheme 27. Cobalt-catalysed carbonylative synthesis of pyrrolidinones.

In the same year, Watanabe and co-workers reported a cobalt catalysed ring-opening carbonylation of cyclic ethers using $N$-(trimethylsilyl)amines as the reaction partner (Scheme 28). ${ }^{[62]}$ This method provide an access to the ring-opening carbonylation of a variety of cyclic ethers such as oxiranes, oxetane, tetrahydrofuran, and 1,3-dioxolane. In the presence of a catalytic amount of $\mathrm{CO}_{2}(\mathrm{CO})_{8}$ under carbon monoxide pressure, the corresponding siloxy amides were formed in good yields.

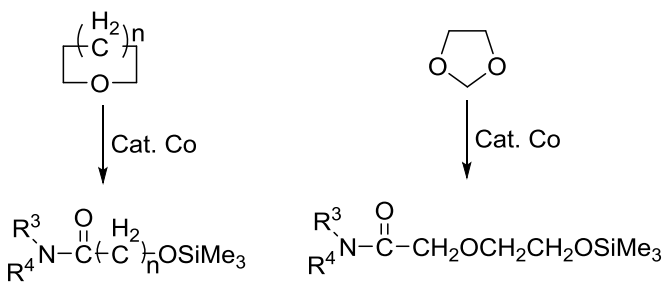

Scheme 28. Cobalt-catalysed carbonylation of cyclic ethers.

Remarkably, the first example on the triple carbonylation of epoxy alcohols was developed in Alper's group in $1990 .{ }^{[63]}$ With cobalt carbonyl and TDA-1 as the catalyst system, the epoxy alcohols were converted into the corresponding 2-C-(2,5-dihydro-2-oxofur-5-yl) lactic acids in moderate yields, under exceptionally mild conditions (Scheme 29).

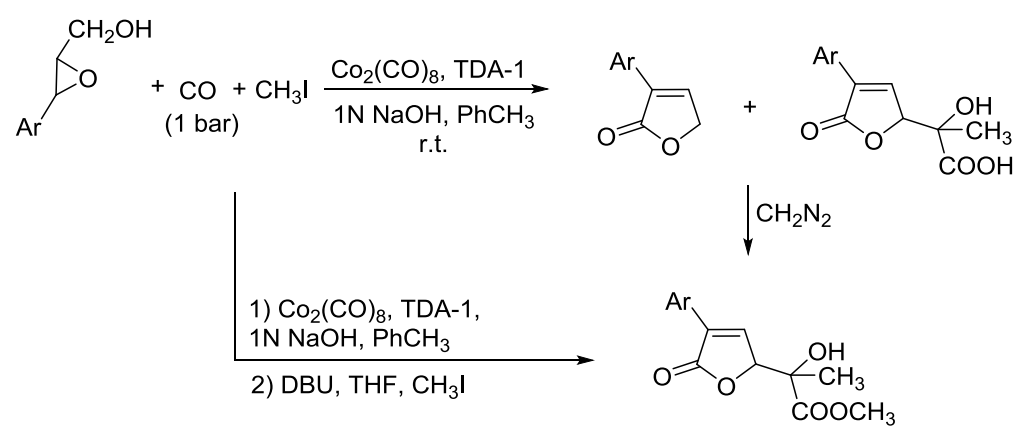

Scheme 29. Cobalt catalysed carbonylation of epoxy alcohols. 
In 1991, Izawa and co-workers reported a methodology for the synthesis of proline and 2-piperidinecarboxylic acid via cobalt catalysed isomerization-carbonylation of $\mathrm{N}$-acyl unsaturated cyclic amines under hydroformylation conditions in the presence of $\mathrm{H}_{2} \mathrm{O}$ (Scheme 30). ${ }^{[64]}$

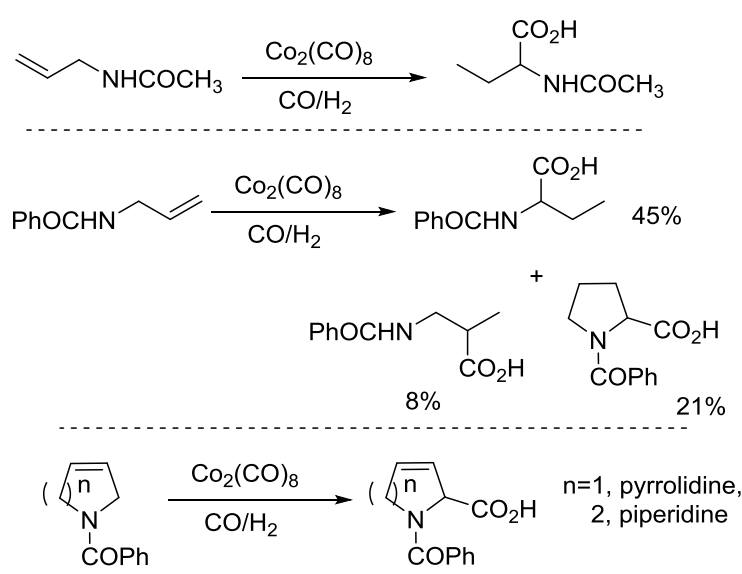

Scheme 30. Synthesis of pyrrolidine and 2-piperidinecarboxylic acid.

In 1991, Alper and Grushin discovered the first example on carbonylative transformation of gem-dibromocyclopropanes by using cobalt and nickel salts as catalysts under phase transfer conditions (Scheme 31). ${ }^{[65]}$ The best yields were obtained when a combination of nickel and cobalt cyanides were applied in the presence of synthesis gas $\left(\mathrm{CO} / \mathrm{H}_{2}\right)$.

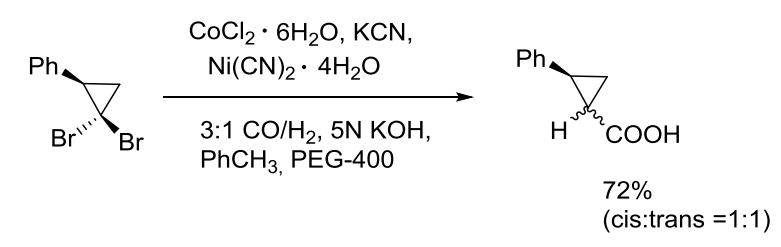

Scheme 31. Carbonylation of of gem-dibromocyclopropanes.

Fuchikami and co-workers reported a procedure on the carbonylative transformation of alkyl sulfonates in $1991 .{ }^{[66]}$ The corresponding esters were produced selectively in the presence of catalytic amount of Co complex, Nal and alcohols with 1,1,3,3-tetramethylurea (TMU) as the base (Scheme 32).

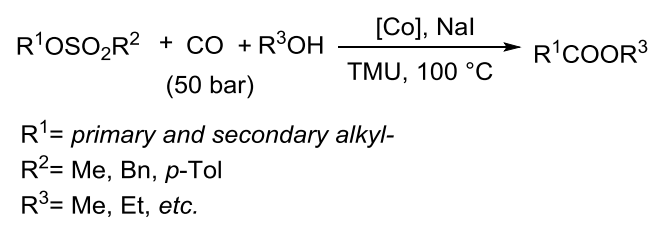

Scheme 32. Cobalt-catalysed carbonylation of alkyl sulfonates. 
In 1992, Alper and co-worker reported the synthesis of piperidinones, which was formed from carbonylation of pyrrolidines catalysed by the cobalt carbonyl (Scheme 33). ${ }^{[67]}$ The reaction was regiospecific in most cases, and the yields of the products were increased in the presence of ruthenium carbonyl as an additive.

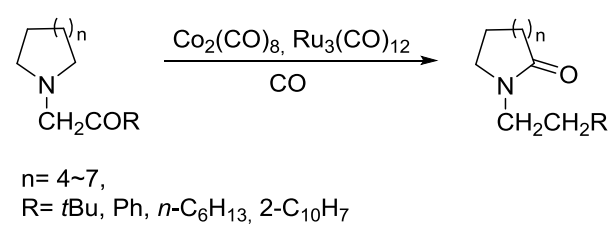

Scheme 33. Cobalt-catalysed carbonylation of pyrrolidines.

Rindone and co-workers studied the substituent effects in cobalt-catalyzed oxidative carbonylation of aromatic amines. ${ }^{[68]}$ Ureas, isocyanates, carbamates and azo derivatives were generated from the $N, N$-bis(salicylidene)ethylenediaminocobalt(II)-catalyzed oxidative carbonylation of ortho-, meta- and para-substituted aromatic primary amines in methanol. In their study, it was found that the para-substituted anilines were mainly transformed into the ureas in high yields, due to the cobalt(III) intermediates had the stability very similar to that of the corresponding cis derivatives, as well as steric effects, which may suggested to be the intermediates in the formation of ureas.

In the same year, Alper's group reported the carbonylative synthesis of highly strained trans-bicyclic 8 -lactams. In the presence of $\mathrm{CO}_{2}(\mathrm{CO})_{8}$ as the catalyst, aziridines were transformed into B-lactams in excellent yields (Scheme 34). ${ }^{[69]}$ This procedure is valuable in the preparation of highly strained bicyclic-8-lactams containing the trans-7-azabicyclo [4.2.0]octan-8-one nucleus. The reaction began by nucleophilic ring opening of the aziridine by in situ-generated tetracarbonyl-cobaltate anion.

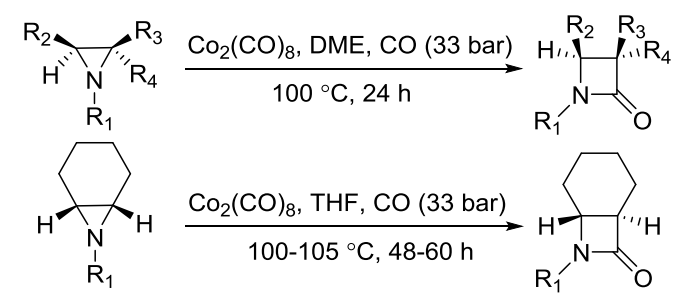

Scheme 34. $\mathrm{Co}_{2}(\mathrm{CO})_{8}$-catalysed carbonylation of aziridines.

In 1996, Pályi, Markó, Alper and their co-workers reported a cobalt-catalysed carbonylation of benzyl halides using polyethylene glycols as the phase-transfer catalyst (Scheme 35). ${ }^{\text {[70] }}$ Hydroxycarbonylation of benzyl and substituted benzyl chloride and bromide derivatives were achieved in good to excellent yields (up to 97.6\%) and quantitative chemoselectivity in two-phase system under mild conditions (1 bar CO, room temperature). $\eta^{1}$-Benzyl-, $\eta^{3}$-benzyl-, and 
( $\eta^{1}$-phenylacetyl) cobalt carbonyls were investigated as intermediates of this carbonylation transformation. It was proposed that: (i) the role of PEG is not simply to transport $\left[\mathrm{Co}(\mathrm{CO})_{4}\right]-$ from aqueous to organic phase but also to accelerate the hydrolysis of the acylcobalt tetracarbonyl complex; (ii) in the presence of the acyl-, alkyl- and $\left(\eta^{3}\right.$-benzyl)cobalt complexes in the hydroxycarbonylation reaction mixtures, $\left(\eta^{3}\right.$-benzyl)cobalt-type complexes and their role as intermediates in phase-transfer reactions was not previously observed.

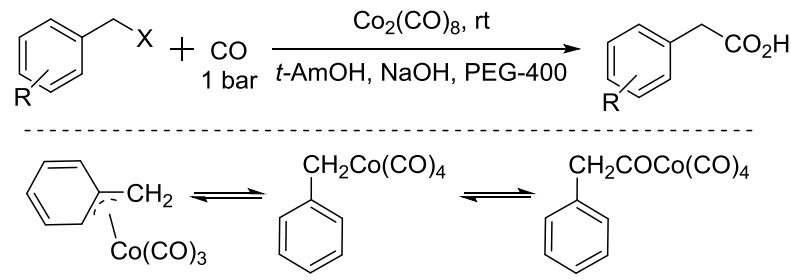

Scheme 35. Cobalt-catalyzed carbonylation of benzyl halides.

Lin and Knifton developed a cobalt-catalysed carbonylation of phenylacetaldehyde to $N$-acetyl-beta-phenylalanine in $1997 .{ }^{[71]}$ The reaction was studied both in batch process and continuous phase reactor. In this reaction, the adding of DPPE (1,2-bis(diphenylphosphino)ethane) ligand was compulsory. High yields of the desired products can be achieved and the catalyst can be recovered successfully as well (Scheme 36).

$$
\mathrm{PhCH}_{2} \mathrm{CHO}+\mathrm{CH}_{3} \mathrm{CONH}_{2} \frac{\mathrm{Co}_{2}(\mathrm{CO})_{8}, \mathrm{DPPE}}{\mathrm{CO}, \mathrm{H}_{2}} \mathrm{PhCH}_{2} \mathrm{CNHCOCH}_{3}
$$

Scheme 36. Cobalt-catalyzed carbonylation of phenylacetaldehyde

In 2001, Alper's group reported a synthetic method on the carbonylative synthesis of 8 -lactones from epoxides. ${ }^{\left[{ }^{[2]}\right.}$ With cobalt complex $\left(\mathrm{PPNCo}(\mathrm{CO})_{4}\right)(\mathrm{PPN}=$ bis(triphenylphosphine)iminium) as the catalyst and Lewis acid $\left(\mathrm{BF}_{3} \cdot \mathrm{Et}_{2} \mathrm{O}\right)$ as the additive, both simple and functionalized epoxides were regioselectively transformed in good yields (Scheme 37). The carbonylation occurred selectively at the unsubstituted $\mathrm{C}-\mathrm{O}$ bond of the epoxide ring, and various functional groups were tolerated, such as alkenyl, halide, hydroxyl, and alkyl ether. Interestingly, the stereochemistry of epoxides and aziridines gave completely different results.

$$
\underset{\mathrm{O}}{\mathrm{R}} \frac{\mathrm{PPNCo}(\mathrm{CO})_{4}, \mathrm{BF}_{3} \cdot \mathrm{Et}_{2} \mathrm{O}}{\mathrm{DME}, \mathrm{CO}, 80^{\circ} \mathrm{C}} \mathrm{O}_{\mathrm{O}}^{\mathrm{R}}
$$

Scheme 37. Cobalt-catalysed carbonylation of epoxides. 
Dragojlovic et. al. reported a cobalt-catalyzed photochemical methoxylcarbonylation of alkenes in the same year. ${ }^{[73]}$ The reaction can be successfully carried out on a multigram scale (5-10 g) on a number of alkenes with appropriate choice of light source, filter, concentration of cobalt catalyst and suitable equipment (Scheme 38). In this process, the stability of cobalt catalyst was crucial for the success of photocarbonylation. For given reaction scale and set of conditions (light source, filter, temperature), there was a narrow range of concentrations of cobalt catalyst at which the catalyst was stable and the reaction proceeded at a reasonable rate. However, the reaction was limited to mono and disubstituted alkenes (69-85\%). Low selectivity was observed with trisubstituted alkenes and dienes.

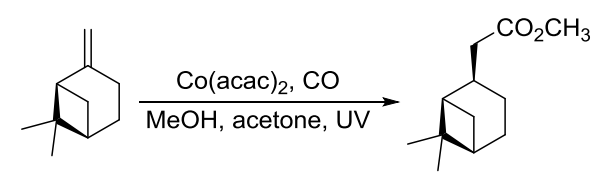

Scheme 38. Methoxycarbonylation of alkenes.

In 2002, an efficient and mild carbonylative protocol for the conversion of optically active epoxides to 6-hydroxy morpholine amides was developed by Jacobsen and Goodman (Scheme 39). ${ }^{\text {[4] }}$ The methodology was effective with a variety of epoxides and pure products could easily be isolated by treatment of the crude product mixture with aqueous acid. Moreover, a valuable new approach for preparing synthetically valuable $\boldsymbol{B}$-hydroxy- 6 -ketoesters was discovered by adding aluminum enolate derivatives cleanly to the morpholine amides.

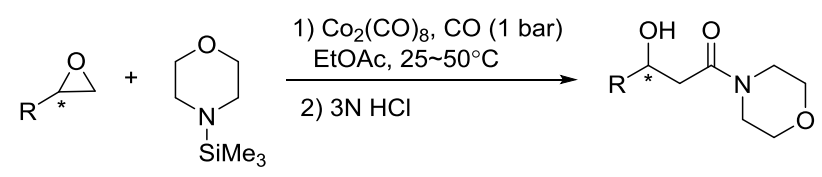

Scheme 39. Carbonylative transformation of epoxides.

Jia and $\mathrm{Xu}$ reported a methodology on the cobalt-catalysed carbonylative ring-expanding of 2-aryl-2-oxazolines in 2003 (Scheme 40). ${ }^{[75]}$ This was the first example on using 2-oxazolines as substrates in transition metal-catalyzed carbonylation reactions. In their mechanistic studies, they proved the cobalt radicals as the catalytically active species.

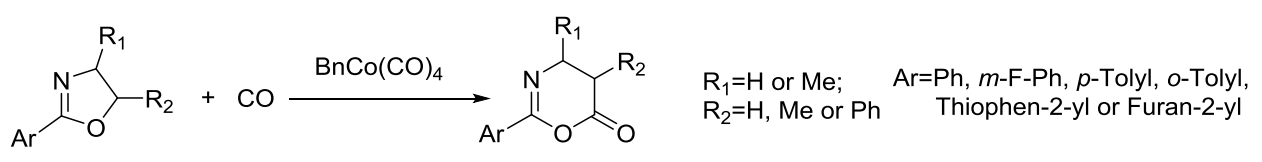

Scheme 40. Cobalt-catalysed carbonylative ring-expanding of 2-aryl-2-oxazolines. 
Meanwhile, they succeeded in the carbonylative ring expansion of other heterocycles as well. ${ }^{[76]}$ With $\mathrm{CO}_{2}(\mathrm{CO})_{8}$ as the catalyst, a rarely studied exocyclic $\mathrm{C}-\mathrm{O}$ bond carbonylation proceeded smoothly. Various cycloimino esters could be activated and further carbonylated to afford $\mathrm{N}$-acyllactams in high yields under relatively mild conditions in the absence of $\mathrm{HI}$ as the co-promoter (Scheme 41). The reaction opens a possible access to the carbonylation of alcohols without the assistance of $\mathrm{HI}$. In this reaction, an organic amide would replace $\mathrm{HI}$ to form the desirable equilibrium that generated the direct reactant for the carbonylation. Later on, they also demonstrated that a catalytic system formed from commercially available $\mathrm{CO}_{2}(\mathrm{CO})_{8}$ and $\mathrm{AIBN}$ can worked effectively in this type of transformation as well. $(4 R, 5 S)$-4-Methyl-2,5-diphenyl-2-oxazoline and $(4 R, 5 R)-4$-methyl-2,5-diphenyl-2-oxazoline can be transformed stereospecifically. The stereoselectivity in all cases favored inversion at the $C(5)$-position with diastereomeric excess up to $>97 \%{ }^{[77]}$

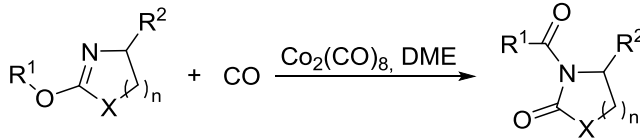

$$
\begin{aligned}
& \mathrm{X}=\mathrm{CH}_{2}, \mathrm{O} \\
& \mathrm{R}_{1}=\mathrm{Me}, \mathrm{Et}, \mathrm{Pr} \\
& \mathrm{R}_{2}=\mathrm{H}, \mathrm{iPr} \\
& \mathrm{n}=1-3
\end{aligned}
$$

Scheme 41. Cobalt-catalysed exocyclic C-O bond carbonylation.

Jia and Liu designed a catalytic procedure for the carbonylative polymerizations of epoxides and $N$-alkylaziridines in $2004 .^{[78]}$ Under their conditions, polyesters and amphiphilic poly-(amide-block-ester)s can be synthesized effectively (Scheme 42). It had been demonstrated that the combinations of cobalt catalyst and pyridines were versatile catalysts for the carbonylative polymerization of both epoxides and aziridines likely under closely resembling mechanisms. While less active for carbonylative epoxide polymerization than the catalysts generated in situ from $\mathrm{Co}_{2}(\mathrm{CO})_{8}$, the well-defined acid-free catalyst allowed the development of a very convenient synthetic method for diblock copolymers with a degradable block and a nondegradable block. The amphiphilic and degradable diblock copolymers are potentially useful for biomedical applications.

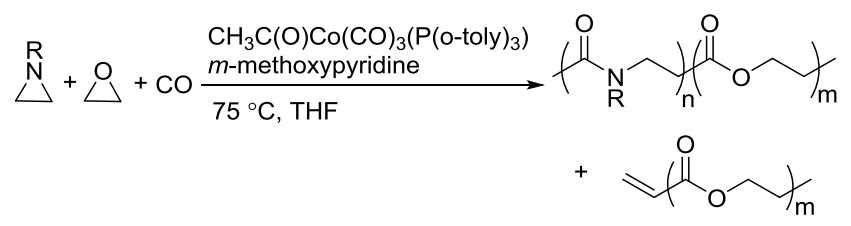

Scheme 42. Cobalt-catalysed carbonylative polymerizations of heterocycles.

Two years later, Jia and Liu reported a new procedure on the carbonylative polymerization of azetidines. ${ }^{\left[{ }^{[9]}\right.}$ With $\left[\mathrm{Co}\left(\mathrm{CH}_{3} \mathrm{CO}\right)(\mathrm{CO})_{3} \mathrm{P}(\mathrm{o} \text {-tolyl })_{3}\right]$ as the catalyst and tetrahydrofuran (THF) as both the 
reagent and solvent, the desired polymers can be selectivity produced (Scheme 43). With the use of Lil as a co-catalyst, the $\gamma$-lactam byproduct can be eliminated. Both the amount and distribution of the ester units in the polymer backbone were influenced by Lil as well, this finding allowed the synthesis of polymers with alternating amide blocks and ester segment that would undergo two-stage degradation.

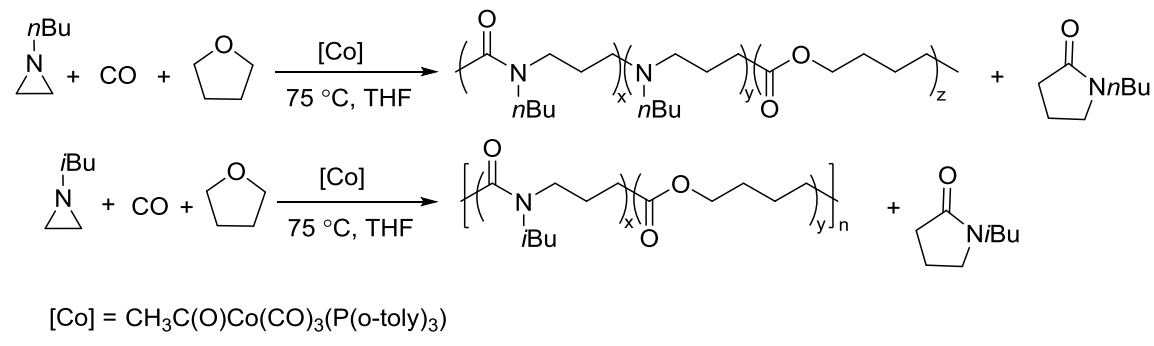

Scheme 43. Cobalt-catalysed carbonylative polymerizations of azetidines.

In 2008, Jia and co-workers provided a systematic study on the cobalt-catalyzed carbonylative polymerization of $\mathrm{N}$-alkylazetidines involving three representative monomers (Scheme 44$).{ }^{[80]}$ The individual $\mathrm{N}$-alkylazetidine monomers displayed different characteristics in the polymerization, which allowed the incorporation of amine and ester units into the amide based polymers. Firstly, the synthesis and characterization of poly(amide-co-amine) with a gradient amine distribution were described. Then, they presented how to control the ester distribution in poly(amide-co-ester)s. Poly(amide-co-ester) containing multiple segments with block or gradient ester distributions could be synthesized by multiple additions of $N$-isobutylazetidine into the reaction mixture in the presence of or absence of Lil. Finally, the discovery of a novel chain transfer pathway via $N$-benzyl abstraction was made. It was found that $\mathrm{N}$-benyzlazetidine was different from the other two monomers in that a chain transfer pathway: which was presented via the nucleophilic abstraction of the $N$-benzyl group. The remaining acyl-azetidine at the chain end could be utilized for further chemical modifications or polymerization.

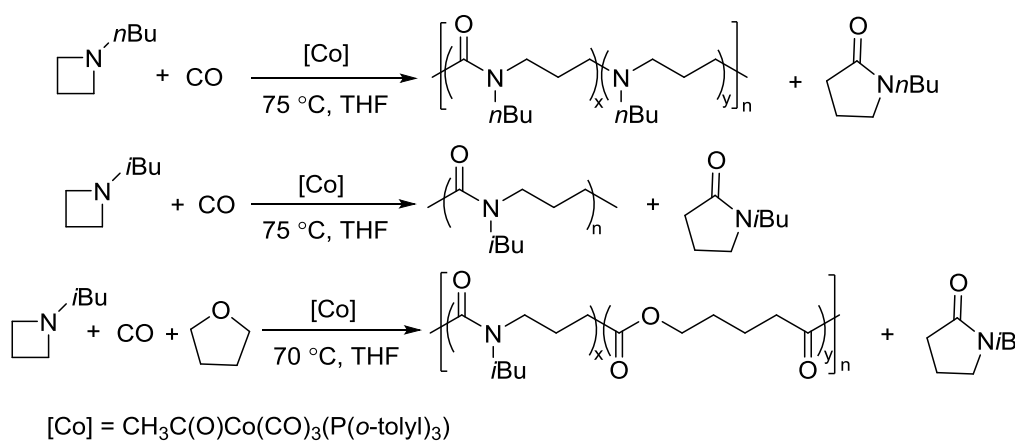

Scheme 44. Cobalt-catalysed carbonylative polymerizations of $N$-alkylazetidines.

Sen and co-workers reported a cobalt-catalysed carbonylation of $N$-alkylbenzaldimines in $2006 .{ }^{\text {[81] }}$ 
N-Alkylphthalimidines can be produced via tandem C-H activation and cyclocarbonylation (Scheme 45). The resulting formation was proposed to occur by $\mathrm{C}-\mathrm{H}$ activation of the aryl ring, migratory insertion of the hydride species into the benzaldimine functionality, CO coordination, and insertion into the Co-C bond, followed by reductive elimination of the $N$-alkylphthalimidine and regeneration of the starting cobalt species.

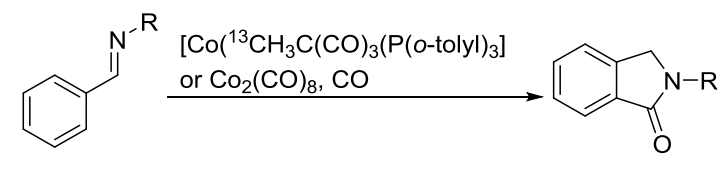

Scheme 45. Co-catalysed carbonylation of $N$-alkylbenzaldimines.

In 2008, Li and co-workers reported a cobalt-catalyzed oxidative carbonylation of aniline to $N$, $N^{\prime}$-diphenyl urea. ${ }^{[82]}$ The catalyst system comprised by Co(II)-Schiff base complex and a pyridine-type promoter (Scheme 46). The Co(II) complexes of substituted salen or salophen ligand with an electron-donating hydroxyl group showed good activity. In the catalytic system, pyridine-type additive as promoter increased the reactivity of catalyst. Among the additives, substituted pyridines had better promoting function than pyridine. The promoting effect of substituted pyridines was correlated with their basicity and steric hindrance of substituents.

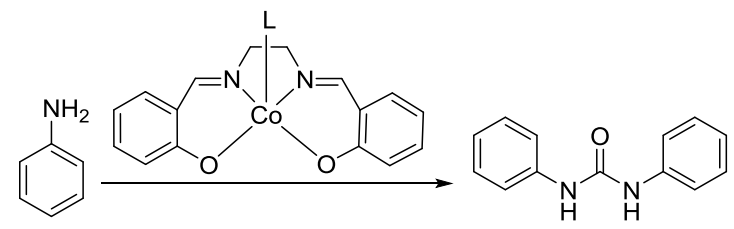

Scheme 46. Cobalt-catalysed carbonylation of aniline.

In 2010, Wang's group reported a cobalt-catalyzed photo-promoted carbonylation of chloroalkanes. ${ }^{[83]}$ With cobalt compounds $\left[\mathrm{Co}(\mathrm{OAc})_{2}, \mathrm{CoCl}_{2}\right]$ as the catalyst and in the presence of $\mathrm{KI}$, the corresponding esters can be selectively produced (Scheme 47). The reactions were carried out under ambient conditions proceeded through two pathways. The role of iodide ion may be to form a more active iodoalkanes via substituting chloride ion in chloroalkanes in situ. Additionally, the activity of this carbonylation can be improved by the addition of $\mathrm{NaOAc}$.

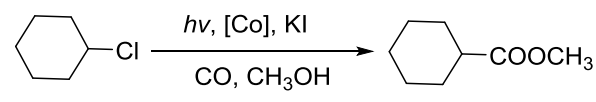

$[\mathrm{Co}]=\mathrm{Co}(\mathrm{OAC})_{2}$ or $\mathrm{CoCl}_{2}$

Scheme 47. Photopromoted carbonylation of chloroalkanes. 
In 2011, an in situ generated catalytic system that allows the ring-expansion carbonylation of epoxides using low precatalyst loadings was developed (Scheme 48). ${ }^{[84]}$ The active catalyst, analogous to Coates' catalyst, was formed in situ from commercially available (TPP) CrCl (TPP = tetraphenylporphyrin) and $\mathrm{Co}_{2}(\mathrm{CO})_{8}$. This practical system circumvented the preparation of air sensitive cobaltate salts, manipulated at low catalyst loadings, and meet the carbonylation of functionalized, sterically demanding and heterocyclic meso-epoxides.

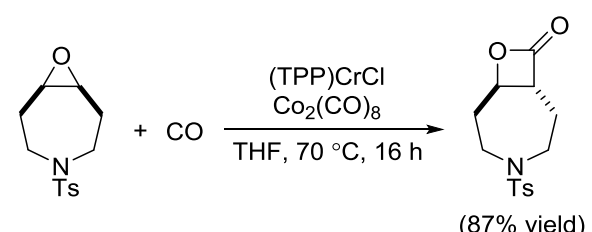

Scheme 48. Cobalt-catalysed ring-expansive carbonylation

In 2011, Ogawa and co-workers reported a novel cobalt carbonyl catalysed thiolative lactonization of alkynes. ${ }^{[85]}$ With thiols as the reaction partner by incorporation of two molecules of carbon monoxide, $\alpha, 6$-unsaturated $\gamma$-thio- $\gamma$-lactones were produced regioselectively (Scheme 49). This process provides a useful method for the catalytic introduction of two molecules of CO into alkynes, regioselectively. Since sulfur compounds were generally believed to be catalyst poisons, these catalytic reactions opened up a new field of transition-metal-catalyzed reactions of organosulfur compounds.

$$
\mathrm{R} \equiv+\mathrm{R} \text { SH }+\underset{40 \mathrm{bar}}{\mathrm{CO} \frac{\mathrm{Co}_{2}(\mathrm{CO})_{8}(9 \mathrm{~mol} \%)}{\mathrm{MeCN}, 140^{\circ} \mathrm{C}}} \mathrm{R}_{\mathrm{RS}}^{\mathrm{R}}=\mathrm{O}
$$

Scheme 49. Cobalt-catalysed thiolative lactonization of alkynes.

Later on, they found that internal alkyne can be applied as substrates in this cobalt-catalyzed thiolative double carbonylation with organosulfur as well (Scheme 50$).{ }^{[86]}$ This process became a useful tool for preparing the corresponding $\alpha, \beta$-unsaturated $\gamma$-thio- $\gamma$-lactones (butenolide derivatives) in good yields. Among the study, it was interestingly found that, for the unsymmetrical alkynes, the thiolative lactonization proceeded with moderate regioselectivity to give the butenolide derivatives on which the carbonyl group preferentially bonds to the less hindered acetylenic carbon.

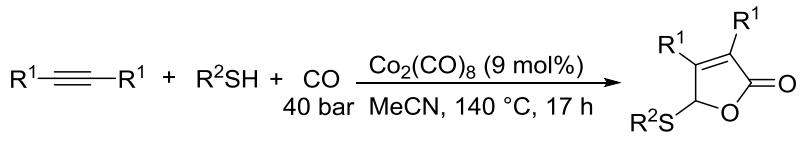

Scheme 50. Cobalt-catalysed thiolative double carbonylation of internal alkynes. 
Recently, Saliu et.al. described a oxidative carbonylation of amine in the presence of bis(salicylaldehyde)ethylenediimine-cobalt(II) catalyst by using TBD (1,5,7-triazabicyclo[4.4.0]dec-5-ene) as the promoter. Here, the application of TBD would be beneficial and could represent an interesting development in the field of the Co-Schiff base complexes catalyzed oxidative carbonylation, as bicyclic guanidine bases are less toxic and more environmentally friendly than pyridine bases. $^{[87]}$

In 2013, Li and co-workers developed a highly efficient cobalt catalysed carbonylation reaction of benzyl chlorides. ${ }^{[88]}$ A variety of phenylacetic acid derivatives were produced under atmosphere pressure of carbon monoxide (Scheme 51). In this methodology, benzimidazole was extended as the ligand. Meanwhile, the catalytic mechanism was also demonstrated by computer simulations.

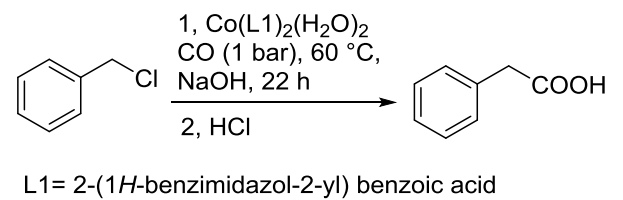

Scheme 51. Cobalt-catalysed carbonylative approach to phenylacetic acid derivatives.

In 2014, a convenient catalyst system consisted by $\mathrm{Co}_{2}(\mathrm{CO})_{8}$ and $\mathrm{LiCl}$ for catalyzing cyclization of CO, imine, and epoxide was established (Scheme 52). ${ }^{[89]}$ This reaction provided an efficient method for the synthesis of substituted 1,3-oxazinan-4-ones from very simple and commercially available starting materials.

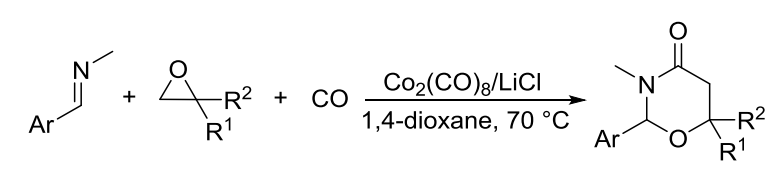

Scheme 52. Cobalt-catalysed carbonylation for synthesis of substituted 1,3-oxazinan-4-ones

Daugulis and Grigorjeva reported a method for the direct carbonylation of aminoquinoline benzamides in 2014 (Scheme 53). ${ }^{[90]}$ Reactions proceeded at room temperature in trifluoroethanol solvent, using oxygen from air as the oxidant and with $\mathrm{Mn}(\mathrm{OAC})_{3}$ as additive. Imides were obtained by the carbonylation of benzoic and acrylic acid derivatives in good yields. The reaction was quite functional groups tolerated, such as halogen, nitro, ether, cyano, ester and so on. The removal of the directing group under mild conditions could afford the corresponding phthalimides. 


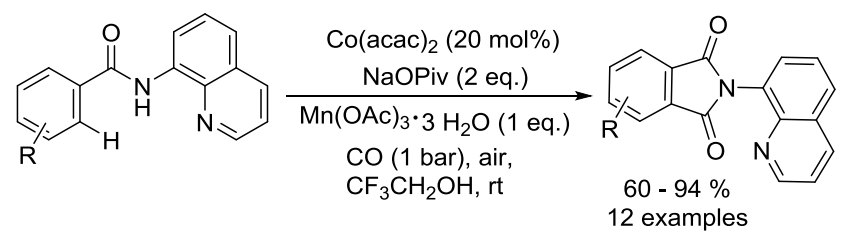

Scheme 53. Cobalt-catalysed carbonylation of aminoquinoline benzamides.

More recently, Zhang and co-workers reported an efficient approach for the $\mathrm{C}\left({ }_{\mathrm{sp} 2}\right)-\mathrm{H}$ bond carbonylation of benzamides with the use of stable and inexpensive $\mathrm{Co}(\mathrm{OAc})_{2} \cdot 4 \mathrm{H}_{2} \mathrm{O}$ as the catalyst. ${ }^{\text {[91] }}$ Interestingly, commercially available and easily handling azodicarboxylates were applied as the nontoxic carbonyl source here (Scheme 54). The reaction revealed broad scope of substrates bearing diverse functional groups.

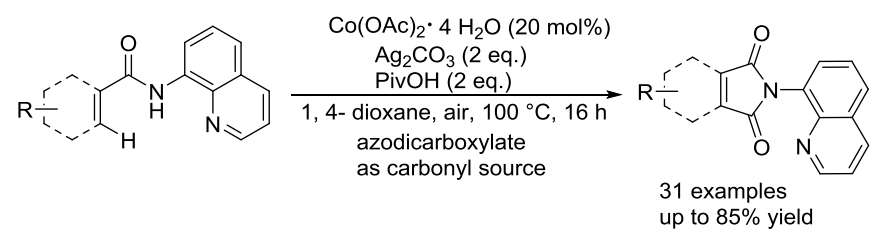

Scheme 54. Cobalt-catalysed $\left.\mathrm{C}_{(\mathrm{sp} 2}\right)-\mathrm{H}$ bond carbonylation of benzamides

In 2017, Gaunt's group reported a cobalt-catalysed carbonylative cyclisation procedure of unactivated aliphatic $\mathrm{C}-\mathrm{H}$ bonds (Scheme 55). ${ }^{[92]}$ The key point of this methodology was the stabilizing effect of the quinolinamide directing group. The process tolerated a wide range of functionalized substrates to generate the corresponding substituted succinimide products. During the manipulation, the operationally simple reaction conditions were complemented by the ability utilizes an atmospheric pressure of carbon monoxide.

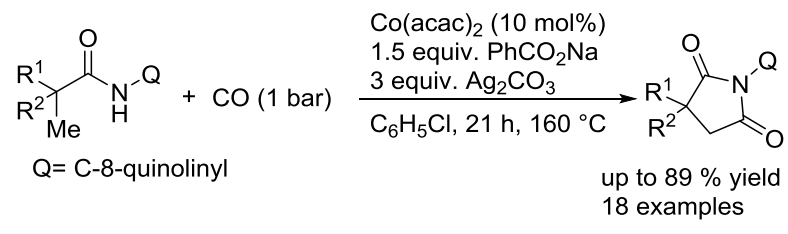

Scheme 55. Cobalt-catalysed carbonylative cyclisation of aliphatic $\mathrm{C}-\mathrm{H}$ bonds.

In the same period, Sundararaju and co-workers reported a similar procedure with trifluorotoluene as the reaction media. ${ }^{[93]}$ Under their reaction conditions, a varieties of unactivated $\left.\mathrm{C}_{(\mathrm{sp} 3}\right)-\mathrm{H}$ bonds were transformed into the corresponding succinimide derivatives (Scheme 56). The initial mechanistic investigation revealed that the involvement of a one electron process operated in the catalytic cycle and the reaction may proceed through Co(IV) to Co(II) cycle. This straightforward 
approach provided an easy access to $\alpha$-spiral succinimides in good yields regioselectively.

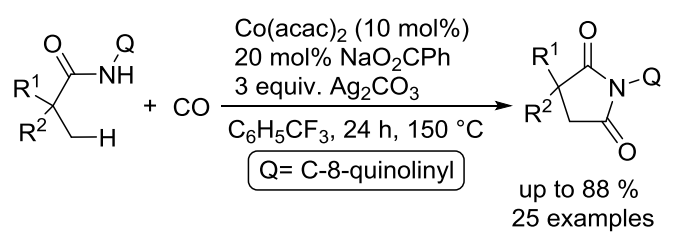

Scheme 56. Cobalt-catalysed synthesis of succinimides.

\section{$1.5 \mathrm{Ni}$-catalysed carbonylation reactions}

Nickel salts are cheap and abundant and have been extensively studied in various organic transformations. However, due to the high risk of the toxic $\mathrm{Ni}(\mathrm{CO})_{5}$ formed from nickel and carbon monoxide, nickel catalyst are studied in CO chemistry with limited cases. As early as in 1969, Corey and Hegedus developed a base-catalysed carboxylation of organic halides with nickel carbonyl as the CO source in protic media. ${ }^{[94]}$ Alkyl halides and allylic halides were transformed effectively with alcohols as reaction partners. Later on, Semmelhack and Brickner further studied this methodology and applied it in the synthesis of five- and six-membered lactones in 1981. With the presences of nickel carbonyl reagents via intramolecular two-step carbonylative cyclization, good yields of the desired products can be obtained (Scheme 57). ${ }^{\text {[95] }}$

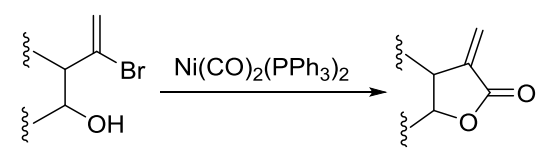

Scheme 57. Ni-mediated synthesized of lactones.

In 1989, Alper and Vasapollo reported the first nickel-catalysed carbonylative transformation of vinyl halides (Scheme 58). ${ }^{[96]}$ Nickel cyanide was found to be the best for the carbonylation of vinyl bromides and chlorides under phase transfer conditions. This method was simple both in execution and work-up, and exhibits excellent stereochemical control. In case with halodienes as the substrates, double carbonylation occurs. ${ }^{[97]}$ For example, good yield of $\alpha$-keto lactone can be produced from 2-bromo-1-phenyl-1,3-butadiene (Scheme 58).

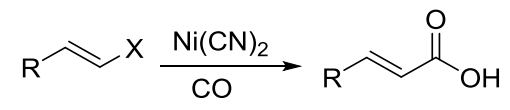

Scheme 58. Nickel-catalysed carbonylation of vinyl halides. 


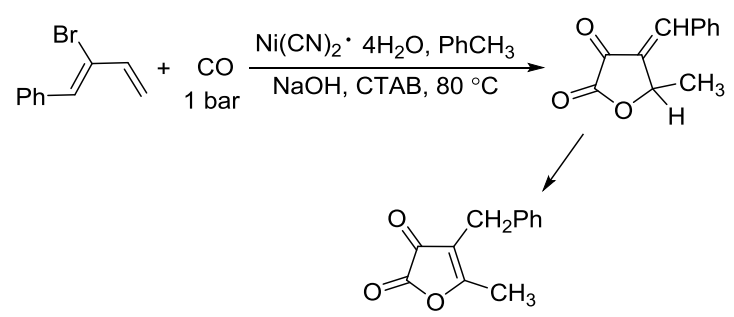

Scheme 59. Double carbonylation of halodienes.

In 1999, Jiang and co-workers reported a procedure on nickel-catalysed carbonylation of methyl acetate to acetic anhydride with methyl iodide as the promoter. ${ }^{[98]}$ Different conditions including catalyst precursors, temperatures, pressures, ligands, lithium acetate and methyl iodide concentration were investigated in detail. Additionally, mechanism and possible side reactions in the carbonylation were studied as well. The in situ reaction monitoring experiments readily enabled the determination of the concentrations of organonickel species as well as the concentration of carbonylation products under fast reaction conditions. In the meantime, an in situ CIR-FTIR investigation of process effects in the nickel catalysed carbonylation of methanol was reported by Okrasinski and co-workers. ${ }^{\text {[9] }} \mathrm{A}$ mechanistic of the phosphine-modified nickel-catalyzed acetic acid process was also investigated in their group. ${ }^{[100]}$ A nickel-aluminum catalysed liquid-phase carbonylation of methanol was reported by Matsumura and Kapoor in 2004 (Scheme 60). ${ }^{[101]}$ In this reaction, methanol was converted into methyl acetate in the presence of methyl iodide at $200{ }^{\circ} \mathrm{C}$. Formation of methyl formate depended on the pressure of carbon monoxide applied, which indicated that insertion of carbon monoxide to methyl iodide was a key step of the carbonylation and dimethyl ether reacted with the intermediate to form the final methyl acetate.

$$
\begin{array}{ll}
\mathrm{CH}_{3} \mathrm{I}+\mathrm{CO} \stackrel{[\mathrm{Ni}]}{\longrightarrow} \mathrm{CH}_{3} \mathrm{COI} \\
\mathrm{CH}_{3} \mathrm{I}+\mathrm{CH}_{3} \mathrm{COI} \stackrel{[\mathrm{Ni}]}{\longrightarrow} \mathrm{DME} \\
\mathrm{CH}_{3} \mathrm{OH}+\mathrm{CH}_{3} \mathrm{COI} \stackrel{[\mathrm{Ni}]}{\longrightarrow} \mathrm{MeOAC}+\mathrm{HI}
\end{array}
$$

Scheme 60. Liquid-phase carbonylation of methanol.

In 2008, Ricart and co-workers reported a nickel-catalysed [2+2+1] carbonylative cycloaddition reaction between norbornenes and allyl halides. ${ }^{[102]}$ Catalyzed by $\mathrm{Ni}(\mathrm{II})$ catalyst under very mild conditions (atmospheric pressure and room temperature), the desired products can be produced effectively (Scheme 61). Interestingly, two major products whose ratio could be tuned by carefully adding water with different amounts. 


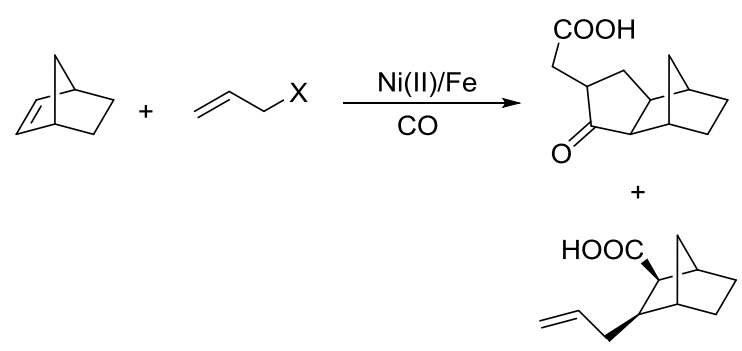

Scheme 61. Carbonylative cycloaddition reaction between norbornenes and allyl halides.

Chen and Wang described an interesting nickel-catalysed carbonylative Negishi cross-coupling reactions in the same year (Scheme 62). ${ }^{[103]}$ This method readily provided various enones from enol triflates and diorganozinc reagents, with catalytic amounts of nickel(II) chloride4,4'-dimethoxyl-2,2'-bipyridyl under carbon monoxide atmosphere. The addition of lithium or magnesium halides, as well as the use of polar solvents facilitated the rate of the carbon monoxide insertion. Carbonylative alkenyl-aryl, alkenyl-alkenyl, and alkenyl-alkyl coupling were achieved effectively.

$$
\mathrm{R}^{1} \overbrace{\mathrm{R}^{3}}^{\mathrm{R}^{2}} \mathrm{X}+\mathrm{R}^{4} \mathrm{Zn}
$$

$X=O T f$, I

$\mathrm{R}^{4}=$ aryl, alkenyl, alky

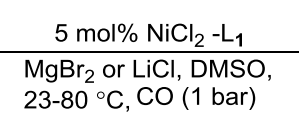<smiles>[R]C(=O)C([R])=C([R])[R]</smiles>
$23-80^{\circ} \mathrm{C}, \mathrm{CO}$ (1 bar)<smiles>COc1ccnc(-c2cc(OC)ccn2)c1</smiles>

Scheme 62. Ni-catalysed carbonylative Negishi reactions.

Meanwhile, Ogoshi's research group demonstrated the formation of a nickeladihydrofuran by oxidative cyclization of an alkyne and an aldehyde with nickel (0) (Scheme 63). ${ }^{[104]}$ The nickeladihydrofuran can be transformed into the corresponding lactone by under $\mathrm{CO}$ pressure in quantitative yields.

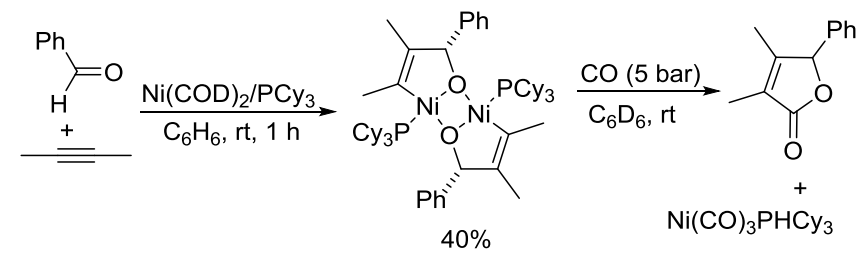

Scheme 63. Formation of nickeladihydrofuran and transformation into lactone.

Interestingly, Lee and co-workers developed a nickel-catalysed coupling reaction of aryl bromides with formamide in 2009 (Scheme 64). ${ }^{[105]}$ Using this nickel-phosphite catalytic system, aryl bromides can react with a range of formamides to give the corresponding aryl amides in moderate to good 
yields. The steric bulkiness of formamides plays a very important role in this reaction. The less hindered formamide required lower catalytic loading for full conversion and produced higher yields than the more hindered one.

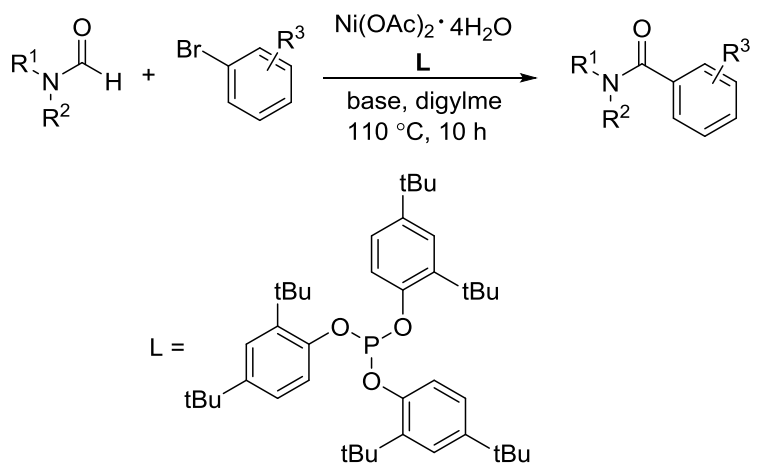

Scheme 64. Nickel-catalysed aminocarbonylation of aryl bromides.

In 2009, Ricart, Ventosa and their co-workers reported a catalytic procedure on the selective mono or double carbonylations of alkenes or acetylenes with allyl bromides (Scheme 65). ${ }^{[106 a]}$ Catalyzed by nickel, cyclopentanes, cyclohexanes or plainly-carbonylated adducts can be obtained. And mechanistic studies were performed as well. ${ }^{[106 b]}$

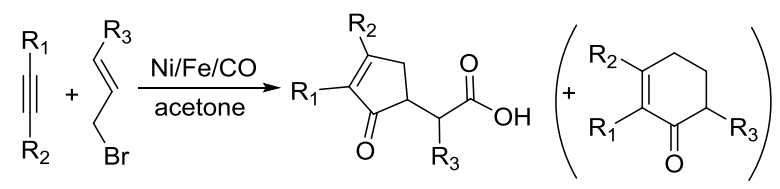

Scheme 65. Carbonylative cycloaddition of alkynes and allyl halides in acetone.

Ogosh and co-workers developed a $\mathrm{Ni}(0)$-catalysed $[2+2+1]$ carbonylative cycloaddition of imines and alkynes using phenyl formate as the CO source in 2014 (Scheme 66). ${ }^{[107]}$ Using $10 \mathrm{~mol} \%$ of

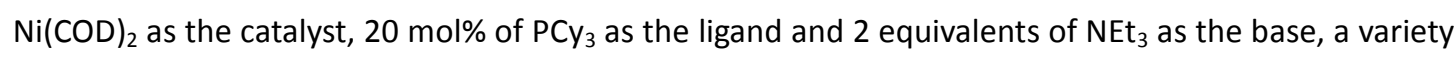
of lactams can be prepared in good to high yields.

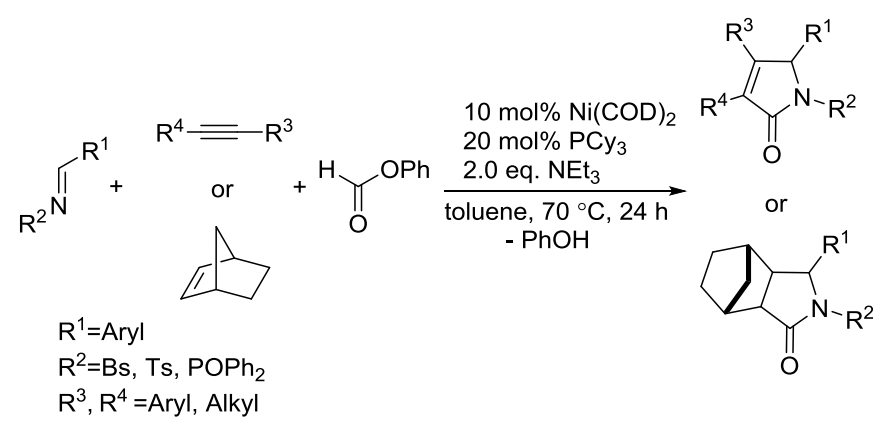

Scheme 66. Ni(0)-catalysed carbonylative cycloaddition of imines. 
In 2015, Bengali, Arndtsen and their co-workers described a nickel-catalysed carbonylative procedure for the synthesis of isoindolinones from aryl iodides and imines (Scheme 67). ${ }^{[108]}$ In the presence of a catalytic amount of $\mathrm{Ni}(\mathrm{COD})_{2}$, using DiPEA (diisopropylethylamine) as the base and $\mathrm{Bu}_{4} \mathrm{NCl}$ as the additive, , various isoindolinones were isolated in good yields under atmospheric pressure (1 bar) of carbon monoxide.

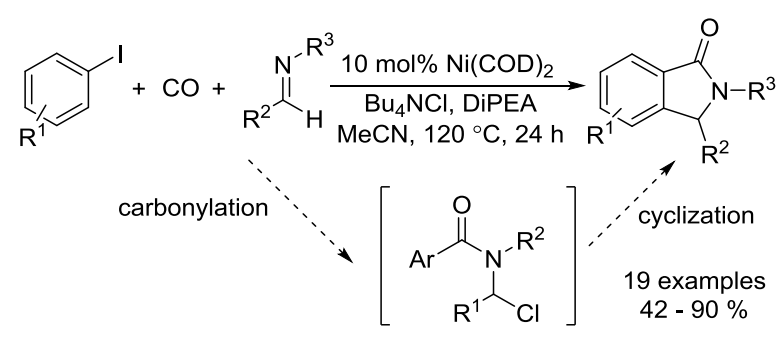

Scheme 67. Nickel-catalysed synthesis of isoindolinones.

Recently, Zhou and co-workers developed a nickel-catalysed hydrocarbonylation of terminal alkynes with formic acid as the CO source (Scheme 68). ${ }^{[109]}$ The high efficiency and low cost of nickel catalysts made this nickel-catalysed hydrocarboxylation of acetylene a promising process for acrylic acids production. At the same time, Fu and co-workers also developed a nickel-catalysed region- and stereselective hydrocarboxylation of alkynes (Scheme 70$).{ }^{[110]}$ In the presence of a catalytic 5 mol\% $\mathrm{Ni}(\text { acac })_{2}, 7 \mathrm{~mol} \% \mathrm{dppbz}, 20 \mathrm{~mol}_{\mathrm{O}} \mathrm{Piv}_{2} \mathrm{O}$, alkyne can reacted with formic acid to afford the desired $\alpha, 6$-unsaturated carboxylic acids.

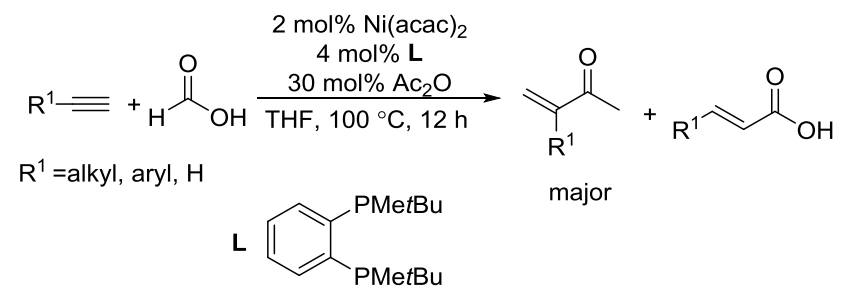

Scheme 68. Nickel-catalysed hydrocarbonylation of terminal alkynes.

$$
\mathrm{R}^{1}, \mathrm{R}^{2}=\text { alkyl, aryl, } \mathrm{H} \quad \mathrm{R}^{2}+\mathrm{R}_{\mathrm{OH}} \frac{\begin{array}{l}
\mathrm{Ni}(\text { acac })_{2} \\
\text { aciphosphine anhydride } \\
\text { toluene, } 100^{\circ} \mathrm{C}
\end{array}}{\begin{array}{l}
42 \text { examples } \\
\text { up to } 95 \% \text { yields }
\end{array}}
$$

Scheme 69. Nickel-catalysed hydrocarbonylation of alkynes with formic acid.

More recently, the direct activation of simple $\mathrm{C}-\mathrm{N}$ bonds via oxidative addition was reported by Huang and co-workers (Scheme 70). ${ }^{[11]}$ Through this method, tertiary benzylamines can be 
transformed into the corresponding amides in moderate to good yields.

$$
\begin{aligned}
& \mathrm{Ni}_{\substack{\text { anisole, } 140^{\circ} \mathrm{C} \\
\mathrm{CO}(10-30 \mathrm{bar})}}^{\mathrm{NiCl}_{2} / \mathrm{L}(5 \mathrm{~mol} \%)} \\
& 20 \text { example } \\
& 15-77 \% \text { yields }
\end{aligned}
$$

Scheme 70. Nickel-catalysed carbonylation of benzyl amines. 


\section{Objectives of this work}

As described in the introduction part, non-noble metal catalysed carbonylative transformations have attracted much research interest both in academics and industries. Compared with noble metal catalysts (Pd and Rh), non-noble catalysts are much less studied. Based on the known obvious advantages of non-noble metals catalysts, it's attractive to explore their activities in carbonylation reactions. The major aim of this work is to develop the novel non-noble metal catalyst systems for carbonylation transformations to useful bulk and fine chemicals, such as esters, amides and amines.

Among all the cheap, copper and manganese are the best catalysts in organic synthesis due to its abundance, low price, and high biological compatibility. Therefore, carbonylative transformations based on these catalysts are proved to be highly economic and efficient, which attracts our interest to further discover unknown transformations for sustainable organic synthesis.

Moreover, the development of general catalytic protocols for more challenging substrates remains an important but challenging goal. Based on our continuous interest in carbonylation reactions, we became attracted by carbonylation of alkanes and alkyl halides, which represents a straightforward and economic method for the synthesis of high value carbonyl compounds.

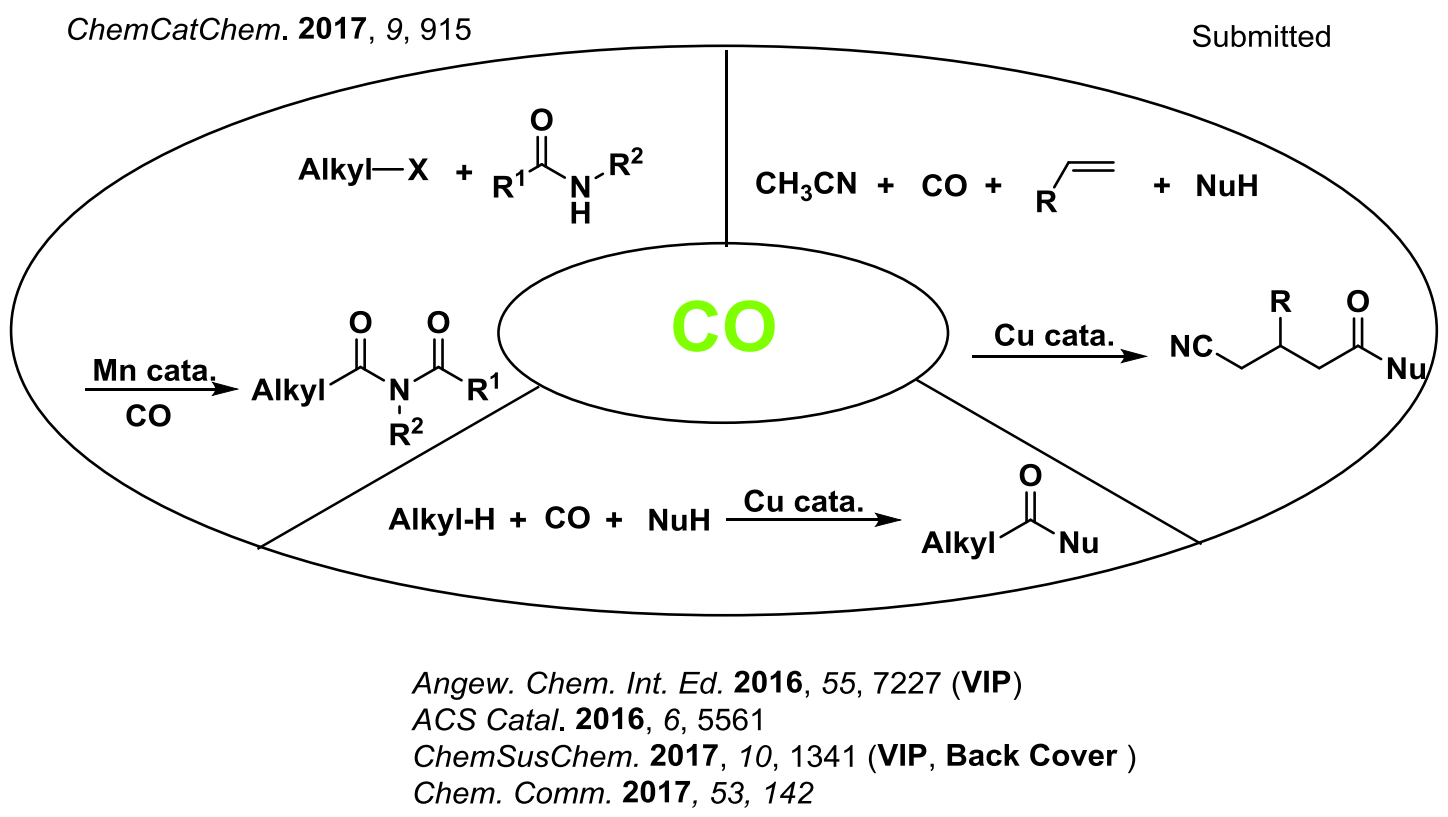

Figure 2: Non-noble metal catalysed carbonylation of alkanes and alkyl bromides 


\section{Summary of works}

\subsection{Copper-Catalysed Carbonylative Coupling of Cycloalkanes and Amides}

Yahui Li, Kaiwu Dong, Fengxiang Zhu, Zechao Wang, and Xiao-Feng Wu*

Angew. Chem. Int. Ed. 2016, 55, $7227-7230$

Author contributions:

Dr. Xiao-Feng Wu and Yahui Li conceived and developed this project. Dr. Xiao-Feng Wu and Yahui Li wrote the manuscript with revisions provided by Dr. Kaiwu Dong, Fengxiang Zhu, Zechao Wang. My contribution as co-author of this paper is approximately $85 \%$. 


\title{
Copper-Catalyzed Carbonylative Coupling of Cycloalkanes and Amides
}

\author{
Yahui Li, Kaiwu Dong, Fengxiang Zhu, Zechao Wang, and Xiao-Feng Wu*
}

\begin{abstract}
Carbonylation reactions are a most powerful method for the synthesis of carbonyl-containing compounds. However, most known carbonylation procedures still require noble-metal catalysts and the use of activated compounds and good nucleophiles as substrates. Herein, we developed a copper-catalyzed carbonylative transformation of cycloalkanes and amides. Imides were prepared in good yields by carbonylation of a $\mathrm{C}\left(s \mathrm{~s}^{3}\right)-\mathrm{H}$ bond of the cycloalkane with the amides acting as weak nucleophiles. Notably, this is the first report of copper-catalyzed carbonylative $\mathrm{C}-\mathrm{H}$ activation.
\end{abstract}

$T_{\mathrm{r}}$ erful methods for the synthesis of carbonyl-containing compounds. ${ }^{[1]}$ Through carbonylation, the carbon chain of a parent molecule can be easily elongated with carbon monoxide $(\mathrm{CO})$ as one of the cheapest and most abundant $\mathrm{C} 1$ building blocks. However, most of the known procedures require either noble-metal catalysts, activated substrates, and/ or sufficiently reactive nucleophiles (Scheme 1a). More specifically, catalysts based on palladium, ruthenium, and rhodium are frequently explored. Aryl halides and analogues thereof are commonly applied reactants whereas alcohols, amines, and organometallic reagents are usually employed as the nucleophiles. Hence, these methods suffer from some common limitations, such as expensive catalysts and tedious substrate preparation.

Various carbonylative $\mathrm{C}-\mathrm{H}$ activation reactions of arenes that benefit from the assistance of directing groups have been reported. ${ }^{[2]}$ In the presence of a noble-metal catalyst and a suitable oxidant, the $\mathrm{C}\left(\mathrm{sp}^{2}\right)-\mathrm{H}$ bonds of arenes were

(a)

$$
\text { Previous work: }
$$
This work:

(b)

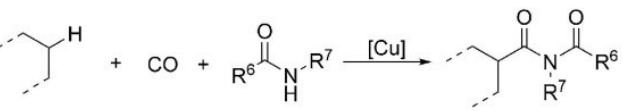

Scheme 1. Carbonylation reactions.

[*] Y. Li, Dr. K. Dong, F. Zhu, Z. Wang, Prof. Dr. X.-F. Wu Leibniz-Institut für Katalyse e.V. an der Universität Rostock Albert-Einstein-Strasse 29a, 18059 Rostock (Germany) E-mail: Xiao-Feng.Wu@catalysis.de

Prof. Dr. X.-F. Wu

Department of Chemistry, Zhejiang Sci-Tech University Xiasha Campus, Hangzhou 310018 (P.R. China)

(2) Supporting information for this article can be found under: http://dx.doi.org/10.1002/anie.201603235. carbonylated and gave the desired products in good yields. A few rare examples of the directing-group-assisted carbonylation of $\mathrm{C}\left(\mathrm{sp}^{3}\right)-\mathrm{H}$ bonds with palladium or ruthenium catalysts have been reported ${ }^{[3]}$ whereas directing-group-free variants are without precedence. ${ }^{[4]}$ On the other hand, the free radical carbonylation of (cyclo)alkanes in the presence of radical initiators has been well established. ${ }^{[1 \mathrm{f}-\mathrm{i}]}$

Among all transitional-metal catalysts, copper salts are particularly inexpensive and benefit from their low toxicity. ${ }^{[5]}$ The use of copper catalysts in carbonylative transformations is thus attractive for both academic and industrial purposes. However, to our surprise, only few examples of coppercatalyzed carbonylative coupling reactions with aryl iodides or diaryliodonium salts have been reported. ${ }^{[6]}$

On the other hand, amides occur frequently in nature, and they are also important intermediates and building blocks in organic synthesis. ${ }^{[7]}$ Based on the diversity of available amides, the development of new reactions that employ amides as reactants is a worthwhile pursuit. However, compared with alcohols and amines, the low nucleophilicity of amides has hindered their application in carbonylative coupling reactions. ${ }^{[8]}$ On the other hand, owing to the comparatively high stability of amides towards oxidants, suitable conditions for the use of amides as coupling partners should be easily found.

With all of these considerations in mind, we herein report the first copper-catalyzed carbonylative $\mathrm{C}-\mathrm{H}$ activation of cycloalkanes. With amides as the reaction partners, the $\mathrm{C}\left(\mathrm{sp}^{3}\right)-\mathrm{H}$ bond of simple cycloalkanes were carbonylated to finally provide the corresponding imides in good yields (Scheme 1b).

Initially, we chose cyclohexane (both as reagent and solvent) and $\mathrm{N}$-methylacetamide as the model substrates to establish this carbonylation reaction (Table 1). Among various metal catalyst precursors (entries 1-10), $\mathrm{CuBr}\left(\mathrm{Me}_{2} \mathrm{~S}\right)$ gave the best result ( $80 \%$ GC yield, product isolated in $75 \%$ yield; entry 6). Notably, the decreased reaction efficiency with $\mathrm{Pd}(\mathrm{OAc})_{2}, \mathrm{PdCl}_{2}, \mathrm{Mn}_{2}(\mathrm{CO})_{10}$, and $\mathrm{Co}(\mathrm{acac})_{2}$ excludes the possibility that such metal impurities in the copper salt play a role in the overall reaction (entries 7-10).

Next, various ligands were studied (entries 11-20). L2, L6, and $\mathbf{L 7}$ achieved similar results to 1,10-phenanthroline hydrate (entries 12, 16, and 17) whereas other ligands were less effective. Subsequently, the CO pressure was varied. To our surprise, the yield of $\mathbf{3} \mathbf{a}$ improved with a decrease in the CO pressure (entries 21 and 22). Other additives, such as $I_{2}$ and $\mathrm{KI}$, were also tested, but led to decreased reaction efficiency (entries 23 and 24). Furthermore, in the absence of catalyst or ligand, only trace amounts of the desired product were observed (entries 25 and 26). Overall, it was found that 
Table 1: Catalyst screen. ${ }^{[a]}$

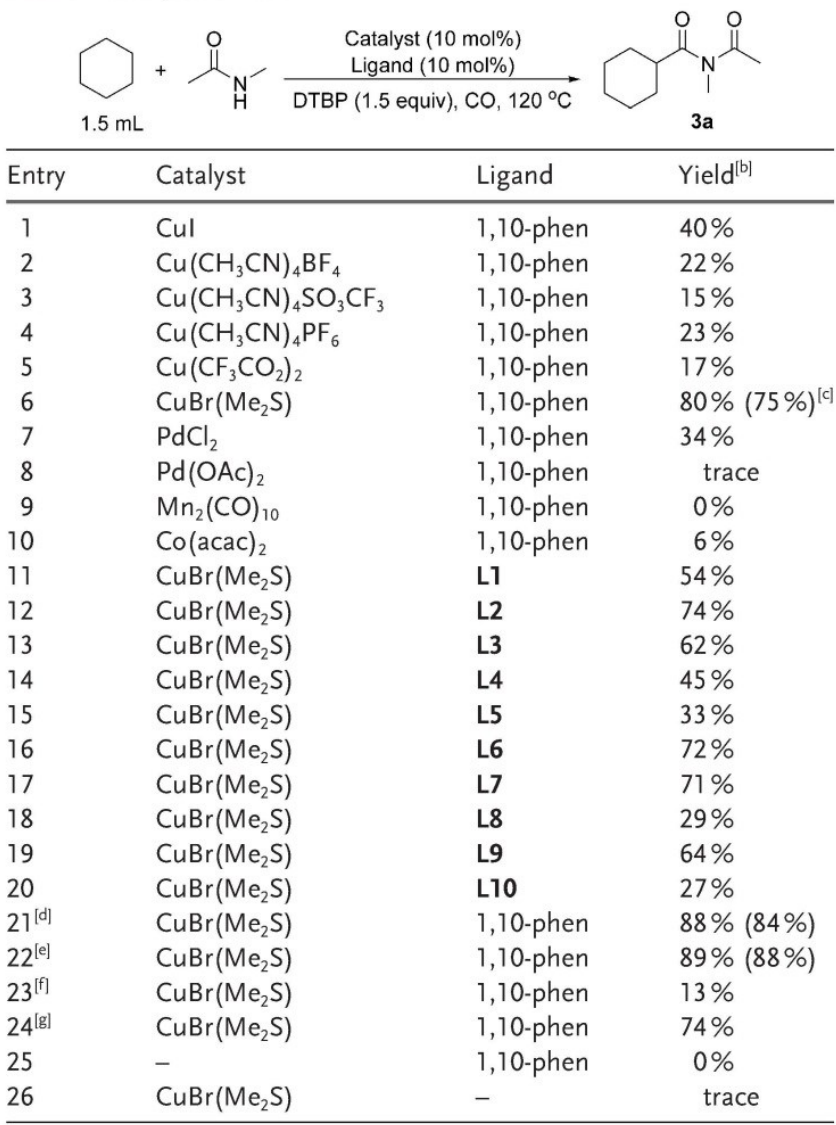

[a] Reaction conditions: $N$-Methylacetamide $(0.5 \mathrm{mmol})$, catalyst (10 mol\%), ligand (10 mol\%), DTBP $(0.75 \mathrm{mmol}), \mathrm{CO}$ (50 bar), cyclohexane $(1.5 \mathrm{~mL}), 24 \mathrm{~h}$. [b] Determined by GC analysis. [c] Yields of isolated products given in parentheses. [d] Catalyst ( $5 \mathrm{~mol} \%)$, ligand (5 mol\%), CO (30 bar). [e] Catalyst (5 mol\%), ligand (5 mol\%), CO (20 bar). [f] I $\mathrm{I}_{2}(10 \mathrm{~mol} \%)$. [g] KI $(10 \mathrm{~mol} \%)$. acac=acetylacetonate, $\mathrm{DTBP}=$ di-tert-butylperoxide, 1,10-phen $=1,10$-phenanthroline hydrate .<smiles>Cc1ccc2ccc3ccc(C)nc3c2n1</smiles><smiles>c1ccc(-c2ccccn2)nc1</smiles>

L2<smiles>O=C1C(=O)c2cccnc2-c2ncccc21</smiles>

L3

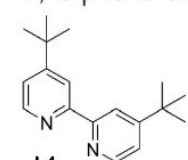

L4
L5

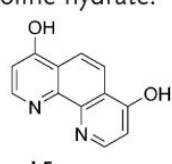<smiles>COc1ccnc2c1ccc1c(OC)ccnc12</smiles>

L6<smiles>O=[N+]([O-])c1cc2cccnc2c2ncccc12</smiles>

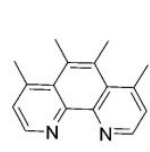

L9

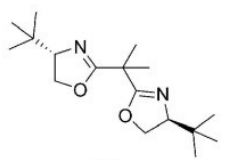

L10 the use of $5 \mathrm{~mol} \%$ of $\mathrm{CuBr}\left(\mathrm{Me}_{2} \mathrm{~S}\right)$ and 1,10-phen together with DTBP (1.5 equiv) under CO atmosphere (20 bar) gave 3a in $89 \%$ yield (determined by GC analysis; entry 22 ).

With the optimized reaction conditions in hand, we examined the scope of the reaction with a range of amides. As shown in Table 2, the desired imides were formed in good yield when $N$-ethylacetamide or $N$-butylpropionamide was used in combination with cyclohexane (yield of isolated $\mathbf{3 b}$ and 3c: $69 \%$ and $74 \%$, respectively). Long-chain imides were also formed in good to excellent yields (such as $\mathbf{3 e}, \mathbf{3 f}, \mathbf{3} \mathbf{g}$, and 3h).

Different cyclic amides were also tested (Table 3). Azepan-2-one (2j) and azocan-2-one $(\mathbf{2} \mathbf{k})$ gave the corre-
Table 2: Copper-catalyzed carbonylative imide synthesis. ${ }^{[\mathrm{a}]}$

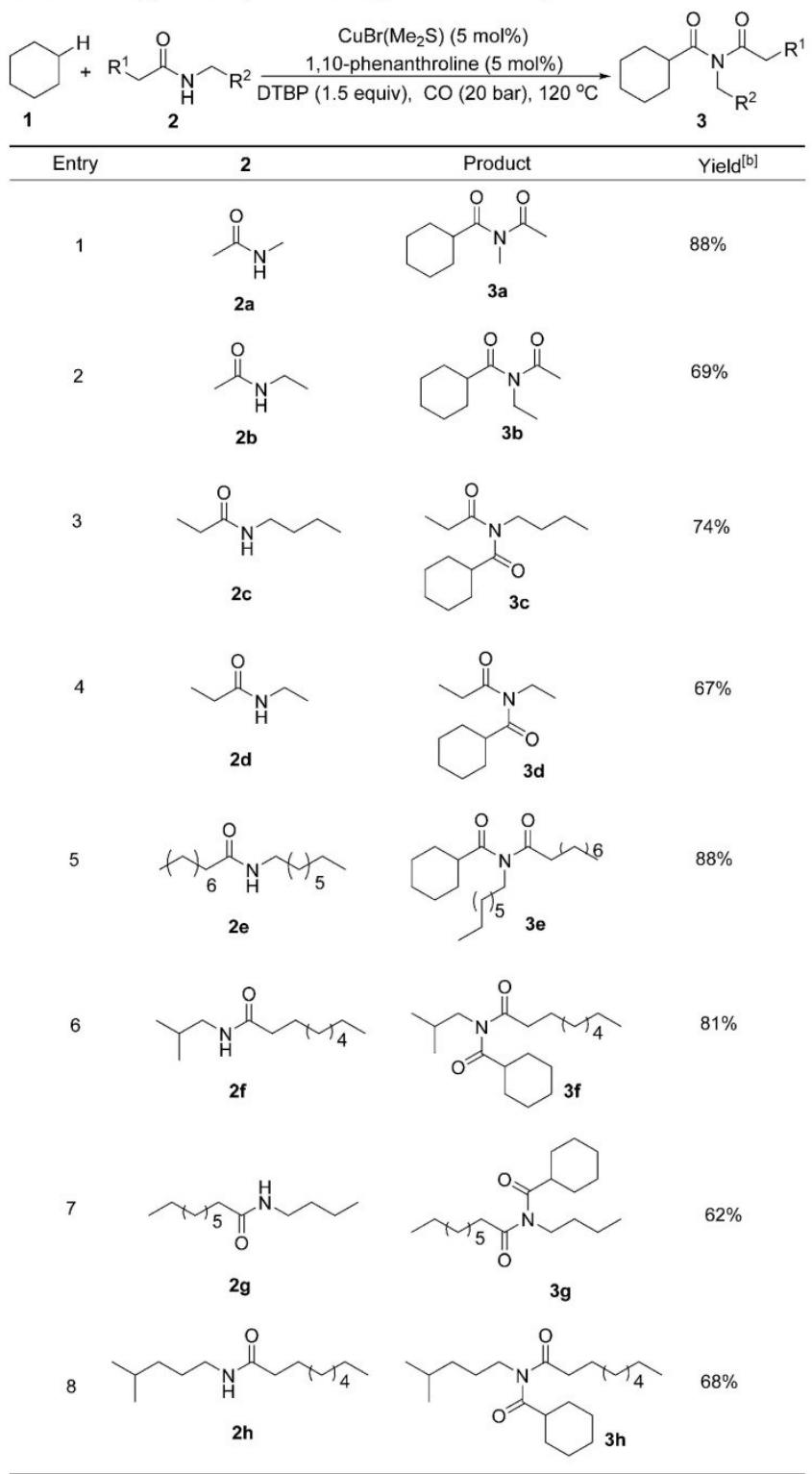

[a] 2 (0.5 mmol), $\mathrm{CuBr}\left(\mathrm{Me}_{2} \mathrm{~S}\right)(5 \mathrm{~mol} \%), 1,10$-phen (5 mol\%), DTBP $(0.75 \mathrm{mmol}), \mathrm{CO}(20 \mathrm{bar})$, cyclohexane $(1.5 \mathrm{~mL}), 24 \mathrm{~h}$. [b] Yields of isolated products.

sponding products in very good yields $(\mathbf{3} \mathbf{j}$ and $\mathbf{3 k}, 91 \%$ and $85 \%$, respectively). Interestingly, these products belong to a family of proinflammatory mediators that promote the recruitment and activation of leukocytes (e.g., monocytes, lymphocytes, and granulocytes). The reactions between phenyl-substituted amides (2l, 2 m, and 2n) and cyclohexane gave the desired products in yields of $85 \%, 86 \%$, and $69 \%$, respectively. Whereas $\mathrm{N}$-methylbenzamide gave the desired coupling product in $61 \%$ yield, with $N$-phenylacetamide and $\mathrm{N}$-phenylformamide, only the corresponding amides were obtained rather than the desired imides. This may due to the low stability of the imides, which decompose immediately to give these amides. Furthermore, benzamide and acetamide, as exemplary primary amides, were reacted with cyclohexane under the standard reaction conditions, but the desired imides were not detected. 
Table 3: Copper-catalyzed carbonylation with lactams and amides. ${ }^{[a]}$

$\underset{1(1.5 \mathrm{~mL})}{{ }_{\text {Entry }}}$

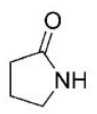

2i<smiles>O=C1CCCCCN1</smiles>

2j

3<smiles>O=C1CCCCCCN1</smiles>

2k

4<smiles>CC(=O)NCc1ccccc1</smiles>

2l

5<smiles>CC(=O)NCCc1ccccc1</smiles>

$2 m$<smiles>O=C1CCCCCN1C(=O)C1CCCCC1</smiles>

3j
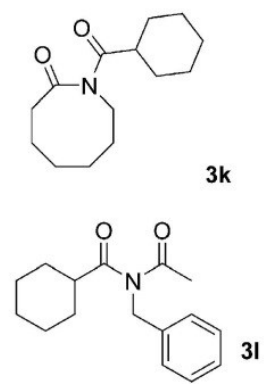

$85 \%$

$69 \%$

6<smiles>CCCNC(=O)CCCc1ccccc1</smiles><smiles>CC(=O)N(CCc1ccccc1)C(=O)C1CCCCC1</smiles>

30<smiles>CN(C(=O)c1ccccc1)C(=O)C1CCCCC1</smiles>

$91 \%$

$5 \%$
8<smiles>CC(=O)Nc1ccccc1</smiles>

$2 p$

9<smiles>O=CNc1ccccc1</smiles>

$2 q$

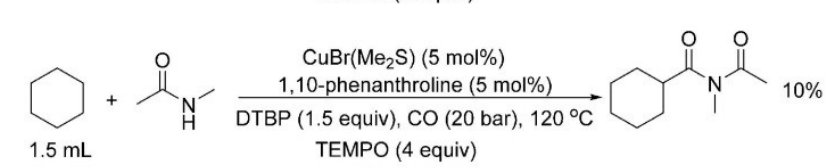

Scheme 2. Control experiments.

Based on our results, a possible reaction mechanism is proposed (Scheme 3 ). The reaction is initiated by the copper(I)-catalyzed or thermal homolytic cleavage of the peroxide to generate a tert-butoxy radical, which reacts with cyclohexane; sequential oxidation of the copper(I) species gives the $\mathrm{Cu}^{\mathrm{III}}$-cyclohexane intermediate $\mathbf{D}$. Then, complex $\mathbf{D}$ reacts with the amide to yield $\mathrm{Cu}^{\mathrm{III}}$ intermediate $\mathbf{E}$. Subsequent $\mathrm{CO}$ insertion forms intermediate $\mathbf{F}$ or $\mathbf{G}$, which then affords the final carbonylation product after reductive elimination while the active $\mathrm{Cu}^{\mathrm{I}}$ species is regenerated for the next catalytic cycle.

In conclusion, we have developed a copper-catalyzed carbonylation reaction of cycloalkanes with amides as the nucleophiles. Various imides were prepared in good yields by carbonylation of a $\mathrm{C}\left(\mathrm{sp}^{3}\right)-\mathrm{H}$ bond of the cycloalkane.

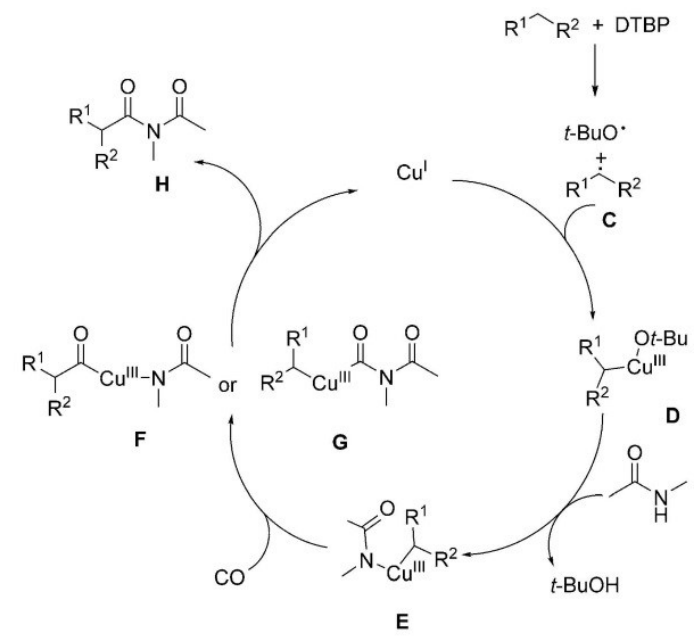

Scheme 3. Proposed reaction mechanism.

$67 \%$ $62 \%$
Furthermore, several cycloalkane derivatives were tested (Table 4). Cyclopentane, cycloheptane, and cyclooctane worked well under the standard reaction conditions moderate to good yields ( $3 \mathbf{q}, \mathbf{3 r}$, and $\mathbf{3 s}$ ). With adamantane as (trifluoromethyl)benzene was used as the solvent (entry 4). The use of pentane under the standard reaction conditions

To gain insight into the reaction mechanism, we conducted some control experiments (Scheme 2). When 2 equiv the desired product was only formed in $30 \%$ yield (determined by GC). The yield further decreased to $10 \%$ in the presence of 4 equiv of TEMPO.

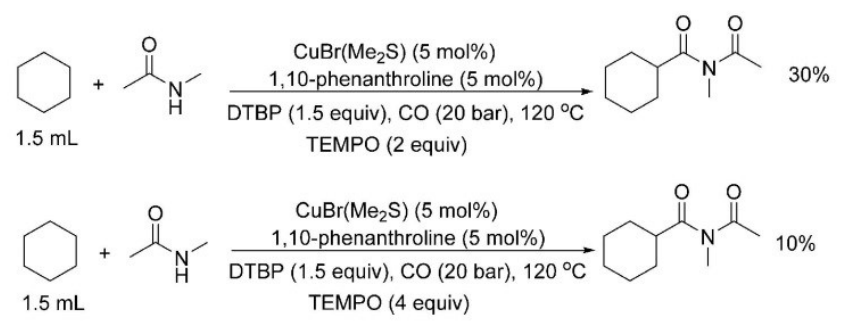

[a] 2 (0.5 mmol), $\mathrm{CuBr}\left(\mathrm{Me}_{2} \mathrm{~S}\right)$ (5 mol\%), 1,10-phen (5 mol\%), DTBP $(0.75 \mathrm{mmol}), \mathrm{CO}$ (20 bar), cyclohexane $(1.5 \mathrm{~mL}), 24 \mathrm{~h}$. [b] Yields of isolated products. 
Table 4: Copper-catalyzed synthesis of imides with various alkanes. ${ }^{[a]}$

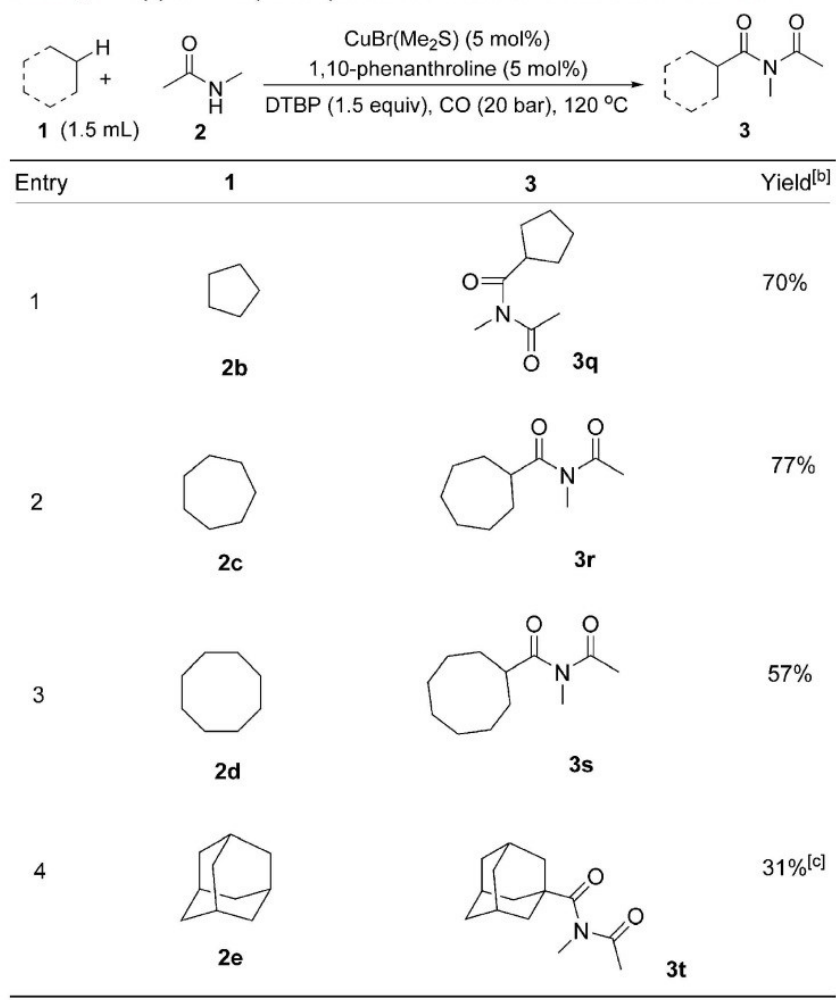

[a] 2 (0.5 mmol), $\mathrm{CuBr}\left(\mathrm{Me}_{2} \mathrm{~S}\right)(5 \mathrm{~mol} \%), 1,10$-phen (5 mol\%), DTBP (0.75 mmol), CO (20 bar), alkane (1.5 mL), 24 h. [b] Yields of isolated products. $[\mathrm{c}] \mathrm{PhCF}_{3}(1.5 \mathrm{~mL})$, adamantane $(0.5 \mathrm{mmol}), \mathrm{CuBr}\left(\mathrm{Me}_{2} \mathrm{~S}\right)$ (5 mol\%), 1,10-phen (5 mol\%), DTBP $(0.75 \mathrm{mmol}), \mathrm{CO}$ (20 bar), $24 \mathrm{~h}$.

Notably, this is the first report of copper-catalyzed carbonylative $\mathrm{C}-\mathrm{H}$ activation.

\section{Experimental Section}

General procedure: A $4 \mathrm{~mL}$ screw-cap vial was charged with $\mathrm{CuBr}$ $\left(\mathrm{Me}_{2} \mathrm{~S}\right) \quad(5.1 \mathrm{mg}, 5 \mathrm{~mol} \%)$, 1,10-phenanthroline hydrate $(5 \mathrm{mg}$, $5 \mathrm{~mol} \%)$, cyclohexane $(1.5 \mathrm{~mL})$, and an oven-dried stir bar. The vial was closed with a Teflon septum and cap and connected to the atmosphere via a needle. After cyclohexane $(1.5 \mathrm{~mL})$ and DTBP $(0.75 \mathrm{mmol})$ had been added with a syringe, the vial was moved to an alloy plate and put into a Paar 4560 series autoclave $(500 \mathrm{~mL})$ under argon atmosphere. At room temperature, the autoclave was flushed with $\mathrm{CO}$ three times and then subjected to $20 \mathrm{bar}$ of $\mathrm{CO}$. The autoclave was placed on a heating plate equipped with a magnetic stirrer and an aluminum block. The reaction mixture was heated to $120^{\circ} \mathrm{C}$ for $24 \mathrm{~h}$. Afterwards, the autoclave was cooled to room temperature, and the pressure was carefully released. After solvent removal under reduced pressure, the product was isolated by column chromatography on silica gel (pentane/ethyl acetate $=20: 1$ ).

\section{Acknowledgements}

We acknowledge financial support from the Chinese Scholarship Council, the NSFC (21472174), and the Zhejiang Natural Science Fund for Distinguished Young Scholars (LR16B020002). We thank Professor Matthias Beller
(LIKAT) for general support and Dr. W. Baumann, Dr. C. Fisher, S. Buchholz, and S. Schareina for analytical support.

Keywords: amides - carbonylation - copper catalysis . cycloalkanes · imides

How to cite: Angew. Chem. Int. Ed. 2016, 55, 7227-7230 Angew. Chem. 2016, 128, 7343-7346

[1] For selected recent reviews on carbonylation, see: a) X. F. Wu, H. Neumann, M. Beller, Chem. Rev. 2013, 113, 1-35; b) X. F. Wu, H. Neumann, M. Beller, Chem. Soc. Rev. 2011, 40, 0; c) X.-F. Wu, H. Neumann, ChemCatChem 2012, 4, 447-458; d) Q. Liu, H. Zhang, A. Lei, Angew. Chem. Int. Ed. 2011, 50, 10788-10799; Angew. Chem. 2011, 123, 10978-10989; e) X. F. Wu, H. Neumann, M. Beller, ChemSusChem 2013, 6, 229-241; for leading reviews on radical carbonylation, see: f) C. H. Schiesser, U. Wille, H. Matsubara, I. Ryu, Acc. Chem. Res. 2007, 40, 303-313; g) S. Sumino, A. Fusano, T. Fukuyama, I. Ryu, Acc. Chem. Res. 2014, 47, 1563 -1574; h) I. Ryu, N. Sonoda, Angew. Chem. Int. Ed. Engl. 1996, 35, 1050-1066; Angew. Chem. 1996, 108, 1140-1157; i) I. Ryu, Chem. Rec. 2002, 2, 249-258.

[2] For selected examples of carbonylative $\mathrm{C}-\mathrm{H}$ activation, see: a) X Li, X. Li, N. Jiao, J. Am. Chem. Soc. 2015, 137, 9246-9249; b) Z. H. Guan, M. Chen, Z.-H. Ren, J. Am. Chem. Soc. 2012, 134, $17490-17493$; c) W. Li, C. Liu, H. Zhang, K. Ye, G. Zhang, W. Zhang, Z. Duan, S. You, A. Lei, Angew. Chem. Int. Ed. 2014, 53, 2443-2446; Angew. Chem. 2014, 126, 2475-2478; d) X. Wu, Y. Zhao, H. Ge, J. Am. Chem. Soc. 2015, 137, 4924-4927; e) R. Shi, L. Lu, H. Zhang, B. Chen, Y. Sha, C. Liu, A. Lei, Angew. Chem. Int. Ed. 2013, 52, 10582-10585; Angew. Chem. 2013, 125, $10776-$ 10779; f) K. Orito, A. Horibata, T. Nakamura, H. Ushito, H. Nagasaki, M. Yuguchi, S. Yamashita, M. Tokuda, J. Am. Chem. Soc. 2004, 126, $14342-14343$; g) B. Haffemayer, M. Gulias, M. J. Gaunt, Chem. Sci. 2011, 2, 312-315; h) Z. Liang, J. Zhang, Z. Liu, K. Wang, Y. Zhang, Tetrahedron 2013, 69, 6519-6526.

[3] a) E. J. Yoo, M. Wasa, J.-Q. Yu, J. Am. Chem. Soc. 2010, 132 , $17378-17380$; b) S. Li, G. Chen, C.-G. Feng, W. Gong, J.-Q. Yu, J. Am. Chem. Soc. 2014, 136, 5267-5270; c) A. McNally, B. Haffemayer, B. S. L. Collins, M. J. Gaunt, Nature 2014, 510, 129 - 133 ; d) N. Hasegawa, V. Charra, S. Inoue, Y. Fukumoto, N. Chatani, J. Am. Chem. Soc. 2011, 133, 8070-8073.

[4] For carbonylation reactions of benzylic C $\left(\mathrm{sp}^{3}\right)-\mathrm{H}$ bonds, see: a) P. Xie, C. Xia, H. Huang, Org. Lett. 2013, 15, 3370-3373; b) P. Xie, Y. Xie, B. Qian, H. Zhou, C. Xia, H. Huang, J. Am. Chem. Soc. 2012, 134, 9902-9905; c) H. Liu, G. Laurenczy, N. Yan, P. J. Dyson, Chem. Commun. 2014, 50, 341-343; for carbonylation reactions of cycloalkanes with alkenes, see: d) I. Ryu, A. Tani, T Fukuyama, D. Ravelli, M. Fagnoni, A. Albini, Angew. Chem. Int. Ed. 2011, 50, 1869-1872; Angew. Chem. 2011, 123, 1909-1912; e) M. Okada, T. Fukuyama, K. Yamada, I. Ryu, D. Ravelli, M. Fagnoni, Chem. Sci. 2014, 5, 2893-2898.

[5] S. E. Allen, R. R. Walvoord, R. Padilla-Salinas, M. C. Kozlowski, Chem. Rev. 2013, 113, 6234-6458.

[6] a) J. M. Liu, R. Z. Zhang, S. F. Wang, W. Sun, C. G. Xia, Org. Lett. 2009, 11, 1321-1324; b) P. Tambade, Y. Patil, N. Nandurkar, B. Bhanage, Synlett 2008, 886-888; c) S.-K. Kang, T. Yamaguchi, T.H. Kim, P.-S. Ho, J. Org. Chem. 1996, 61, 9082-9083.

[7] Novel Synthetic Chemistry of Ureas and Amides (Ed.: M. Hutchby), Springer, New York, 2013.

[8] a) A. Schnyder, A. F. Indolese, J. Org. Chem. 2002, 67, 594-597; b) H. Li, K. Dong, H. Neumann, M. Beller, Angew. Chem. Int. Ed. 2015, 54, 10239-10243; Angew. Chem. 2015, 127, 10377-10381.

Received: April 2, 2016

Published online: May 11, 2016 
3.2 Copper-Catalysed Carbonylative Synthesis of Aliphatic Amides from Alkanes and

Primary Amines via $\mathrm{C}(\mathrm{sp} 3)-\mathrm{H}$ Bond Activation

Yahui Li, Fengxiang Zhu, Zechao Wang, and Xiao-Feng Wu*

ACS Catal. 2016, 6, 5561-5564

Author contributions:

Dr. Xiao-Feng Wu and Yahui Li conceived and developed this project. Dr. Xiao-Feng Wu and Yahui Li wrote the manuscript with revisions provided by Fengxiang Zhu, Zechao Wang. My contribution as co-author of this paper is approximately $85 \%$. 


\title{
Copper-Catalyzed Carbonylative Synthesis of Aliphatic Amides from Alkanes and Primary Amines via $\mathrm{C}_{(\mathrm{sp} 3)}-\mathrm{H}$ Bond Activation
}

\author{
Yahui $\mathrm{Li}^{\dagger}{ }^{\dagger}$ Fengxiang Zhu, ${ }^{\dagger}$ Zechao Wang, ${ }^{\dagger}$ and Xiao-Feng $\mathrm{Wu}^{*},+$, \\ †Leibniz-Institut für Katalyse e.V. an der Universität Rostock, Albert-Einstein-Strasse 29a, 18059 Rostock, Germany \\ ${ }^{\ddagger}$ Department of Chemistry, Zhejiang Sci-Tech University, Xiasha Campus, Hangzhou 310018, People’s Republic of China
}

Supporting Information

ABSTRACT: Amides are important intermediates and building blocks in organic synthesis. Among the known preparation procedures, aminocarbonylation is an interesting and powerful tool. However, most of the studies were focused

alkanes $+\mathrm{H}_{2} \mathrm{~N}-\mathrm{R}^{2} \frac{\mathrm{CuF}_{2}, 1,10 \text {-phen }}{\mathrm{DTBP}, \mathrm{CO}, 120^{\circ} \mathrm{C}}$

21 examples

up to $91 \%$ yields

$\mathrm{R} 2=\mathrm{Ph}$, Benzyl, Alkyl on noble metal-catalyzed synthesis of aromatic amides. Herein,
we describe an attractive copper-catalyzed synthesis of aliphatic amides from alkanes and amines. A variety of amides were prepared in good yields by carbonylation of the $\mathrm{C}_{(\mathrm{sp} 3)}-\mathrm{H}$ bond of alkanes with different amines. Good functional groups tolerance can be observed.

KEYWORDS: copper catalyst, amides synthesis, carbonylation, amines, alkanes

\begin{abstract}
A mides are important chemicals that are prevalent in pharmaceuticals, natural products, and many functional materials. ${ }^{1}$ Hence, the development of efficient and selective procedure for new amide bonds construction is a long-standing task for organic chemists. ${ }^{2}$ Among the known methodologies, aminocarbonylation is a straightforward process for the synthesis of amide moieties. ${ }^{3}$ Depending on the amides needed, by choosing proper amines and reaction partners, $\mathrm{CO}$, as one of the least expensive and most abundant $\mathrm{C} 1$ sources, can be easily installed into the amide products. However, by examining the literature, the majority of the reported aminocarbonylation procedures are based on using $\mathrm{C}_{(\mathrm{sp2} 2)}-\mathrm{X}$ (where $\mathrm{X}=\mathrm{I}, \mathrm{Br}, \mathrm{H}$, etc.) as the starting materials. With a noble-metal complex as the catalyst, aromatic amides (benzamides) can be selectively produced (Scheme 1, eq a). ${ }^{4}$ In comparison, studies on carbonylative transformation of $\mathrm{C}_{(\mathrm{sp} 3)}-\mathrm{X}$ bonds are already become limited, which can produce important aliphatic carbonyl containing compounds (Scheme 1, eq b). The developed methods also require a noble-metal complex catalyst and/or UV irradiation under high CO pressure (50-80 bar). ${ }^{5}$ Not surprisingly, reports on the aminocarbonylation of $\mathrm{C}_{(\mathrm{sp} 3)}-\mathrm{X}(\mathrm{X}=$
\end{abstract}

Scheme 1. General Carbonylative Coupling Reactions

$$
\begin{aligned}
& \text { Previous Work } \\
& \text { (a) } \mathrm{Ar}-\mathrm{X}+\mathrm{CO}+\mathrm{H}_{2} \mathrm{~N}-\mathrm{R}^{\prime}[\mathrm{Pd}][\mathrm{Rh}] \\
& \mathrm{X}=\mathrm{I}, \mathrm{Br}, \mathrm{H} \text {, etc. } \\
& \text { (b) } \mathrm{R}-\mathrm{l} / \mathrm{Br}+\mathrm{CO}+\mathrm{NuH} \stackrel{[\mathrm{Catal}]}{\mathrm{Nu}}=\text { alkene, alkyne, etc. } \\
& \text { This Work } \\
& \text { (c) } \mathrm{R}-\mathrm{H}+\mathrm{CO}+\mathrm{H}_{2} \mathrm{~N}-\mathrm{R}^{\prime} \underset{\mathrm{DTBP}}{[\mathrm{Cu}]}
\end{aligned}
$$

$\mathrm{I}, \mathrm{Br}, \mathrm{H}$, etc.) bonds are even more rare, ${ }^{6}$ which can be explained by the following four reasons:

(1) the increased difficulty of oxidative addition of $\mathrm{C}_{(\mathrm{sp} 3)}-\mathrm{X}$ $(\mathrm{X}=\mathrm{I}, \mathrm{Br}, \mathrm{Cl})$ bond toward metal center;

(2) easier $\beta$-hydrogen elimination of the intermediate complex;

(3) easy and fast nucleophilic substitution reaction of $\mathrm{C}_{(\mathrm{sp} 3)}-\mathrm{X}$ $(\mathrm{X}=\mathrm{I}, \mathrm{Br}, \mathrm{Cl})$ and amines with amines as the reaction partner and also as the base; and

(4) the easier oxidation of amines under oxidative conditions. Hence, the aminocarbonylation of $\mathrm{C}_{(\mathrm{sp} 3)}-\mathrm{X}$ bonds is remaining challenge.

On the other hand, copper salts have advantages, including being inexpensive and having low toxicity, which have been extensively applied as catalysts and additives in organic synthesis.' In some topics, such as oxidation reactions, the catalysis behavior of copper catalyst is comparable or even better then palladium catalysts. ${ }^{8}$ However, in the area of carbonylative coupling transformations, the copper catalyst is still in its infancy, while palladium catalysts are already matured. The few reports on copper-catalyzed carbonylative coupling reactions are limited with aryl iodides or diaryliodonium salts as the substrates. ${ }^{9}$ In addition, we recently extended to carbonylative coupling of cycloalkanes with amides, which is stable under oxidative conditions. ${ }^{10}$ As our continuing interests on developing new carbonylative coupling reactions and also been attracted by copper catalysts, we wish to report here an interesting procedure on copper-catalyzed aminocarbonylation of alkanes. With amines as the reaction partners and copper as the catalyst, the

Received: May 19, 2016

Revised: July 21, 2016

Published: July 22, 2016 
$\mathrm{C}_{(\mathrm{sp} 3)}-\mathrm{H}$ bond of simple alkanes were selectively carbonylated and give the corresponding aliphatic amides in good yields (Scheme 1, eq c).

Initially, we chose cyclohexane and aniline as the model substrates in the presence of 20 bar of $\mathrm{CO}$ and the effects of copper catalysts were tested (see Table 1, entries 1-9). Under

Table 1. Cu-Catalyzed Amide Synthesis: Optimization Reaction Conditions ${ }^{a}$

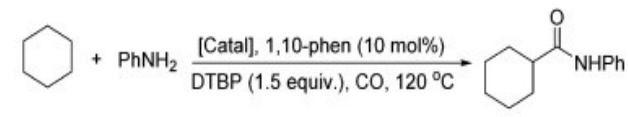

\begin{tabular}{rlr} 
entry & \multicolumn{1}{c}{ catalyst } & yield $^{b}(\%)$ \\
1 & $\mathrm{CuBr}\left(\mathrm{Me}_{2} \mathrm{~S}\right)$ & 19 \\
2 & $\mathrm{Cu}(\mathrm{acac})_{2}$ & 42 \\
3 & $\mathrm{CuBr}_{2}$ & 36 \\
4 & $\mathrm{Cu}\left(\mathrm{CH}_{3} \mathrm{CN}\right)_{4} \mathrm{PF}_{6}$ & 48 \\
5 & $\mathrm{Cu}\left(\mathrm{CF}_{3} \mathrm{CO}_{2}\right)_{2}$ & 18 \\
6 & $\mathrm{CuI}$ & 27 \\
7 & $\mathrm{CuCl}$ & 42 \\
8 & $\mathrm{CuF}_{2}$ & $67^{c}$ \\
9 & $\mathrm{Cu}^{c}\left(\mathrm{OTf}_{2}\right.$ & 24 \\
10 & ${\mathrm{Pd}(\mathrm{OAc})_{2}}_{1}$ & trace \\
$11^{d}$ & $\mathrm{CuF}_{2}$ & 48 \\
$12^{c}$ & $\mathrm{CuF}_{2}$ & 26 \\
$13^{f}$ & $\mathrm{CuF}_{2}$ & 23 \\
$14^{g}$ & $\mathrm{CuF}_{2}$ & 54 \\
$15^{h}$ & $\mathrm{CuF}_{2}$ & 65
\end{tabular}

${ }^{a}$ Aniline $(0.5 \mathrm{mmol})$, catalyst (10 mol \%), ligand (10 mol \%), DTBP ( $0.75 \mathrm{mmol} ; 1.5$ equiv), CO (50 bar), cyclohexane $(1.5 \mathrm{~mL}), 24 \mathrm{~h}$. ${ }^{b} \mathrm{GC}$ yields with hexadecane as the internal standard. "Isolated yields. ${ }^{d} \mathrm{CO}\left(10\right.$ bar). ${ }^{e} \mathrm{~K}_{2} \mathrm{CO}_{3}$ (1 equiv). ${ }^{f} \mathrm{CH}_{3} \mathrm{CO}_{2} \mathrm{H}$ (1 equiv). ${ }^{g} 100{ }^{\circ} \mathrm{C}$. ${ }^{h}$ Catalyst $(5 \mathrm{~mol} \%)$, ligand $(5 \mathrm{~mol} \%)$. 1,10-phen $=1,10$-phenanthroline hydrate.

our former reaction conditions, only $19 \%$ of the desired $\mathrm{N}$ phenylcyclohexanecarboxamide can be produced (see Table 1, entry 1). Nitrobenzene, nitrosobenzene, azobenzene, and other noncharactable could be detected with the full conversion of aniline. Nevertheless, these results proven our hypothesis and encouraged us to move forward. In the other tested copper salts, improved yields generally can be achieved and the best selectivity can be obtained with $\mathrm{CuF}_{2}$ as the catalyst (see Table 1, entry 8 ). Excitingly, $67 \%$ of $\mathrm{N}$-phenylcyclohexanecarboxamide was isolated and with good reproducibility. In the case with $\mathrm{Pd}(\mathrm{OAc})_{2}$ as the catalyst, only a trace of the desired amide can be detected, together with the aniline oxidation byproducts (Table 1, entry 10). In addition, in the absence of a copper catalyst or ligand, no desired product can be observed. Screening of other nitrogen ligands (pyridine, bipyridine, TMEDA, DMEDA, DMPA, L-proline) revealed that 1,10-phenanthroline hydrate is the most effective ligand for delivering the desired amide product. We then tested the influences of reaction temperature, additives, and $\mathrm{CO}$ pressure on this aminocarbonylation reaction (Table 1 , entries 11-15). Dramatically decreased yields were observed when $\mathrm{K}_{2} \mathrm{CO}_{3}$ or $\mathrm{AcOH}$ was added into the reaction mixture (Table 1 , entries 12 and 13; yields of $26 \%$ and $23 \%$, respectively). Interestingly, moderate yields can still be obtained under lower $\mathrm{CO}$ pressure ( $10 \mathrm{bar}$; see Table 1 , entry 11$)$, lower temperature $\left(100^{\circ} \mathrm{C}\right.$; see Table 1 , entry 14), and lower catalyst loading ( $5 \mathrm{~mol} \%$; see Table 1 , entry 15$)$.
It is meaningful to mention that full conversion of aniline could be observed in all of the reactions performed.

With the optimized reaction conditions in hand, we examined the scope of the reaction with a range of amines. As shown in Table 2, various aliphatic amines were successfully applied. Good

Table 2. Cu-Catalyzed Carbonylative Synthesis of Aliphatic Amides $^{a}$

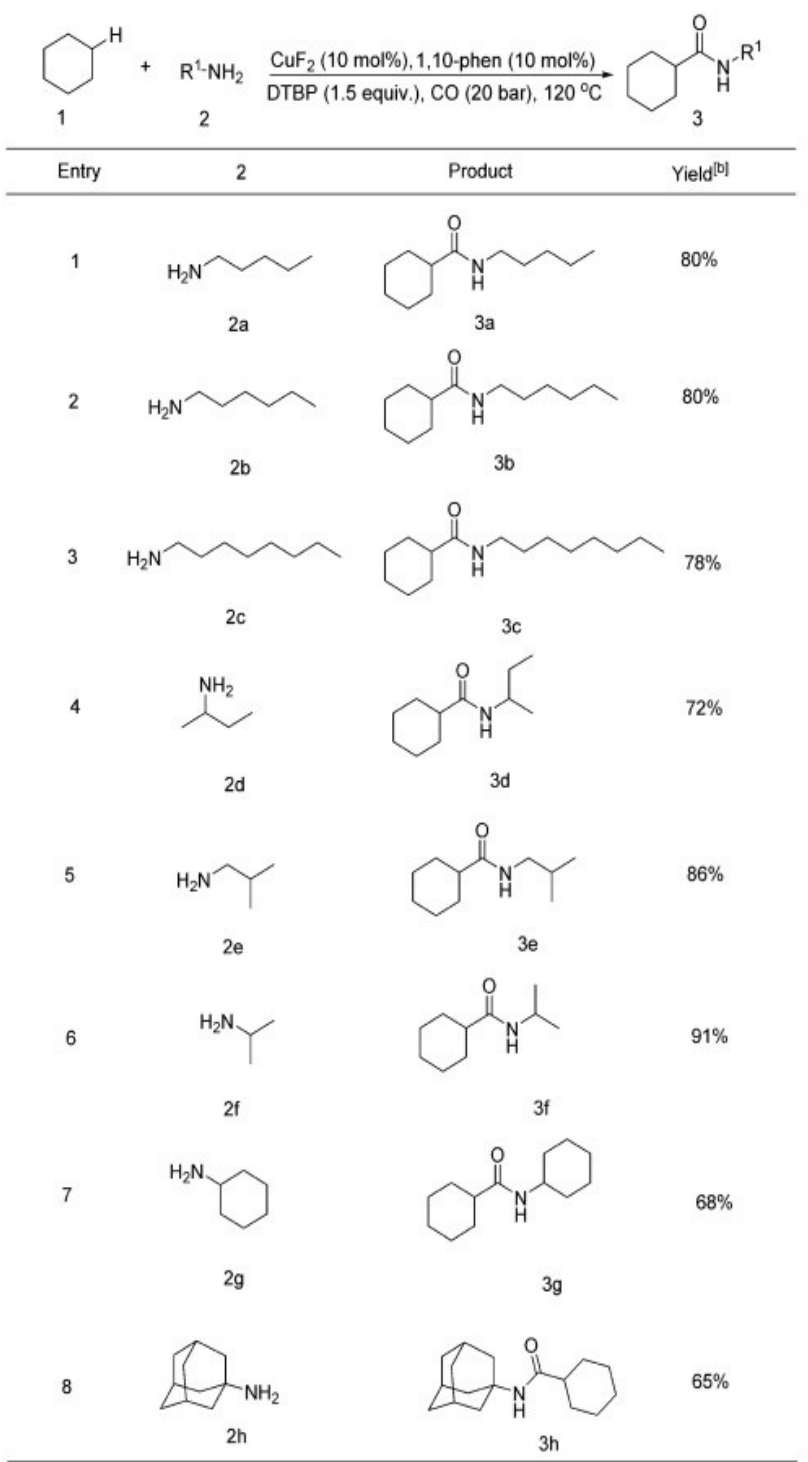

$a_{2}$ (0.5 mmol), $\mathrm{CuF}_{2}$ (10 mol \%), 1,10-phen (10 mol \%), DTBP (0.75 $\mathrm{mmol}), \mathrm{CO}(20 \mathrm{bar})$, cyclohexane $(1.5 \mathrm{~mL}), 120{ }^{\circ} \mathrm{C}, 24 \mathrm{~h}$. ${ }^{b}$ Isolated yields.

yields of the desired amides can be produced by reacting pentylamine, hexylamine, and octylamine with cyclohexane (Table 2, entries 1-3). Branched amines can be applied as reaction partners as well and give the corresponding aliphatic amides in good to excellent yields (Table 2, entries 4-8). Cyclohexylamine and amantadine can provide the desired amides in yields of $65 \%-68 \%$ (Table 2, entries 7 and 8 ).

To reveal the generality of this method, aniline and benzylic amines were also tested (Table 3), these substrates are more intended to be oxidized, compared with aliphatic amines tested. To our delight, aniline was smoothly transformed into the desired amide in $67 \%$ yield (Table 3, entry 1 ). Various benzyl amines can be reacted as well and give the corresponding amides 
Table 3. Cu-Catalyzed Synthesis of Amides from Aromatic and Benzyl Amines ${ }^{a}$

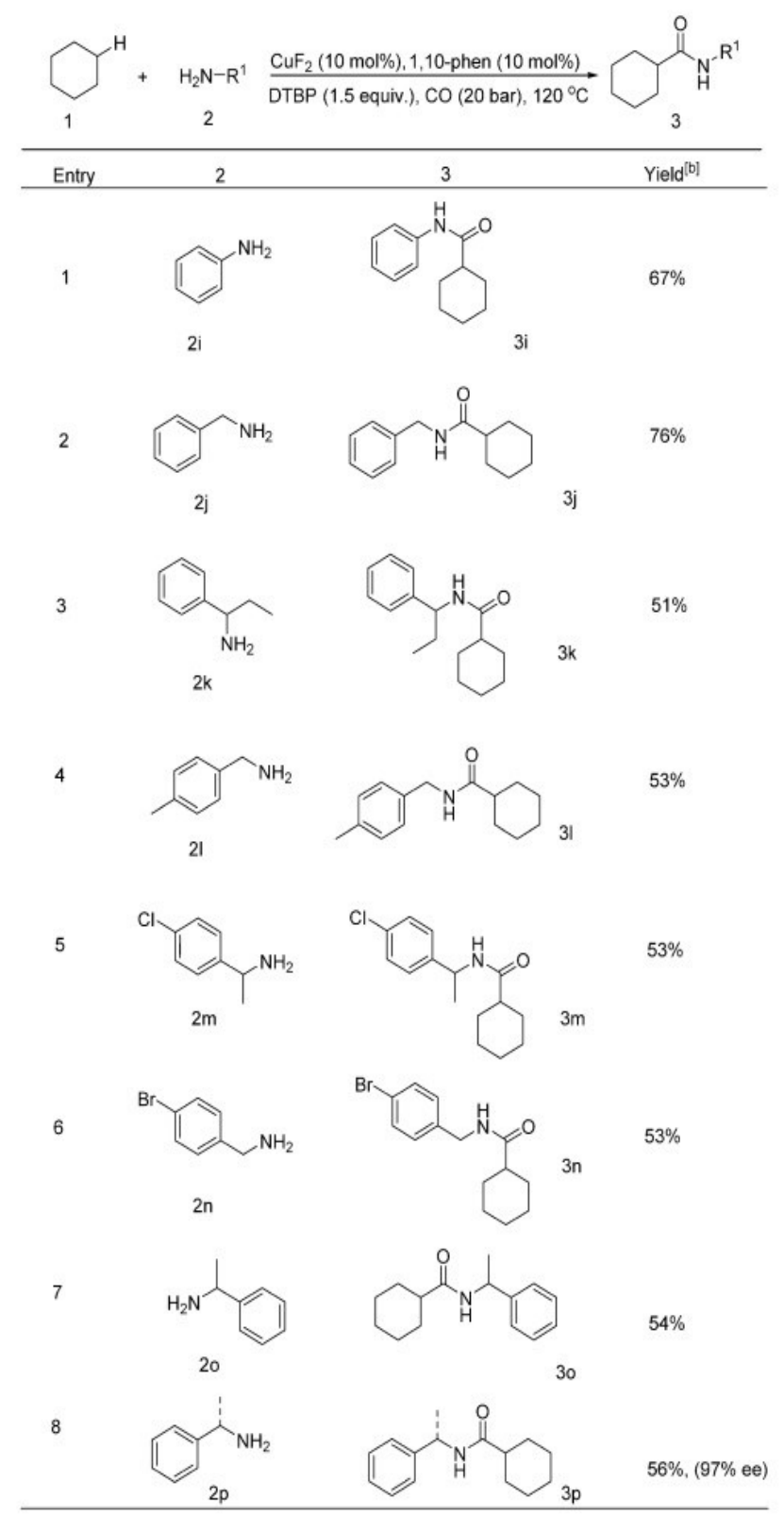

${ }^{a_{2}}$ (0.5 mmol), $\mathrm{CuF}_{2}(10 \mathrm{~mol} \%), 1,10$-phen ( $\left.10 \mathrm{~mol} \%\right)$, DTBP $(0.75$ $\mathrm{mmol}), \mathrm{CO}(20 \mathrm{bar})$, cyclohexane $(1.5 \mathrm{~mL}), 120{ }^{\circ} \mathrm{C}, 24 \mathrm{~h} .{ }^{b}$ Isolated yields.

in moderate to good yields (Table 3, entries 2-8). For example, (4-bromophenyl)-methanamine and 1-(4-chlorophenyl)ethan1 -amine can successfully give the desired products, which are ready for further modification via cross-coupling reactions. Notably, an enantio-enriched substrate also can be applied and one can maintain excellent chirality in the final product (Table 3 , entry 8).

In addition, alkane derivatives were tested under our standard reaction conditions (Table 4). Cyclopentane and cycloheptane worked well under our reaction conditions and give the corresponding amides in yields of $57 \%-66 \%$ (Table 4, entries 1 and 2). Noncyclic alkanes were applied as well, and moderate selectivity can generally be obtained. The reaction of 3 ethylpentane occurred preferentially at secondary and primary $\mathrm{C}-\mathrm{H}$ bonds over the tertiary $\mathrm{C}-\mathrm{H}$ bond (Table 4, entry 3 ). In the case of using pentane and hexane as the reactants and
Table 4. Cu-Catalyzed Synthesis of Amides from Alkanes ${ }^{a}$

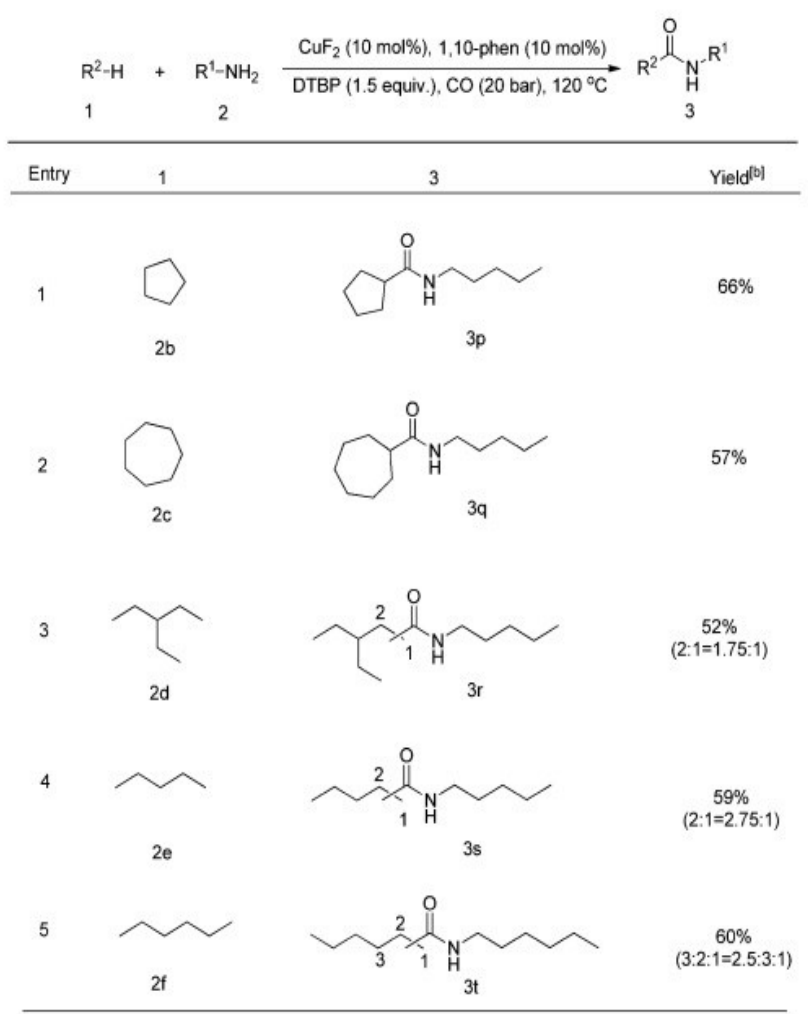

$a_{2}$ (0.5 mmol), $\mathrm{CuF}_{2}$ (10 mol \%), 1,10-phen (10 mol \%), DTBP (0.75 $\mathrm{mmol}), \mathrm{CO}(20 \mathrm{bar})$, alkane $(1.5 \mathrm{~mL}), 120^{\circ} \mathrm{C}, 24 \mathrm{~h}$. 'Tsolated yields.

solvents, moderate to good yields of the corresponding amides can be isolated with moderate selectivity (Table 4, entries 4 and 5). Remarkably, $\sim 5 \%$ of the $\mathrm{C} 3$ product of pentane can be detected in the crude NMR. Because of the low amount, we did not isolate it.

In order to gain insight into the reaction mechanism, an experiment with TEMPO was carried out and is shown in Scheme 2. When 4 equiv of TEMPO were added to the standard

\section{Scheme 2. Control Experiment}

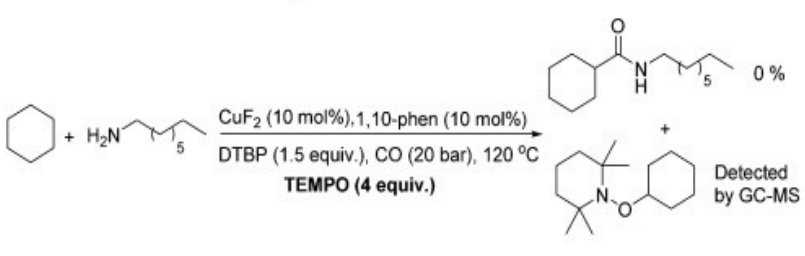

reaction mixture, no desired amide product can be obtained. A product from the reaction between cyclohexane and TEMPO was found in GC-MS analysis.

Based on our results, a possible reaction mechanism is been proposed (Scheme 3). The reaction started with a copper(II)catalyzed or thermal hemolytic cleavage of a peroxide to generate the tert-butoxy radical, which reacts with cyclohexane and sequential oxidation of the copper(II) species to give the $\mathrm{Cu}(\mathrm{III})$-cyclohexane species $\mathrm{B}$. Complex $\mathbf{B}$ then undergoes $\mathrm{X}$ ligand exchange with amine to produce $\mathrm{Cu}(\mathrm{III})$ intermediate $\mathbf{C}$ with alkyl and amine $\mathrm{X}$ ligands. Subsequent $\mathrm{CO}$ coordination and insertion forms the intermediate $\mathbf{D}$ or $\mathbf{D}^{\prime}$, which then afford the final aminocarbonylation product $\mathbf{E}$ after reductive elimination, along with a $\mathrm{Cu}(\mathrm{I})$ intermediate, which can be oxidized by the 
Scheme 3. Proposed Reaction Mechanism

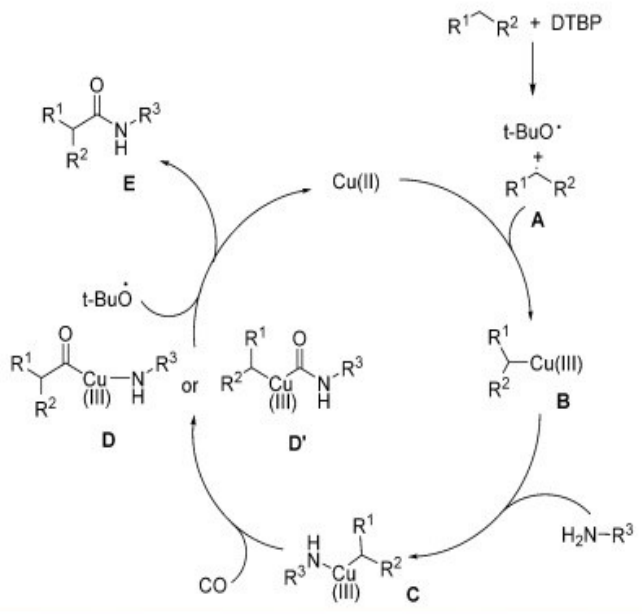

$t \mathrm{BuO}$ radical to form the active $\mathrm{Cu}(\mathrm{II})$ species for the next catalytic cycle.

In conclusion, a novel copper-catalyzed aminocarbonylation reaction of alkanes with amines has been developed. With copper salt as the catalyst, various aliphatic amides were prepared in good yields by carbonylative activation of the $\mathrm{C}_{(\mathrm{sp} 3)}-\mathrm{H}$ bond of alkanes. Notably, this is the first report on copper-catalyzed aminocarbonylation reaction for aliphatic amides synthesis.

\section{GENERAL PROCEDURE}

A $4 \mathrm{~mL}$ screw-cap vial was charged with $\mathrm{CuF}_{2}(5.05 \mathrm{mg}, 10 \mathrm{~mol}$ $\%), 1,10$-phenanthroline hydrate $(9.9 \mathrm{mg}, 10 \mathrm{~mol} \%)$, aniline ( 0.5 $\mathrm{mmol})$, cyclohexane $(1.5 \mathrm{~mL})$, and an oven-dried stirring bar. The vial was closed, using a Teflon septum and phenolic cap, and connected with atmosphere with a needle. After cyclohexane (1.5 $\mathrm{mL})$ and DTBP $(0.75 \mathrm{mmol})$ were injected by using a syringe, the vial was fixed in an alloy plate and placed into Paar 4560 series autoclave $(500 \mathrm{~mL})$ under argon atmosphere. At room temperature, the autoclave is flushed with carbon monoxide for three times and 20 bar of carbon monoxide was charged. The autoclave was placed on a heating plate equipped with magnetic stirring and an aluminum block. The reaction is allowed to be heated under $120^{\circ} \mathrm{C}$ for $24 \mathrm{~h}$. Afterward, the autoclave is cooled to room temperature and the pressure was carefully released. After the removal of solvent under reduced pressure, pure product was obtained by column chromatography on silica gel (eluent:pentane/ethyl acetate ratio of 10:1).

\section{ASSOCIATED CONTENT}

\section{(S Supporting Information}

The Supporting Information is available free of charge on the ACS Publications website at DOI: 10.1021/acscatal.6b01413.

General procedure, NMR data, and NMR spectrum (PDF)

\section{AUTHOR INFORMATION}

\section{Corresponding Author}

*E-mail: Xiao-Feng.Wu@catalysis.de.

\section{Notes}

The authors declare no competing financial interest.

\section{ACKNOWLEDGMENTS}

The authors thank the Chinese Scholarship Council for financial Support. We also thank the financial supports from NSFC (No.
21472174) and Zhejiang Natural Science Fund for Distinguished Young Scholars (No. LR16B020002). The analytic support of Dr. W. Baumann, Dr. C. Fisher, S. Buchholz, and S. Schareina is gratefully acknowledged. We also appreciate the generous supports from Professor Matthias Beller in LIKAT.

\section{REFERENCES}

(1) (a) Hutchby, M. Novel Synthetic Chemistry of Ureas and Amides; Springer: Berlin, 2013. (b) Mintzer, M. A.; Simanek, E. E. Chem. Rev. 2009, 109, 259-302.

(2) (a) Carey, J. S.; Laffan, D.; Thomson, C.; Williams, M. T. Org. Biomol. Chem. 2006, 4, 2337-2347. (b) Cupido, T.; Tulla-Puche, J.; Spengler, J.; Albericio, F. Curr. Opin. Drug Discovery Dev. 2007, 10, 768783.

(3) (a) Brennführer, A.; Neumann, H.; Beller, M. Angew. Chem., Int.Ed. 2009, 48, 4114-4133. (b) Fujiwara, Y.; Tabaki, K.; Taniguchi, Y. Synlett $1996,7,591-599$.

(4) For selected reports on aminocarbonylation for benzamides synthesis, see: (a) Schoenberg, A.; Heck, R. F. J. Org. Chem. 1974, 39, 3327-3331. (b) Hosoi, K.; Nozaki, K.; Hiyama, T. Org. Lett. 2002, 4, 2849-2851. (c) Cunico, R. F.; Maity, B. C. Org. Lett. 2002, 4, 43574359. (d) Yamazaki, K.; Kondo, Y. J. Comb. Chem. 2004, 6, 121-125. (e) Schnyder, A.; Indolese, A. F. J. Org. Chem. 2002, 67, 594-597. (f) Morera, E.; Ortar, G. Tetrahedron Lett. 1998, 39, 2835-2838. (g) Ueda, K.; Sato, Y.; Mori, M. J. Am. Chem. Soc. 2000, 122, 1072210723. (h) Liang, Z.; Zhang, J.; Liu, Z.; Wang, K.; Zhang, Y. Tetrahedron 2013, 69, 6519-6526. (i) Orito, K.; Horibata, A.; Nakamura, T.; Ushito, H.; Nagasaki, H.; Yuguchi, M.; Yamashita, S.; Tokuda, M. J. Am. Chem. Soc. 2004, 126, 14342-14343. (j) Haffemayer, B.; Gulias, M.; Gaunt, M. J. Chem. Sci. 2011, 2, 312-315.

(5) For leading reviews on radical carbonylation, see: (a) Schiesser, C. H.; Wille, U.; Matsubara, H.; Ryu, I. Acc. Chem. Res. 2007, 40, 303-313. (b) Sumino, S.; Fusano, A.; Fukuyama, T.; Ryu, I. Acc. Chem. Res. 2014, 47, 1563-1574. (c) Ryu, I.; Sonoda, N. Angew. Chem., Int. Ed. Engl. 1996, 35, 1050-1066. (d) Ryu, I. Chem. Rec. 2002, 2, 249-258. For reports on carbonylation of cycloalkanes with alkenes, see: (e) Ryu, I.; Tani, A.; Fukuyama, T.; Ravelli, D.; Fagnoni, M.; Albini, A. Angew. Chem., Int. Ed. 2011, 50, 1869-1872. (f) Okada, M.; Fukuyama, T.; Yamada, K.; Ryu, I.; Ravelli, D.; Fagnoni, M. Chem. Sci. 2014, 5, 28932898.

(6) (a) Yoo, E. J.; Wasa, M.; Yu, J.-Q. J. Am. Chem. Soc. 2010, 132, 17378-17380. (b) Li, S.; Chen, G.; Feng, C.-G.; Gong, W.; Yu, J.-Q. J. Am. Chem. Soc. 2014, 136, 5267-5270. (c) McNally, A.; Haffemayer, B.; Collins, B. S. L.; Gaunt, M. J. Nature 2014, 510, 129-133. (d) Hasegawa, N.; Charra, V.; Inoue, S.; Fukumoto, Y.; Chatani, N. J. Am. Chem. Soc. 2011, 133, 8070-8073. (e) Wang, C.; Zhang, L.; Chen, C.; Han, J.; Yao, Y.; Zhao, Y. Chem. Sci. 2015, 6, 4610-461410.1039/C5SC00519A. For reports on carbonylation of $\mathrm{C}_{\left(\mathrm{sp}_{3}\right)}-\mathrm{H}$ bond of benzylic substrates, see: (f) Xie, P.; Xie, Y.; Qian, B.; Zhou, H.; Xia, C.; Huang, H. J. Am. Chem. Soc. 2012, 134, 9902-9905. (g) Xie, P.; Xia, C.; Huang, H. Org. Lett. 2013, 15, 3370-3373. (h) Liu, H.; Laurenczy, G.; Yan, N.; Dyson, P. J. Chem. Commun. 2014, 50, 341-343. For a general review on $\mathrm{C}_{(\mathrm{sp} 3)}-\mathrm{X}$ bond carbonylations, see: (i) Wu, L.; Fang, X.; Liu, Q.; Jackstell, R.; Beller, M.; Wu, X.-F. ACS Catal. 2014, 4, 2977-2989.

(7) Allen, S. E.; Walvoord, R. R; Padilla-Salinas, R; Kozlowski, M. C. Chem. Rev. 2013, 113, 6234-6458.

(8) McCann, S. D.; Stahl, S. S. Acc. Chem. Res. 2015, 48, 1756-1766. (9) (a) Liu, J. M.; Zhang, R. Z.; Wang, S. F.; Sun, W.; Xia, C. G. Org. Lett. 2009, 11, 1321-1324. (b) Tambade, P.; Patil, Y.; Nandurkar, N.; Bhanage, B. Synlett 2008, 2008, 886-888. (c) Kang, S.-K.; Yamaguchi, T.; Kim, T.-H.; Ho, P.-S. J. Org. Chem. 1996, 61, 9082-9083. (d) Romano, U.; Tesel, R.; Rebora, P.; Mauri, M. Ind. Eng. Chem. Prod. Res. Dev. 1980, 19, 396-403.

(10) Li, Y.; Dong, K.; Zhu, F.; Wang, Z.; Wu, X.-F. Angew. Chem., Int. Ed. 2016, 55, 7227-7230. 


\subsection{Copper-Catalysed Alkoxycarbonylation of Alkanes with Alcohols}

Yahui Li, Changsheng Wang, Fengxiang Zhu, Zechao Wang, Pierre H. Dixneuf, and Xiao-Feng Wu*

ChemSusChem 2017, 10, $1341-1345$

Author contributions:

Dr. Xiao-Feng Wu, Yahui Li and Changsheng Wang conceived and developed this project. Dr. Xiao-Feng Wu and Yahui Li wrote the manuscript with revisions provided by Pierre H. Dixneuf, Fengxiang Zhu, Zechao Wang. My contribution as co-author of this paper is approximately $80 \%$. 


\title{
Copper-Catalyzed Alkoxycarbonylation of Alkanes with Alcohols
}

\author{
Yahui $\mathrm{Li}^{+}{ }^{\left[{ }^{[a]}\right.}$ Changsheng Wang ${ }^{+\left[{ }^{[b]}\right.}$ Fengxiang Zhu, ${ }^{[a]}$ Zechao Wang, ${ }^{[a]}$ Pierre H. Dixneuf, ${ }^{[b]}$ and \\ Xiao-Feng $\mathrm{Wu}^{*[a]}$
}

\begin{abstract}
Esters are important chemicals widely used in various areas, and alkoxycarbonylation represents one of the most powerful tools for their synthesis. In this communication, a new coppercatalyzed carbonylative procedure for the synthesis of aliphatic esters from cycloalkanes and alcohols was developed. Through direct activation of the $\mathrm{C}_{\mathrm{sp}^{3}}-\mathrm{H}$ bond of alkanes and with alcohols as the nucleophiles, the desired esters were prepared in moderate-to-good yields. Paraformaldehyde could also be applied for in situ alcohol generation by radical trapping, and moderate yields of the corresponding esters could be produced. Notably, this is the first report on copper-catalyzed alkoxycarbonylation of alkanes.
\end{abstract}

Transition-metal-catalyzed carbonylative transformation is a powerful class of methodologies for the synthesis of carbonyl-containing chemicals, extending the carbon chain and intro- ducing a synthetically versatile carbonyl group. ${ }^{[1]}$ However, a look at the literature shows that most of the known procedures either require a noble metal as the catalyst or use (pseudo)aryl halides and their analogues as starting materials. Owing to the high price of noble-metal catalysts and the tedious substrate pre-activation and preparation steps, alternative procedures are desirable. Recently, $\mathrm{C}_{\mathrm{sp}^{3}}-\mathrm{H}$ activation and functionalization has attracted much attention from the synthetic community. Carbonylative activation of $\mathrm{C}_{\mathrm{sp}^{3}}-\mathrm{H}$ bonds with the assistance of directing groups has also been reported with palladium or ruthenium as the catalyst. ${ }^{[2,3]}$ Among transitionmetal catalysts, copper salts hold many advantages, including low price and low toxicity. ${ }^{[4]}$ The exploration of copper catalysts in carbonylative transformations is therefore attractive from the point of view of both academic and industrial applications. ${ }^{[5]}$<smiles>COC(=O)[C@H](c1ccccc1Cl)N1CCc2sccc2C1</smiles>

Plavix<smiles>CCOC(=O)C1=C[C@H](OC(CC)CC)[C@H](NC(C)=O)[C@H](N)C1</smiles>

Tamiflu<smiles>CC(C)OC(=O)C(C)(C)Oc1ccc(C(=O)c2ccc(Cl)cc2)cc1</smiles>

Tricor<smiles>CC/C=C\C/C=C\C/C=C\C/C=C\C/C=C\C/C=C\C/C=C\C/C=C\C/C=C\C/C=C\CCC(=O)OCC</smiles>

Lovaza

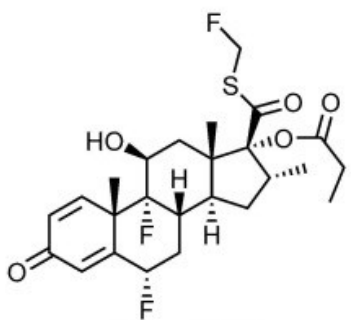

Flovent HFA<smiles>COC(=O)[C@H](c1ccccc1)[C@H]1CCCCN1</smiles>

Focalin XR

Scheme 1. Selected examples of bioactive esters.

[a] Y. Li, F. Zhu, Z. Wang, Prof. Dr. X.-F. Wu Leibniz-Institut für Katalyse e.V. an der Universität Rostock Albert-Einstein-Straße 29a, 18059 Rostock (Germany) E-mail:Xiao-Feng.Wu@catalysis.de

[b] C. Wang, ${ }^{+}$Prof. Dr. P. H. Dixneuf

Catalyse et Organométalliques, Institut Sciences Chimiques de Rennes UMR 6226-CNRS-Université de Rennes Av. Général Leclerc, 35042 Rennes (France)

$\left[{ }^{+}\right]$These authors contributed equally to this work.

Supporting Information for this article can be found under http:// dx.doi.org/10.1002/cssc.201601587.
Esters are naturally occurring and important intermediates and building blocks for pharmaceutical and natural products. ${ }^{[6]}$ Selected examples of bioactive esters are shown in Scheme $1 .^{[7]}$ Plavix is a thienopyridine-class antiplatelet agent used to inhibit blood clots in coronary artery disease, peripheral vascular disease, cerebrovascular disease, and to prevent heart attack and stroke. Tricor is a drug for the fibrate class. Flovent HFA is used to treat asthma, allergic rhinitis, nasal polyps, various skin disorders, Crohn's disease, and ulcerative colitis. Tamiflu is an antiviral medication used to treat influenza 


\begin{tabular}{|c|c|c|}
\hline \multicolumn{3}{|c|}{ 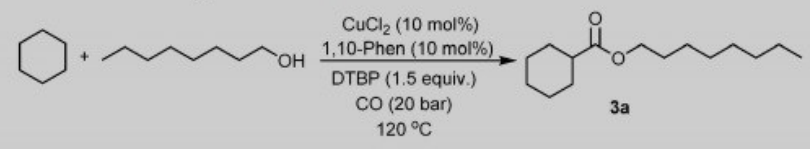 } \\
\hline Entry & Variation from the standard conditions & Yield $^{[b]}[\%]$ \\
\hline 1 & without catalyst and ligand & trace \\
\hline 2 & - & $85(78)^{[c]}$ \\
\hline 3 & $\mathrm{CuBr}\left(\mathrm{Me}_{2} \mathrm{~S}\right)$ & 75 \\
\hline 4 & $\mathrm{Cu}\left(\mathrm{CH}_{3} \mathrm{CN}\right)_{4} \mathrm{BF}_{4}$ & 34 \\
\hline 5 & 1.0 equiv. DTBP & 58 \\
\hline 6 & TBHP instead of DTBP & trace \\
\hline 7 & $5 \mathrm{~mol}^{2} \mathrm{CuCl}_{2}$ and 1,10-phen & 84 \\
\hline 8 & 10 instead of $20 \mathrm{bar}$ & 83 \\
\hline 9 & $2,2^{\prime}$-bipyridine instead of 1,10 -phen & 64 \\
\hline 10 & $\mathrm{PPh}_{3}(20 \mathrm{~mol} \%)$ instead of 1,10 -phen & 46 \\
\hline \multicolumn{3}{|c|}{$\begin{array}{l}\text { [a] 1-Octanol }(0.5 \mathrm{mmol}) \text {, catalyst }(10 \mathrm{~mol} \%) \text {, ligand }(10 \mathrm{~mol} \%) \text {, DTBP } \\
(0.75 \mathrm{mmol}), 20 \text { bar } \mathrm{CO} \text {, cyclohexane }(2 \mathrm{~mL}), 24 \mathrm{~h} \text {. [b] NMR yields deter- } \\
\text { mined using mesitylene as the internal standard. [c] lsolated yield in pa- } \\
\text { rentheses. }\end{array}$} \\
\hline
\end{tabular}

pyridine or $\mathrm{PPh}_{3}$ as the ligand (Table 1, entries 9 and 10). Taking the results of this screening into consideration, we used $10 \mathrm{~mol} \% \mathrm{CuCl}_{2}$ and 1,10-phenanthroline together with DTBP (1.5 equiv.) at 20 bar $\mathrm{CO}$ for further studies.

With the optimized reaction conditions in hand, we examined the scope of the reaction with a range of alcohols. As shown in Table 2, various alcohols were studied. We tested different aliphatic alcohols at the first stage, and moderate-togood yields of the desired products could be produced in all cases under standard conditions. Not only primary alcohols, but also secondary and tertiary alcohols were applicable, and the reactions with tert-butanol and 4-heptanol afforded good isolated yields of the products (Table 2, entries 8 and 9; 63 and $73 \%$ yield, respectively). To further explore the applicability of alcohols, phenyl-substituted substrates were studied subsequently (Table 2, entries 11-17). The reactions of benzyl alcohol, phenethyl alcohol, and 3-phenyl-1-propanol with cyclohexane afforded the desired products in 81,87 , and $86 \%$ yield, respectively (Table 2, entries 11-13). To study the generality of this method, other kinds of alcohols were also tested. 2-Phe-
A and influenza B (flu), and to prevent flu after exposure. With this background, we report here the first example of copper-catalyzed alkoxycarbonylation of alkanes with alcohols through $\mathrm{C}-\mathrm{H}$ activation. Moderate-to-good yields of the desired esters can be obtained. Additionally, paraformaldehyde can also be applied for in situ alcohol generation by radical trapping, and affords moderate yields of the corresponding esters.

Initially, we chose cyclohexane and 1-octanol as model substrates to establish the carbonylation procedure. Upon variation of reaction conditions, different product yields could be obtained (Table 1). Among the different tested metal-catalyst precursors (Table 1, entries 1-4), $\mathrm{CuCl}_{2}$ showed the best results ( $85 \%$ NMR yield, $78 \%$ isolated yield; Table 1, entry 2 ). Lower reaction efficiency was obtained with $\mathrm{CuBr}\left(\mathrm{Me}_{2} \mathrm{~S}\right)$ or $\mathrm{Cu}\left(\mathrm{CH}_{3} \mathrm{CN}\right)_{4} \mathrm{BF}_{4}$ as the catalyst (Table 1, entries 3 and 4). Only traces of the desired product could be obtained in the absence of a catalyst (Table 1, entry 1). The amount and usage of di-tertbutyl peroxide (DTBP) played an important role in this reaction. If we decreased the amount of DTBP from 1.5 to 1 equiv., only $58 \%$ of the desired product was obtained, and no ester was produced with tertbutyl hydroperoxide solution (TBHP, 70 wt \% in $\mathrm{H}_{2} \mathrm{O}$; Table 1, entries 5 and 6). To our delight, no significant variation of yield was observed with decreased loading of catalyst and ligand (Table 1, entry 7). The pressure of $\mathrm{CO}$ could also be decreased to $10 \mathrm{bar}$ (Table 1, entry 8); however, the yield decreased upon further decrease of the CO pressure ( 2 bar, $32 \%$ yield). Finally, two different ligands were studied instead of 1,10-phenanthroline (1,10-phen), and lower reaction efficiency was obtained with either 2,2 '-bi-

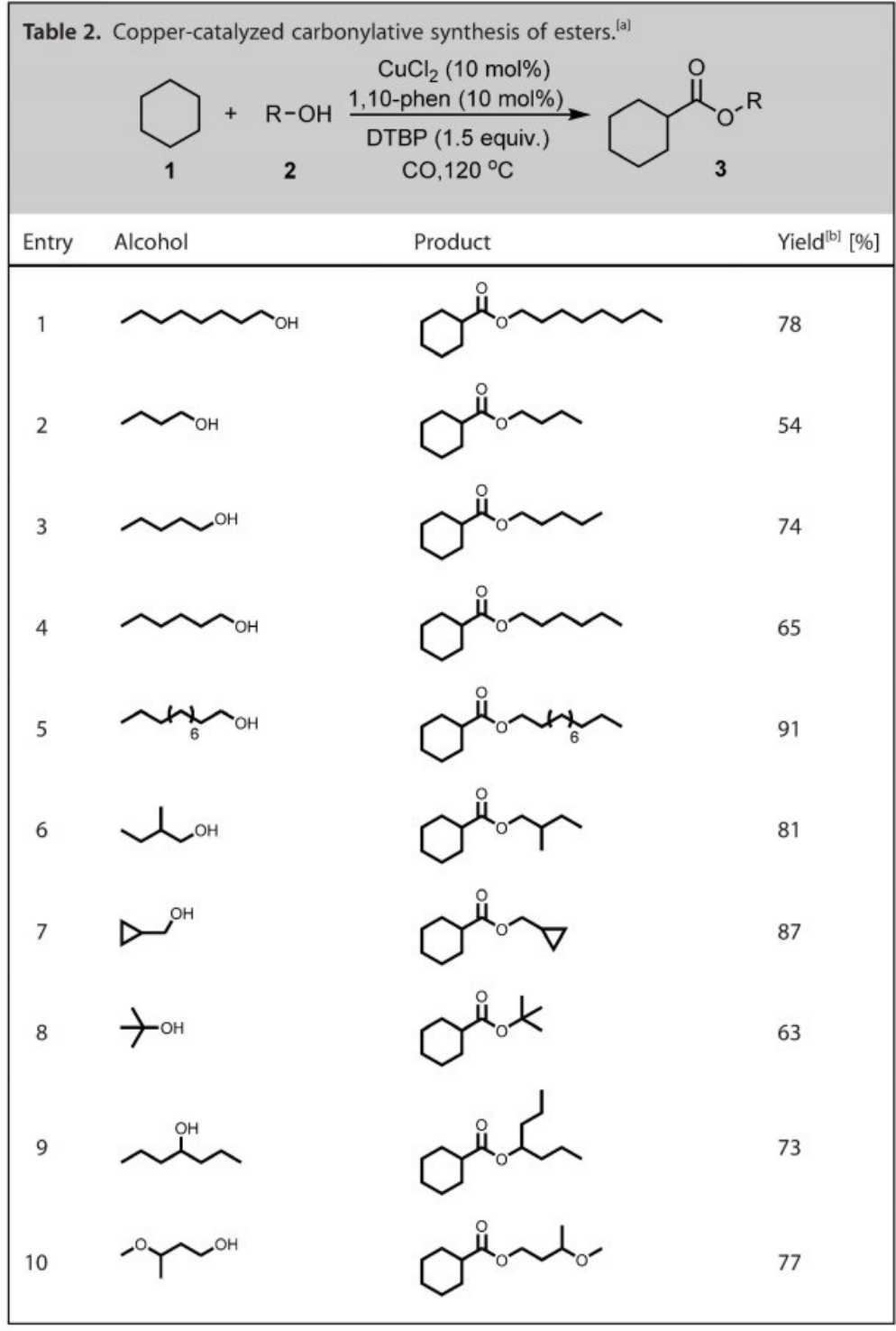




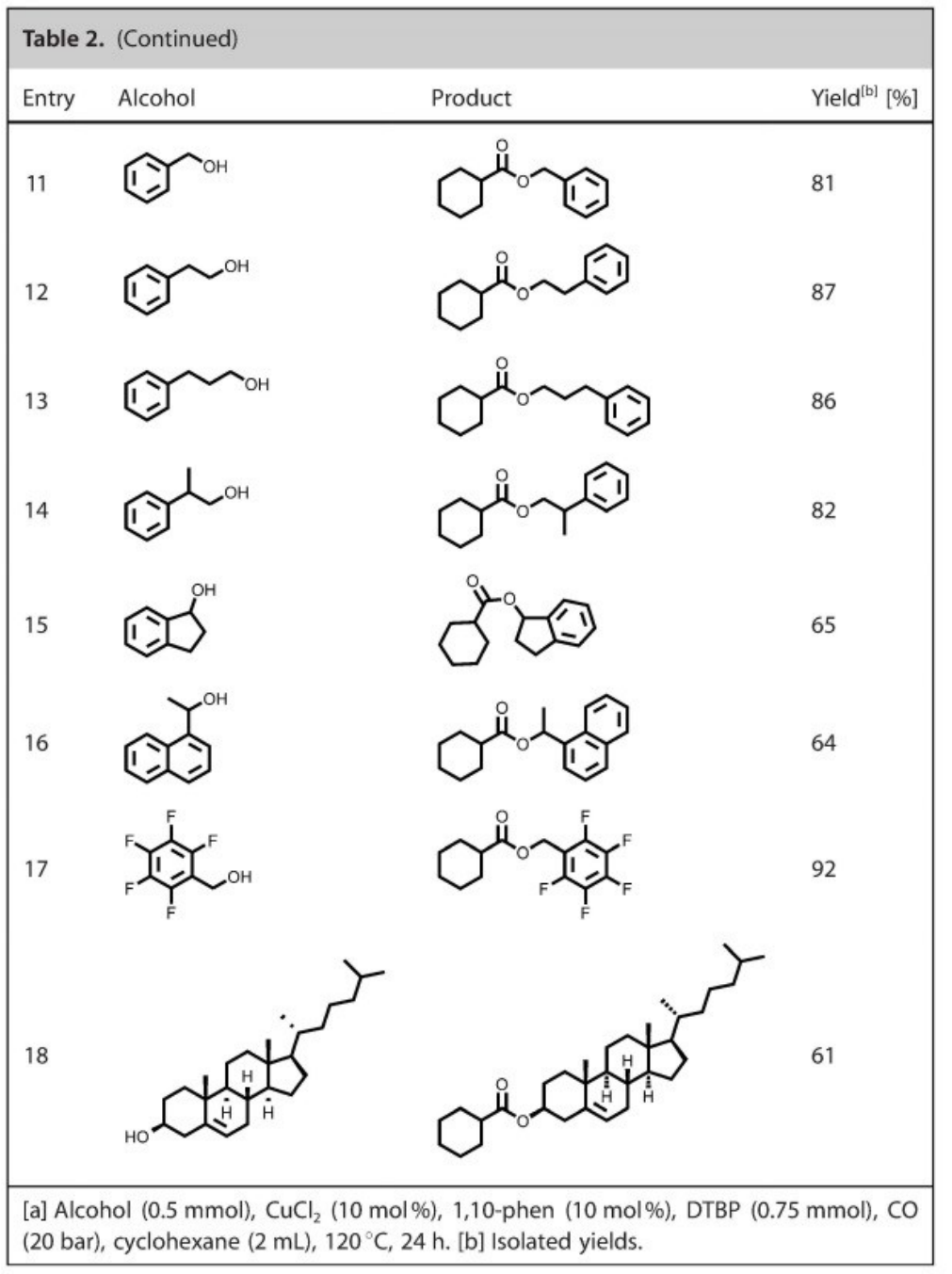

sequential oxidation of the copper(II) species to afford the copper(III)-cyclohexane species D. Then, complex $\mathbf{D}$ reacts with alcohols to produce copper(III) intermediate $\mathbf{E}$. Subsequent $\mathrm{CO}$ insertion forms the intermediates $\mathbf{F}$ or $\mathbf{G}$, which then afford the final carbonylation product after reductive elimination. The concomitantly formed copper(I) reacts with radicals and regenerates the active copper(II) species for the next catalytic cycle. The radical nature of this reaction was proven by experiments with $(2,2,6,6$-tetramethylpiperidin-1-yl)oxyl (TEMPO). The reaction was totally inhibited by the addition of 2 or 4 equiv. TEMPO to the standard conditions.

In conclusion, a new copper-catalyzed alkoxycarbonylation of alkanes with alcohols was developed. With copper salt as the catalyst, various esters were prepared in moderate-to-good yields through $\mathrm{C}_{\mathrm{sp}^{3}}-\mathrm{H}$ bond activation of alkanes. Paraformaldehyde could also be applied for in situ alcohol generation by radical trapping, and moderate yields of the corresponding esters could be produced. Notably, this is the first report on copper-catalyzed alkoxycarbonylation of alkanes.

\section{Experimental Section}

\section{General procedure A}

A $4 \mathrm{~mL}$ screw-cap vial was charged with $\mathrm{CuCl}_{2}(6.7 \mathrm{mg}$, $10 \mathrm{~mol} \%)$ 1,10-phenanthroline hydrate (9 mg, $10 \mathrm{~mol} \%)$, and an oven-dried stirring bar. The vial was closed with a Teflon septum and phenolic cap and connected to the atmosphere with a needle. After cyclohex- nylpropan-1-ol afforded a good result with $82 \%$ yield. Interestingly, if (perfluorophenyl)methanol was used in this reaction, an excellent yield was obtained (Table 2, entry 17). Importantly, cholesterol, an essential structural component of all animal cell membranes, reacted smoothly with cyclohexane and afforded the desired product in $61 \%$ isolated yield (Table 2, entry 18).

Furthermore, some alkane derivatives were tested, and the results are listed in Table 3. Cyclopentane and cycloheptane reacted smoothly under the standard reaction conditions (Table 3, entries 1 and 2). Good yields of the corresponding esters were isolated ( 72 and $71 \%$, respectively). Pentane and hexane were also tested under the same conditions, and a mixture of different regioselective products was obtained (Table 3 , entries 3 and 4).

To further explore the applicability of this reaction in aliphatic ester synthesis, we used paraformaldehyde for in situ alcohol generation by radical trapping and obtained the desired products in 52 and $51 \%$ yield, respectively (Scheme 2). ${ }^{[8]}$ In these cases, no addition of alcohol was required.

Based on our results, a possible reaction mechanism is proposed (Scheme 3). The reaction starts with a copper(II)-catalyzed or thermal hemolytic cleavage of a peroxide to generate the tert-butoxy radical, which reacts with cyclohexane under

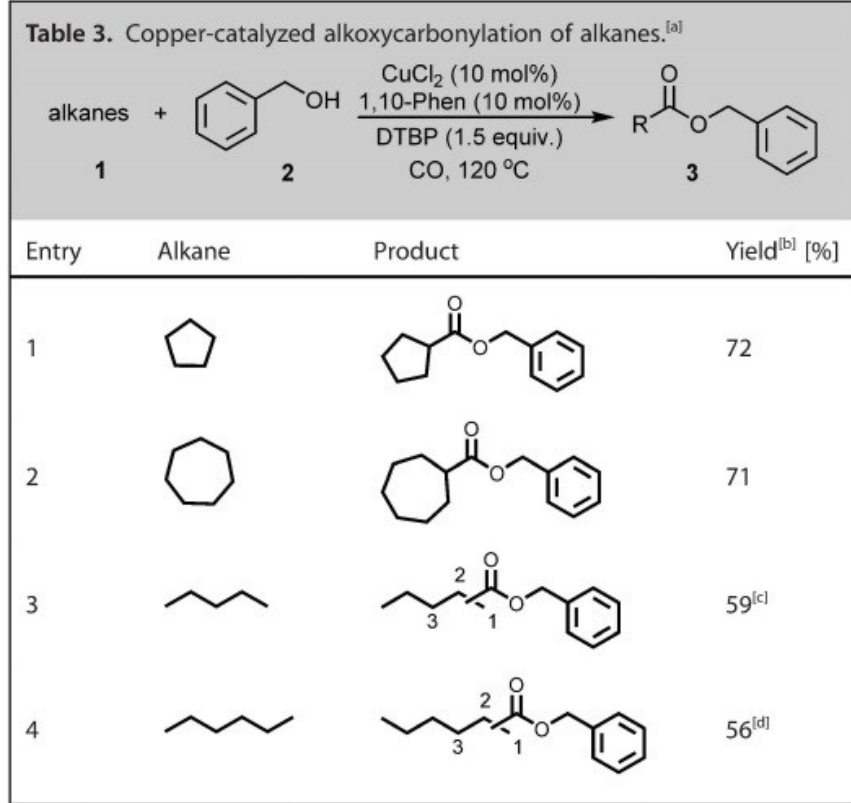

[a] Benzyl alcohol $(0.5 \mathrm{mmol}), \mathrm{CuCl}_{2}(10 \mathrm{~mol} \%), 1,10$-phen $(10 \mathrm{~mol} \%)$, DTBP $(0.75 \mathrm{mmol}), 20 \mathrm{bar} \mathrm{CO}$, alkane $(2 \mathrm{~mL}), 120^{\circ} \mathrm{C}, 24 \mathrm{~h}$. [b] Isolated yields. [c] The ratio was determined by ${ }^{1} \mathrm{H}$ NMR $(\mathrm{C} 1 / \mathrm{C} 2 / \mathrm{C} 3=1.15: 2.92: 1)$. [d] Mixture. 
(1)

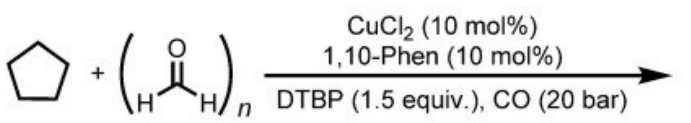

$120^{\circ} \mathrm{C}$
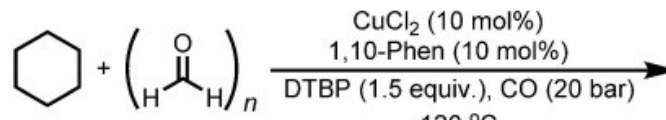<smiles>O=C(OCC1CCCC1)C1CCCC1</smiles>

$52 \%$

$120^{\circ} \mathrm{C}$

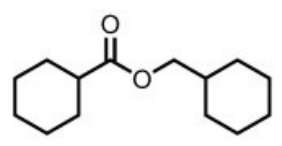

Scheme 2. Using paraformaldehyde for in situ generation of alcohols.

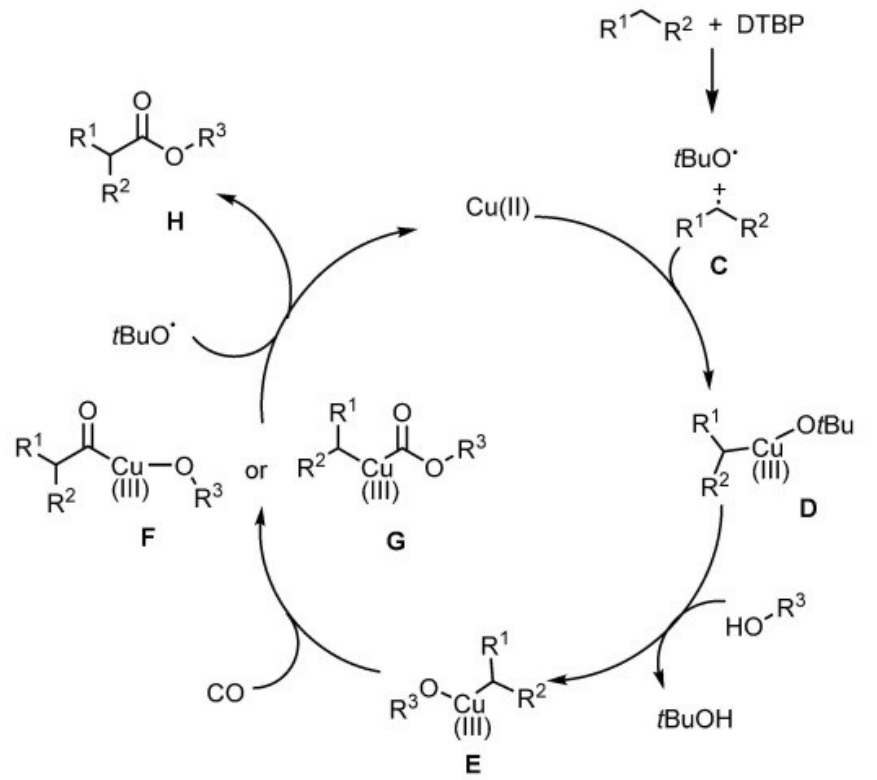

Scheme 3. Proposed reaction mechanism.

ane $(2 \mathrm{~mL})$, DTBP $(0.75 \mathrm{mmol})$, and alcohol $(0.5 \mathrm{mmol})$ were injected by syringe, the vial was fixed in an alloy plate and placed in a Parr 4560 series autoclave $(300 \mathrm{~mL})$ under argon atmosphere. At room temperature, the autoclave was flushed with $\mathrm{CO}$ three times and charged with 20 bar CO. The autoclave was placed on a heating plate equipped with magnetic stirring and an aluminum block. The reaction was heated at $120^{\circ} \mathrm{C}$ for $24 \mathrm{~h}$. Afterwards, the autoclave was cooled to room temperature and the pressure was carefully released. After removal of the solvent under reduced pressure, the pure product was obtained by column chromatography on silica gel (eluent: pentane/ethyl acetate $=100: 1)$.

\section{General procedure B}

A $4 \mathrm{~mL}$ screw-cap vial was charged with $\mathrm{CuCl}_{2}(6.7 \mathrm{mg}, 10 \mathrm{~mol} \%)$, 1,10-phenanthroline hydrate $(9 \mathrm{mg}, 10 \mathrm{~mol} \%)$, paraformaldehyde (15 mg, $0.5 \mathrm{mmol}$ ), and an oven-dried stirring bar. The vial was closed with a Teflon septum and phenolic cap and connected to the atmosphere with a needle. After cyclohexane $(2 \mathrm{~mL})$ and DTBP $(0.75 \mathrm{mmol})$ were injected by syringe, the vial was fixed in an alloy plate and placed in a Parr 4560 series autoclave $(300 \mathrm{~mL})$ under argon atmosphere. At room temperature, the autoclave was flushed with $\mathrm{CO}$ three times and charged with $20 \mathrm{bar} \mathrm{CO}$. The autoclave was placed on a heating plate equipped with magnetic stirring and an aluminum block. The reaction was heated at $120^{\circ} \mathrm{C}$ for $24 \mathrm{~h}$. Afterwards, the autoclave was cooled to room temperature and the pressure was carefully released. After removal of the solvent under reduced pressure, the pure product was obtained by column chromatography on silica gel (eluent: pentane/ethyl acetate $=100: 1)$.

\section{Acknowledgements}

The authors thank the Chinese Scholarship Council for financial Support. The analytic supports of Dr. W. Baumann, Dr. C. Fisher, S. Buchholz, and S. Schareina are gratefully acknowledged. We also appreciate the general support from Prof. Matthias Beller in LIKAT.

Keywords: alcohols · alkanes · carbonylation · copper catalyst · esters

[1] For selected recent reviews on carbonylation, see: a) X. F. Wu, H. Neumann, M. Beller, Chem. Rev. 2013, 113, 1-35; b) X. F. Wu, H. Neumann, M. Beller, Chem. Soc. Rev. 2011, 40, 4986-5009; c) X.-F. Wu, H. Neumann, ChemCatChem 2012, 4, 447-458; d) Q. Liu, H. Zhang, A. Lei, Angew. Chem. Int. Ed. 2011, 50, 10788-10799; Angew. Chem. 2011, 123, 1097810989; e) X. F. Wu, H. Neumann, M. Beller, ChemSusChem 2013, 6, 229 241 ; f) C. H. Schiesser, U. Wille, H. Matsubara, I. Ryu, Acc. Chem. Res. 2007, 40, 303-313; g) S. Sumino, A. Fusano, T. Fukuyama, I. Ryu, Acc. Chem. Res. 2014, 47, 1563-1574; h) B. Gabriele, R. Mancuso, G. Salerno, Eur. J. Org. Chem. 2012, 6825-6839; i) S. D. Friis, A. T. Lindhardt, T. Skrydstrup, Acc. Chem. Res. 2016, 49, 594-605; j) X. F. Wu, RSC Adv. 2016, 6, 83831 83837; k) J.-B. Peng, X. Qi, X.-F. Wu, ChemSusChem 2016, 9, 2279-2283.

[2] a) E. J. Yoo, M. Wasa, J.-Q. Yu, J. Am. Chem. Soc. 2010, 132, 17378-17380; b) S. Li, G. Chen, C.-G. Feng, W. Gong, J.-Q. Yu, J. Am. Chem. Soc. 2014 136, 5267-5270; c) A. McNally, B. Haffemayer, B. S. L. Collins, M. J. Gaunt, Nature 2014, 510, 129-133; d) N. Hasegawa, V. Charra, S. Inoue, Y. Fukumoto, N. Chatani, J. Am. Chem. Soc. 2011, 133, 8070-8073; e) G. Liao, X. Yin, K. Chen, Q. Zhang, S. Zhang, B. F. Shi, Nat. Commun. 2016, 7, 12901 12909; f) B. Sundararaju, M. Achard, G. V. M. Sharma, C. Bruneau, J. Am. Chem. Soc. 2011, 133, 10340-10343.

[3] a) P. Xie, C. Xia, H. Huang, Org. Lett. 2013, 15, 3370-3373; b) P. Xie, Y. Xie, B. Qian, H. Zhou, C. Xia, H. Huang, J. Am. Chem. Soc. 2012, 134, $9902-$ 9905; c) H. Liu, G. Laurenczy, N. Yan, P. J. Dyson, Chem. Commun. 2014 50, $341-343$; d) I. Ryu, A. Tani, T. Fukuyama, D. Ravelli, M. Fagnoni, A. Albini, Angew. Chem. Int. Ed. 2011, 50, 1869-1872; Angew. Chem. 2011 123, 1909-1912; e) M. Okada, T. Fukuyama, K. Yamada, I. Ryu, D. Ravelli, M. Fagnoni, Chem. Sci. 2014, 5, 2893-2898; f) L. Lu, R. Shi, L. Liu, J. Yan, F. Lu, A. Lei, Chem. Eur. J. 2016, 22, 14484-14488; g) Y. Fujiwara, K. Takaki, J. Watanabe, Y. Uchida, H. Taniguchi, Chem. Lett. 1989, 18, 1687 1688.

[4] S. E. Allen, R. R. Walvoord, R. Padilla-Salinas, M. C. Kozlowski, Chem. Rev. 2013, 113, 6234-6458.

[5] a) J. M. Liu, R. Z. Zhang, S. F. Wang, W. Sun, C. G. Xia, Org. Lett. 2009, 11, 1321-1324; b) P. J. Tambade, Y. P. Patil, N. S. Nandurkar, B. M. Bhanage, Synlett 2008, 886-888; c) Y. Li, K. Dong, F. Zhu, Z. Wang, X.-F. Wu, Angew. 
Chem. Int. Ed. 2016, 55, 7227-7230; Angew. Chem. 2016, 128, $7343-$ 7346; d) Y. Li, F. Zhu, Z. Wang, X.-F. Wu, ACS Catal. 2016, 6, 5561-5564; e) S.-K. Kang, T. Yamaguchi, T.-H. Kim, P.-S. Ho, J. Org. Chem. 1996, 61, 9082-9083.

[6] a) Esterification: methods, reactions, and applications (Ed.: J. Otera), WileyVCH, Weinheim, 2010; b) K. Ekoue-Kovi, C. Wolf, Chem. Eur. J. 2008, 14, 6302-6315; c) D. Milstein, Top. Catal. 2010, 53, 915-923; d) S. Tang, J. Yuan, C. Liu, A. Lei, Dalton Trans. 2014, 43, 13460-13470; e) H. Miyamura, S. Kobayashi, Acc. Chem. Res. 2014, 47, 1054-1066; f) B. Liu, F. Hu, B. F. Shi, ACS Catal. 2015, 5, 1863-1881.
[7] N. A. McGrath, M. Brichacek, J. T. Njardarson, J. Chem. Educ. 2010, 87, $1348-1349$

[8] a) W. Li, X. F. Wu, Adv. Synth. Catal. 2015, 357, 3393-3418; b) T. Kawamoto, T. Fukuyama, I. Ryu, J. Am. Chem. Soc. 2012, 134, 875-877.

Manuscript received: November 4, 2016

Revised: November 25, 2016

Accepted Article published: November 29, 2016

Final Article published: December 21, 2016 


\subsection{An unexpected copper-catalysed carbonylative acetylation of amines}

Yahui Li, Changsheng Wang, Fengxiang Zhu, Zechao Wang, Jean François Soule, Pierre H. Dixneuf, and Xiao-Feng Wu*

Chem. Commun., 2017, 53, 142--144

Author contributions:

Dr. Xiao-Feng Wu, Yahui Li and Changsheng Wang conceived and developed this project. Dr. Xiao-Feng Wu and Yahui Li wrote the manuscript with revisions provided by Pierre H. Dixneuf, Jean François Soule, Fengxiang Zhu, Zechao Wang. My contribution as co-author of this paper is approximately $80 \%$. 


\title{
ChemComm
}

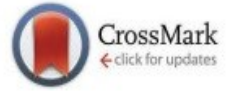

Cite this: Chem. Commun., 2017, 53, 142

Received 8th November 2016 Accepted 1st December 2016

DOI: $10.1039 / \mathrm{c} 6 \mathrm{cc0} 0829 \mathrm{a}$

www.rsc.org/chemcomm

\section{An unexpected copper-catalyzed carbonylative acetylation of amines $\dagger$}

\author{
Yahui Li, $\neq^{\mathrm{a}}$ Changsheng Wang, $\$^{\mathrm{b}}$ Fengxiang Zhu, ${ }^{a}$ Zechao Wang, ${ }^{\mathrm{a}}$ \\ Jean François Soulé, ${ }^{b}$ Pierre H. Dixneuf ${ }^{b}$ and Xiao-Feng $W_{u^{* a}}$
}

\section{A novel copper-catalyzed carbonylative acetylation of amines has been developed. With peroxide as the oxidant as well as the methyl source with a copper catalyst under $\mathrm{CO}$ pressure, good yields of $\mathrm{N}$-acetyl amides could be obtained. Notably, this is the first example of carbonylative acetylation.}

The acetylation of amine is one of the fundamental transformations in organic chemistry. ${ }^{1}$ Additionally, its importance has also been verified by the numerous applications in pharmaceutical and agricultural industries. ${ }^{2}$ Traditionally, the acetylation of amines usually took place with acetic acid/acetic anhydride/acetyl chloride under either basic or acidic conditions (Scheme 1, eqn (a)). ${ }^{3}$ Although acetylation with acetic acid represents the most straightforward procedure, however from the acetic acid synthesis point of view, acetic acid is mainly produced via a carbonylation procedure (Cativa process and Monsanto process). ${ }^{4}$ With methanol as the starting material under CO pressure and with Ir or Rh catalysts, acetic acid is produced in million of tonnes per year. According to retrosynthetic analysis, ${ }^{5}$ it should be possible and interesting to

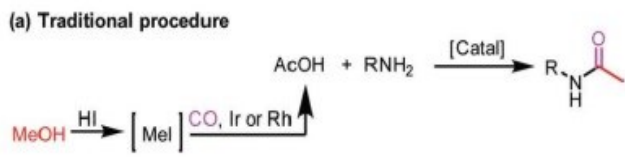

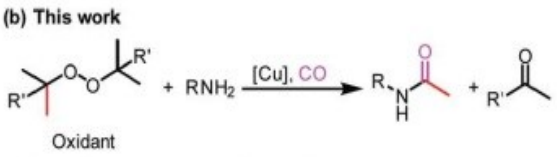

Scheme 1 Acetylation methodologies.

${ }^{a}$ Leibniz-Institut für Katalyse e.V. an der Universität Rostock, Albert-Einstein-Straße 29a, 18059 Rostock, Germany. E-mail: Xiao-Feng.Wu@catalysis.de

${ }^{b}$ Catalyse et Organométalliques, Institut Sciences Chimiques de Rennes, UMR 6226-CNRS-Université de Rennes, Av. Général Leclerc, 35042 Rennes, France $\dagger$ Electronic supplementary information (ESI) available: General procedure, analytical data and NMR spectra. See DOI: 10.1039/c6cc08929a

\$ These authors contributed equally to this work. realize the application of carbonylation in acetylation. Nevertheless, the choice of the methyl source is a challenge. With methyl iodide (the intermediate in the Cativa process by the reaction of $\mathrm{MeOH}$ with $\mathrm{HI}$ ) as the methyl source, the methylation of amines via the nucleophilic substitution reaction between MeI and amines is much faster; with $\mathrm{MeOH}$ as the methyl source, the needed $\mathrm{HI}$ is not compatible with amines. Hence, no carbonylative acetylation has been developed to date.

On the other hand, transitional metal-catalyzed carbonylative transformations have already become a powerful toolbox in modern organic synthesis. ${ }^{6}$ With noble metals as the catalysts, CO can be easily introduced into the parent molecules. Taking into consideration the high price of noble metals and the required phosphine ligands, the exploration of non-noble catalysts for this area is a challenge and will be interesting. By looking at the catalytic behaviours and their advantages, copper catalysts will be a good option. ${ }^{7}$ Indeed, copper catalysts are rarely applied in

Table 1 Optimization of reaction conditions ${ }^{a}$

\begin{tabular}{|c|c|c|}
\hline & $\widehat{N H}_{2}+\operatorname{CO} \frac{\mathrm{CuF}_{2}(10 \mathrm{~mol} \%)}{\operatorname{CO}(40 \text { bar }), \mathrm{DCP}, 140^{\circ} \mathrm{C}, \mathrm{PhCl}}$ & \\
\hline Entry & Variations from the standard conditions & Yield $^{b}(\%)$ \\
\hline 1 & - & 79 \\
\hline 2 & Without $\mathrm{CuF}_{2}$ & Trace \\
\hline 3 & Without 1,10-phen & Trace \\
\hline 4 & $\mathrm{CuBr}\left(\mathrm{Me}_{2} \mathrm{~S}\right)$ instead of $\mathrm{CuF}_{2}$ & 31 \\
\hline 5 & $\begin{array}{l}\text { 2,9-Dimethyl-1,10-phenanthroline instead } \\
\text { of 1,10-phen }\end{array}$ & 61 \\
\hline 6 & $\begin{array}{l}4,4^{\prime} \text {-Di-tert-butyl-2,2'-dipyridyl instead } \\
\text { of } 1,10 \text {-phen }\end{array}$ & 52 \\
\hline 7 & $100^{\circ} \mathrm{C}, 20$ bar $\mathrm{CO}$ & 48 \\
\hline 8 & $120^{\circ} \mathrm{C}, 20$ bar $\mathrm{CO}$ & 55 \\
\hline 9 & 20 bar CO & 67 \\
\hline 10 & DTBP instead of DCP & 56 \\
\hline 11 & TBHP instead of DCP & 0 \\
\hline
\end{tabular}

${ }^{a}$ 1-Octanamine (0.5 mmol), catalyst (10 $\left.\mathrm{mol} \%\right)$, ligand (10 mol\%), $1 \mathrm{mmol} \mathrm{DCP}, 40$ bar CO, PhCl $(2 \mathrm{~mL}), 24 \mathrm{~h} .{ }^{b}$ Isolated yields, the yields were calculated based on the amount of amine used. TBHP: $t$-butyl hydroperoxide solution $70 \mathrm{wt} \%$ in $\mathrm{H}_{2} \mathrm{O}$. DCP: dicumyl peroxide. DTBP: di-tert-butyl peroxide. 1,10-phen: 1,10-phenanthroline hydrate. 
carbonylation reactions. ${ }^{8,9}$ We recently studied the application of copper catalysts in carbonylative transformations of alkanes with amines and amides. ${ }^{9}$ With copper as the catalyst and DTBP (di-tert-butyl peroxide) as the oxidant, amides or imides can be produced effectively from the corresponding alkanes and amines or amides. Interestingly, in some cases, acetylation of amine was observed during the optimization process. Under thermal conditions or in the presence of a metal catalyst, peroxides could decompose into the corresponding alkoxy radical, which could give a methyl radical through $\beta$-scission of the alkoxy radical. ${ }^{10}$ In the analysis of the reaction conditions, we realized that the methyl group is from DTBP and trapped by CO to give the acetyl group. With the

Table 2 Cu-Catalyzed carbonylative acetylation of amines ${ }^{a}$

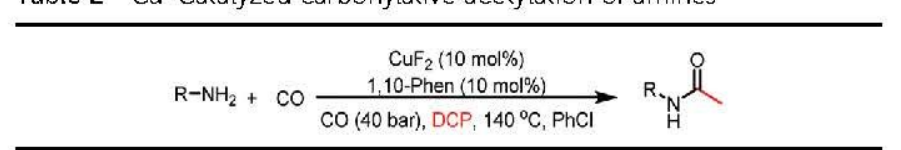

\begin{tabular}{|c|c|c|c|}
\hline Entry & $\mathrm{R}-\mathrm{NH}_{2}$ & Product & Yield $^{b}(\%)$ \\
\hline
\end{tabular}

2

3

4

6

8

9

10

11

12

13

14

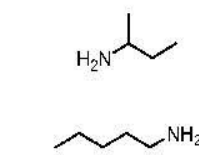

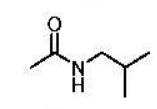

71

80
${ }^{a}$ Amine (0.5 mmol), $\mathrm{CuF}_{2}(10 \mathrm{~mol} \%), 1,10$-phen. (10 mol $\left.\%\right), 1 \mathrm{mmol}$ $\mathrm{DCP}, 40$ bar CO, PhCl $(2 \mathrm{~mL}), 140^{\circ} \mathrm{C}, 24 \mathrm{~h} .{ }^{b}$ Isolated yields; the yields were calculated based on the amount of amine used. awareness of the importance of acetylation reactions and also the academic meaningfulness of using peroxide as a methyl source in carbonylation, we focused on this transformation (Scheme 1, eqn (b)). In this procedure, peroxide acts both as an oxidant and a methyl source to give the first example of carbonylative acetylation.

With 1-octanamine as the model substrate, we established this catalytic system. With dicumyl peroxide ${ }^{11}$ as the oxidant as well as the methyl source, using $\mathrm{CuF}_{2}(10 \mathrm{~mol} \%)$ and 1,10phenanthroline hydrate $(1,10$-phen., $10 \mathrm{~mol} \%)$ as the catalyst system in chlorobenzene under CO pressure at $140{ }^{\circ} \mathrm{C}, 79 \%$ of $\mathrm{N}$-octylacetamide can be isolated (Table 1, entry 1). Only a trace amount of acetamide can be detected in the absence of copper or a ligand (Table 1, entries 2 and 3). A decreased reaction efficiency was observed upon catalyst or ligand variation (Table 1, entries 4-6). And decreasing the reaction temperature or CO pressure resulted in decreased yields of acetamide (Table 1, entries 7-9). DTBP is shown to be a suitable reagent as well, $56 \%$ of $N$-octylacetamide was isolated (Table 1 , entry 10 ); while no product could be detected with TBHP as the reagent (Table 1, entry 11).\$

With the best reaction conditions in hand (Table 1, entry 1), we performed substrate testing of this novel procedure (Table 2). Good to excellent yields of acetamide can be produced with the tested alkyl amines (Table 2, entries 1-6).

Benzylic and other aromatic substituted amines are proven to be suitable substrates as well; moderate to good yields can be obtained in general (Table 2, entries 7-14). The chirality of the starting amine was retained, and a good yield of the acetylated product can be isolated (Table 2, entry 14). Additionally, aniline was tested as well. Around $30 \%$ of $\mathrm{N}$-phenylacetamide was obtained together with aniline-oxidized products.

Based on our results, a possible reaction mechanism is proposed (Scheme 2). The reaction starts with a copper(I)-catalyzed or thermal hemolytic cleavage of a peroxide to generate the corresponding alkoxy radical. A methyl radical is generated through $\beta$-scission of the alkoxy radical, which reacts with the copper(II) species to give the corresponding $\mathrm{Cu}(\mathrm{m})-$-methyl species A. Then complex A reacts with the amine through $\mathrm{X}$ ligand exchange to produce the $\mathrm{Cu}(\mathrm{mI})$ intermediate B. Then the insertion of $\mathrm{CO}$ forms the intermediate $\mathrm{C}$ or $\mathrm{C}^{\prime}$,

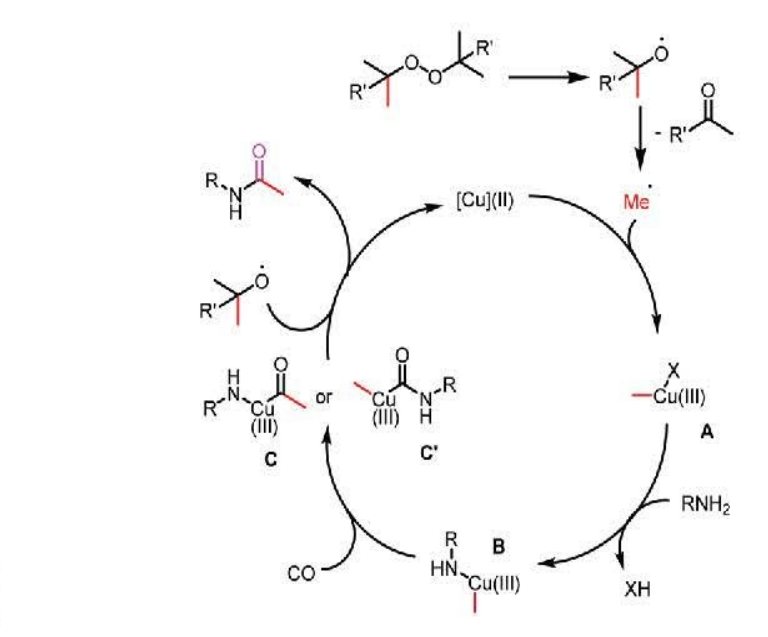

Scheme 2 Proposed reaction pathway. 
which will give the final carbonylation product after reductive elimination. Meanwhile, the formed $\mathrm{Cu}(\mathrm{I})$ intermediate reacted with the alkoxy radical to produce $\mathrm{Cu}$ (II) species for the next catalytic cycle.

In conclusion, an interesting copper-catalyzed carbonylative acetylation of amine has been developed. With peroxide as the oxidant as well as the methyl source, good yields of $\mathrm{N}$-acetyl amides were formed from the corresponding amines. Notably, this is the first example of carbonylative acetylation.

The authors thank the Chinese Scholarship Council for financial Support. The analytical support from Dr W. Baumann, Dr C. Fisher, S. Buchholz, and S. Schareina is gratefully acknowledged. We also appreciate the generous support from Professor Matthias Beller in LIKAT.

\section{Notes and references}

$\S$ General procedure: A $4 \mathrm{~mL}$ screw-cap vial was charged with $\mathrm{CuF}_{2}$ ( $5.05 \mathrm{mg}, 10 \mathrm{~mol} \%), 1,10$-phenanthroline hydrate $(9.9 \mathrm{mg}, 10 \mathrm{~mol} \%$ ) and an oven-dried stirring bar. The vial was closed by a Teflon septum and a phenolic cap and connected with a needle. After amine $(0.5 \mathrm{mmol})$, DCP $(1 \mathrm{mmol})$ and $\mathrm{PhCl}(2 \mathrm{~mL})$ were injected using a syringe, the vial was fixed in an alloy plate and put into a Paar 4560 series autoclave $(300 \mathrm{~mL})$ under an argon atmosphere. At room temperature, the autoclave was flushed with carbon monoxide thrice and 40 bar of carbon monoxide was charged. The autoclave was placed on a heating plate equipped with a magnetic stirrer and an aluminium block. Then the reaction was heated at $140^{\circ} \mathrm{C}$ for 24 hours. Afterwards, the autoclave was cooled to room temperature and the pressure was carefully released. After the removal of the solvent under reduced pressure, the pure product was obtained by column chromatography on silica gel (eluent: pentane/ethyl acetate $=1: 1$ ).

1 (a) R. C. Larock, Comprehensive Organic Transformations, VCH, Weinheim, Germany, 2nd edn, 1989; (b) T. W. Greene and
P. G. M. Wuts, Protective Groups in Organic synthesis, John Wiley \& Sons, Inc., New York, 3rd edn, 1999.

2 (a) J. M. Humphrey and A. R. Chamberlin, Chem. Rev., 1997, 97, 2243; (b) A. Scozzafava, T. Owa, A. Mastrolorenzo and C. T. Supuran, Curr. Med. Chem., 2003, 10, 925; (c) J. S. Carey, D. Laffan, C. Thomson and M. T. Williams, Org. Biomol. Chem, 2006, 4, 2337; (d) F. Abbate, C. T. Supuran, A. Scozzafava, P. Orioli, M. T. Stubbs and G. Klebe, J. Med. Chem, 2002, 45, 3583.

3 (a) A. Vogel, Practical Organic Chemistry, Langman Scientific \& Technical and Wiley, New York, 1989; (b) J. March, Advanced Organic Chemistry, John Wiley \& Sons, New York, 4th edn, 1992.

4 (a) J. H. Jones, Platinum Met. Rev., 2000, 44, 94; (b) G. J. Sunley and D. J. Watson, Catal. Today, 2000, 58, 293.

5 (a) E. J. Corey, Chem. Soc. Rev., 1988, 17, 111; (b) E. J. Corey, Angew. Chem., Int. Ed., 1991, 30, 455.

6 For selected recent reviews on carbonylation reaction, see: (a) X. F. Wu, H. Neumann and M. Beller, Chem. Rev., 2013, 113, 1; (b) X. F. Wu, H. Neumann and M. Beller, Chem. Soc. Rev., 2011, 40, 4986; (c) X.-F. Wu and H. Neumann, ChemCatChem, 2012, 4, 447; (d) Q. Liu, H. Zhang and A. Lei, Angew. Chem., Int. Ed., 2011, 50, 10788; (e) X. F. Wu, H. Neumann and M. Beller, ChemSusChem, 2013, 6, 229; $(f)$ C. H. Schiesser, U. Wille, H. Matsubara and I. Ryu, Acc. Chem. Res., 2007, 40, 303; (g) S. Sumino, A. Fusano, T. Fukuyama and I. Ryu, Acc. Chem. Res., 2014, 47, 1563; (h) B. Gabriele, R. Mancuso and G. Salerno, Eur. J. Org. Chem., 2012, 6825; (i) S. D. Friis, A. T. Lindhardt and T. Skrydstrup, Acc. Chem. Res., 2016, 49, 594.

7 S. E. Allen, R. R. Walvoord, R. Padilla-Salinas and M. C. Kozlowski, Chem. Rev., 2013, 113, 6234.

8 (a) J. M. Liu, R. Z. Zhang, S. F. Wang, W. Sun and C. G. Xia, Org. Lett., 2009, 11, 1321; (b) P. Tambade, Y. Patil, N. Nandurkar and B. Bhanage, Synlett, 2008, 886; (c) S.-K. Kang, T. Yamaguchi, T.-H. Kim and P.-S. Ho, J. Org. Chem., 1996, 61, 9082.

9 (a) Y. Li, K. Dong, F. Zhu, Z. Wang and X.-F. Wu, Angew. Chem. Int. Ed., 2016, 55, 7227; (b) Y. Li, F. Zhu, Z. Wang and X.-F. Wu, ACS Catal, 2016, 6, 5561.

10 P. Gray and A. Williams, Chem. Rev., 1959, 59, 239.

11 T. Kubo and N. Chatani, Org. Lett., 2016, 18, 1698. 
3.5 Practical and General Manganese-Catalysed Carbonylative Coupling of Alkyl Iodides with Amides

Yahui Li, Fengxiang Zhu, Zechao Wang, Jabor Rabeah, Angelika Breckner, and Xiao-Feng Wu*

ChemCatChem 2017, 9, 915 - 919

Author contributions:

Dr. Xiao-Feng Wu and Yahui Li conceived and developed this project. Yahui Li and Dr. Jabor Rabeah performed the mechanistic study (EPR). Dr. Xiao-Feng Wu and Yahui Li wrote the manuscript with revisions provided by Prof. Angelika Breckner, Fengxiang Zhu, Zechao Wang. My contribution as co-author of this paper is approximately $85 \%$. 


\title{
Practical and General Manganese-Catalyzed Carbonylative Coupling of Alkyl lodides with Amides
}

\author{
Yahui Li, ${ }^{[a]}$ Fengxiang Zhu, ${ }^{[a]}$ Zechao Wang, ${ }^{[a]}$ Jabor Rabeah, ${ }^{[a]}$ Angelika Brückner, ${ }^{[a]}$ and \\ Xiao-Feng $\mathrm{Wu}^{*[\mathrm{~b}]}$
}

\begin{abstract}
A selective manganese-catalyzed carbonylative transformation of alkyl iodides and amides was developed. A variety of imides were prepared in moderate to good yields. Alkyl bromides could also be applied by in situ treatment with Nal to give the corresponding alkyl iodides. Notably, no additives or expensive ligands were required here. As the first example of the carbonylative coupling of alkyl iodides with amides, the simple reaction conditions and the advantages of a manganese catalyst make this new general procedure more attractive and practical than conventional techniques. Mechanistically, control experiments and electron paramagnetic resonance spectroscopy studies were also performed, and the radical nature of this new process was proven.
\end{abstract}

Imides are produced as important intermediates in the bulkand fine-chemical industries. They are used as detergents, pharmaceutical intermediates, and agrochemicals, and they are also found in various bioactive molecules. ${ }^{[1]}$ Selected examples of valuable imide compounds are shown in Scheme 1,
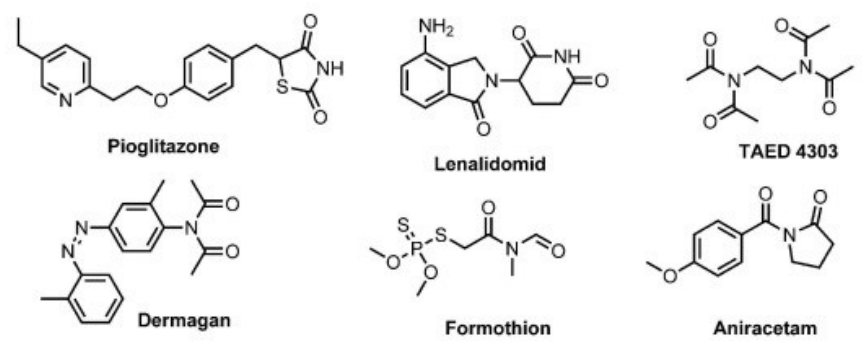

Scheme 1. Selected examples of bioactive imides derivatives.

including pioglitazone (Actos), ${ }^{[2 a]}$ which is a prescription drug to treat diabetes; lenalidomide (Revlimid), ${ }^{[2 a]}$ which is intended as a treatment for multiple myeloma;

[a] Y. Li, F. Zhu, Z. Wang, Dr. J. Rabeah, Prof. Dr. A. Brückner Leibniz-Institut für Katalyse e.V. an der Universität Rostock Albert-Einstein-Straße 29a, 18059 Rostock (Germany)

[b] Prof. Dr. X.-F. Wu

Department of Chemistry

Zhejiang Sci-Tech University, Xiasha Campus Hangzhou 310018 (People's Republic of China) E-mail:Xiao-Feng.Wu@catalysis.de (D) author(s) of this article can be found under http://dx.doi.org/10.1002/ cctc. 201601712. tetraacetylethylenediamine (TAED), which is used as a peroxide bleach activator in detergents, ${ }^{[2 b]}$ diacetazotol (Dermagan), which stimulates wound epithelization; formothion, which is a chemical compound used in acaricides and insecticides; and aniracetam (Ampamet), which is an anxiolytic drug. ${ }^{[2]}$ Traditional procedures for the synthesis of imides are based on the nucleophilic substitution of activated carboxylic acid derivatives such as acid chlorides and anhydrides with amides in the presence of base or acid under cautious conditions. ${ }^{[3]}$ Owing to the availability and stability of the substrates applied and also limitations on the functional-group tolerance, the development of new methodologies for imides synthesis are still in demand.

Transition-metal-catalyzed carbonylative transformations have found tremendous applications in the synthesis of a wide range of carbonyl-containing chemicals. ${ }^{[4]}$ Carbonylation reactions involving the use of carbon monoxide (CO) as one of the cheapest $C_{1}$ building blocks continues to attract the interest of organic chemists in academic and industrial areas. In the past decades, many of the achievements on this topic have involved noble-metal-catalyzed carbonylative transformations of aryl halides with various nucleophiles. More specifically, catalysts based on palladium, ruthenium, and rhodium have been extensively explored; nucleophiles such as alcohols and amines are more frequently applied. ${ }^{[5]}$ Additionally, free-radical carbonylation in the presence of various radical initiators is also well established. ${ }^{[6]}$ In general, as one of the most important intermediates and building blocks in organic synthesis, the development of new reactions that employ amides as reactants is worth pursuit. However, owing to the low nucleophilicity of amides, reports on their applications in carbonylative coupling reactions are very much limited. In 2002, Indolese and Schnyder reported an interesting method for the palladium-catalyzed carbonylative coupling of aryl bromides with primary amides to the corresponding aromatic imides [Scheme 2, Eq. (1)]. ${ }^{[7 a]}$ Recently, Beller's group succeeded in using amides as reaction partners for hydroamidocarbonylation with alkenes. ${ }^{[7 b]}$ Various imides were produced in good yields with palladium as the catalyst [Scheme 2, Eq. (2)]. More recently, our group reported a novel copper-catalyzed carbonylative coupling of alkanes with amides by $\mathrm{C}\left(\mathrm{sp}^{3}\right)-\mathrm{H}$ activation [Scheme 2 , Eq. (3)]. ${ }^{[7 c]}$ Moderate to good yields of the desired aliphatic imides were obtained. Nevertheless, upon using linear (noncyclic) alkanes, regioselectivity between $\mathrm{C} 1, \mathrm{C} 2$, and C3 became a challenge. Theoretically, such a problem could easily be resolved by using the corresponding alkyl halides as the substrates. However, because of the limited ability of transitionmetal catalysts in $\mathrm{C}\left(\mathrm{sp}^{3}\right)-\mathrm{H}(\mathrm{X}=\mathrm{l}, \mathrm{Br}$, etc.) bond activation, the 


$$
\begin{aligned}
& \text { Previous work: }
\end{aligned}
$$

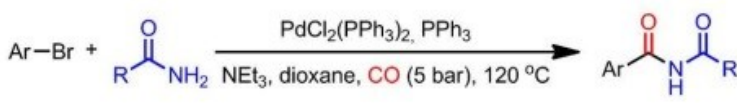

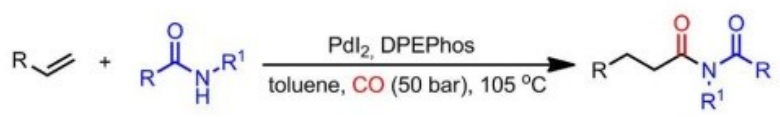

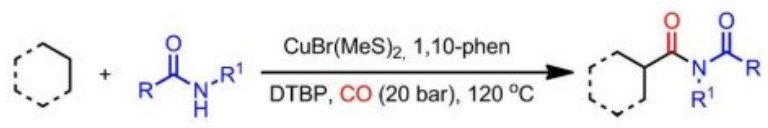

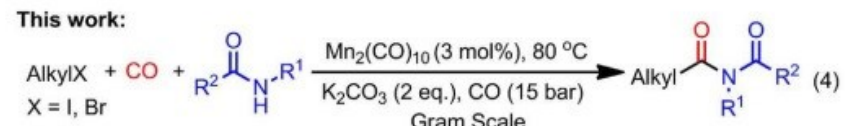

Scheme 2. Carbonylation reactions with amides as the reaction partners (10 bar = $1 \mathrm{MPa}$ ). DPEPhos = bis [2-(diphenylphosphino)phenyl] ether; 1,10phen $=1,10$-phenanthroline; DTBP $=$ di-tert-butyl peroxide.

carbonylative coupling of alkyl halides with amides is still a challenge that needs to be overcome [Scheme 2, Eq. (4)].

On the other hand, manganese salts are abundant, cheap, and environmentally benign. In organic synthesis, manganese salts have been extensively applied as catalysts in the preparation of fine and bulk chemicals. ${ }^{[8]}$ To our surprise, reports on the use of manganese catalysts in carbonylative transformations are still limited. ${ }^{[9]}$ Taking all of the above-discussed challenges into consideration and on the basis of our continued research interests, we report here the first examples of the carbonylation of alkyl iodides with amides. With manganese as the catalyst, various imides were prepared in good yields from ready available alkyl halides and amides. Excellent selectivities and functional-group tolerance were observed in the new procedure.

To start, we chose 1-iodobutane and caprolactam as the model substrates to establish this new carbonylation procedure. Upon varying the reaction conditions, different reaction outcomes were obtained (Table 1). Among the different metal catalyst precursors (Table 1, entries 1-6), $\mathrm{Mn}_{2}(\mathrm{CO})_{10}$ showed the best result ( $77 \%$ yield; Table 1 , entry 6$)$. Notably, $\mathrm{Pd}(\mathrm{OAc})_{2}$, a powerful catalyst in the carbonylative transformation of aryl halides, did not give any trace of the desired product (Table 1, entries 3). Among the other tested manganese salts, no reaction occurred with $\mathrm{MnCl}_{2}, \mathrm{MnF}_{2}$, or $\mathrm{Mn}(\mathrm{acac})_{2}$ (acac=acetylacetonate) as the catalyst, and the desired imide was obtained in $65 \%$ yield with $\mathrm{Mn}(\mathrm{CO})_{5} \mathrm{Br}$ as the catalyst. Subsequent optimization studies were focused on using $\mathrm{Mn}_{2}(\mathrm{CO})_{10}$ as the catalyst, and various solvents were checked (Table 1, entries 7-13). Good yields were obtained with benzotrifluoride and THF as the solvents. Then, fine-tuning was performed with $\mathrm{PhCF}_{3}$ as the solvent (Table 1, entries 14-17). The pressure of $\mathrm{CO}$ would be decreased to 15 bar without losing reaction efficiency, and this result was obtained at $80^{\circ} \mathrm{C}$. At that stage, we found that the combination of $\mathrm{Mn}_{2}(\mathrm{CO})_{10}(3 \mathrm{~mol} \%)$ and $\mathrm{K}_{2} \mathrm{CO}_{3}$ (2 equiv.) in $\mathrm{PhCF}_{3}$ at $80^{\circ} \mathrm{C}$ under $\mathrm{CO}$ pressure (15 bar) resulted in the isolation of the desired imide in $85 \%$ yield (Table 1 , entry 16 ).

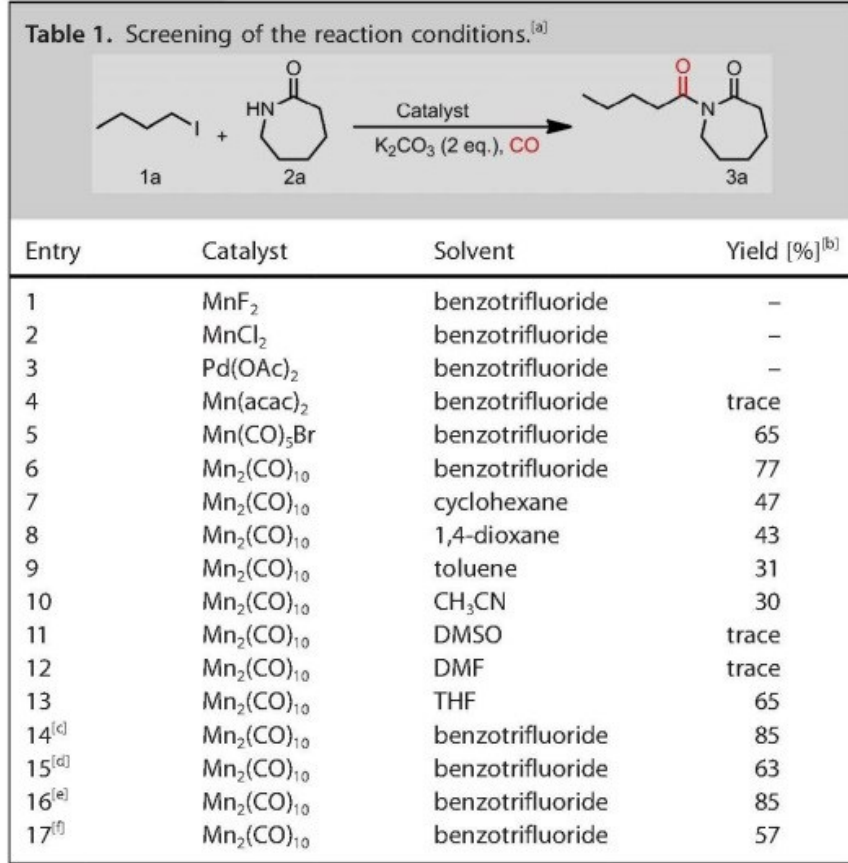

[a] Reaction conditions: 1 -iodobutane $(0.5 \mathrm{mmol})$, amide (1.5 equiv.), catalyst ( $3 \mathrm{~mol} \% ; 6 \mathrm{~mol} \%$ for monomer catalysts), $\mathrm{K}_{2} \mathrm{CO}_{3}$ (2 equiv.), $\mathrm{CO}$ ( $2 \mathrm{MPa})$, benzotrifluoride $(2 \mathrm{~mL}), 120^{\circ} \mathrm{C}, 12 \mathrm{~h}$. [b] Yield of isolated product. [c] $120^{\circ} \mathrm{C}, \mathrm{CO}(1.5 \mathrm{MPa}), 24 \mathrm{~h}$. [d] $120^{\circ} \mathrm{C}, \mathrm{CO}(1 \mathrm{MPa}), 24 \mathrm{~h}$. [e] $80^{\circ} \mathrm{C}, \mathrm{CO}$ (1.5 MPa), $24 \mathrm{~h}$. [f] $60^{\circ} \mathrm{C}, \mathrm{CO}(1.5 \mathrm{MPa}), 24 \mathrm{~h}$.

With the optimized reaction conditions in hand, we examined the scope and limitations of this procedure with a range of alkyl halides. As shown in Table 2, not only primary alkyl iodides but also secondary and tertiary alkyl iodides were all suitable substrates. Good to excellent yields of desired imides 3 a and $\mathbf{3} \mathbf{b}$ were obtained by treating butyl iodide and 2 -iodobutane with caprolactam ( 85 and $92 \%$; Table 2, entries 1 and 2). 1-lodoadamantane could be transformed successfully as well, and it gave the corresponding imide in $73 \%$ yield (Table 2, entry 3). Other alkyl halides were then examined. As shown, the reactions of iodoethane ( $\mathbf{1} \mathbf{d})$ and 1-iodopropane ( 1 e) with amides gave desired products $\mathbf{3} \mathbf{d}$ and $\mathbf{3 e}$ in moderate yields (53 and 55\%; Table 2, entries 4 and 5). Also, long-chain alkyl halides were tolerated in the reaction. For example, upon using 1-iodooctane and 1-iodohexane as the substrates, good yields were obtained for products $\mathbf{3} \mathbf{f}$ and $\mathbf{3 g}$ (72 and $86 \%$; Table 2, entries 6 and 7). A chloro-substituted substrate was also tolerated and provided the desired imide in moderate yield (Table 2, entry 9). Alkyl bromides, such as 1-bromobutane (1 k), 2-bromobutane (1) I), and 1-bromooctane (1 $\mathbf{m})$, were efficiently transformed under the reaction conditions with $\mathrm{Nal}$ as an additive (Table 2, entries 11-13). In these cases, the alkyl bromides were transformed in situ into the corresponding alkyl iodides upon reaction with $\mathrm{Nal}$.

Subsequently, different amides were tested with iodobutane (Table 3). In general, moderate to good yields were obtained in all the tested cases without further optimization. In addition to amides, lactams could also be applied. However, primary amides were shown to be unsuitable coupling partners. 
Table 2. Manganese-catalyzed carbonylative synthesis of imides from alkyl iodides. ${ }^{[a]}$

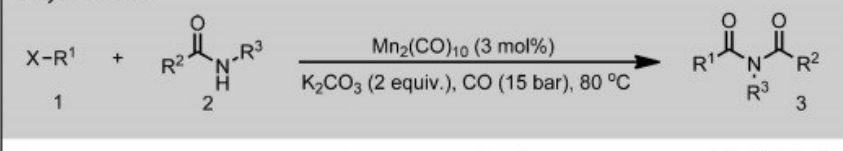

\begin{tabular}{|c|c|c|c|}
\hline Entry 1 & 2 & Product & Yield $d^{[b]}[\%]$ \\
\hline
\end{tabular}

$1 \sim_{1}^{1 a}$

$\overbrace{3 a}^{2} 85$

$2 \underbrace{}_{1 b}$

$\stackrel{\text { IN }}{\longrightarrow}$

$\overbrace{}^{\text {III }}$

92

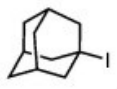

$\underbrace{\stackrel{1}{11}}$

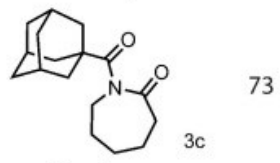

$\widehat{\gamma}_{1}$

$1 d$

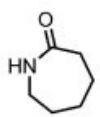<smiles>CCC(=O)N1CCCCCC1=O</smiles>

53

$\sim_{1}$

$\underbrace{\stackrel{O}{11}}$<smiles>CCCC(=O)N1CCCCCCC1=O</smiles>

55

$\sim_{1}$<smiles>O=C1CCCCN1</smiles><smiles>CCC(=O)N1CCCCCC1=O</smiles><smiles>CCCCCCCCI</smiles>

$1 \mathrm{~g}$<smiles>O=C1CCCCCN1</smiles><smiles>CCC(=O)N1CCCCCC1=O</smiles>

86

W16.<smiles>O=C1CCCCCN1</smiles>

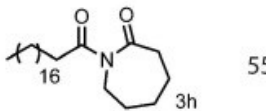

$\mathrm{Cl}_{\mathrm{I}}$<smiles>O=C1CCCCCN1</smiles><smiles>O=C(CCCCl)N1CCCCCC1=O</smiles>

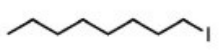

10<smiles>O=C1CCCCCN1</smiles>

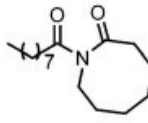

69

$2 \mathrm{~b}$<smiles>CCCCC(=O)N1CCCCCC1=O</smiles>

$12 \overbrace{}^{\mathrm{Br}}$<smiles>O=C1CCCCC1</smiles><smiles>CCC(C)C(=O)N1CCCCCC1=O</smiles>

$62^{[d]}$

13

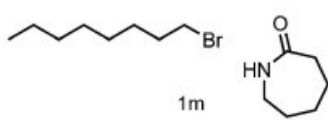

$54^{[d]}$

$3 \mathrm{~m}$

[a] Reaction conditions: alkyl halide $(0.5 \mathrm{mmol})$, amide $(0.75 \mathrm{mmol})$, $\mathrm{Mn}_{2}(\mathrm{CO})_{10}(3 \mathrm{~mol} \%), \mathrm{K}_{2} \mathrm{CO}_{3}(0.75 \mathrm{mmol}), \mathrm{CO}(1.5 \mathrm{MPa})$, benzotrifluoride $(2 \mathrm{~mL}), 80^{\circ} \mathrm{C}, 24 \mathrm{~h}$. [b] Yield of isolated product. [c] Nal $(1 \mathrm{mmol})$. [d] $\mathrm{Nal}$ (0.6 mmol).

Finally, to illustrate the synthetic potential of this method, we performed a gram-scale synthesis of imide $\mathbf{3} \mathbf{r}$, and it was isolated in an overall yield of $81 \%$ (Scheme 3 ).

Table 3. Manganese-catalyzed carbonylative synthesis of imides from amides. ${ }^{[a]}$

Entry

[a] Reaction conditions: alkyl halide $(0.5 \mathrm{mmol})$, amide $(0.75 \mathrm{mmol})$, $\mathrm{Mn}_{2}(\mathrm{CO})_{10}(3 \mathrm{~mol} \%), \mathrm{K}_{2} \mathrm{CO}_{3}(0.75 \mathrm{mmol}), \mathrm{CO}(1.5 \mathrm{MPa})$, benzotrifluoride $(2 \mathrm{~mL}), 80^{\circ} \mathrm{C}, 24 \mathrm{~h}$. [b] Yield of isolated product. [c] $120^{\circ} \mathrm{C}$.

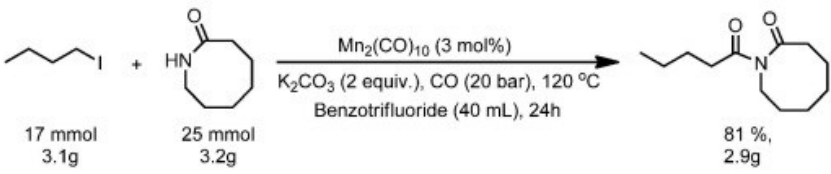

Scheme 3. Gram-scale synthesis of imide $3 \mathbf{r}(10 \mathrm{bar}=1 \mathrm{MPa})$,

To obtain some insight into the reaction pathway, 2 equivalents of 2,2,6,6-tetramethylpiperidin-1-oxyl (TEMPO) was added to our standard reactions, and the desired product could not be detected (Scheme 4). Therefore, a radical pathway was suggested.

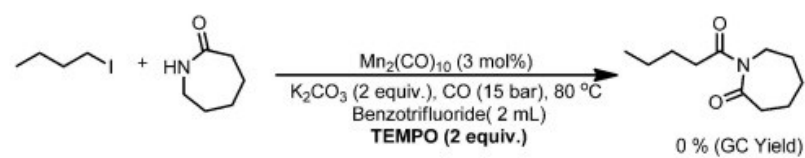

Scheme 4. Reaction with TEMPO (2,2,6,6-tetramethylpiperidin-1-oxyl). $(10 \mathrm{bar}=1 \mathrm{MPa})$ 
Additionally, electron paramagnetic resonance (EPR) spectroscopy investigations with 5,5-dimethyl-1-pyrroline $\mathrm{N}$-oxide as a spin trap to detect the short-lived radicals were performed. A catalytic test was performed in cyclohexane for $2 \mathrm{~h}$ at $65^{\circ} \mathrm{C}$ [reaction mixture containing $\mathrm{Mn}_{2}(\mathrm{CO})_{10}$, caprolactam, and butyl iodide in cyclohexane under pressure of $\mathrm{CO}$ (20 bar)]. After that, an aliquot $(\approx 0.5 \mathrm{~mL})$ of the reaction mixture was transferred into the EPR tube under an inert atmosphere and measured directly. The EPR spectrum of the mixture did not show any signal (Figure $1 \mathrm{a}$ ), probably as a result of the

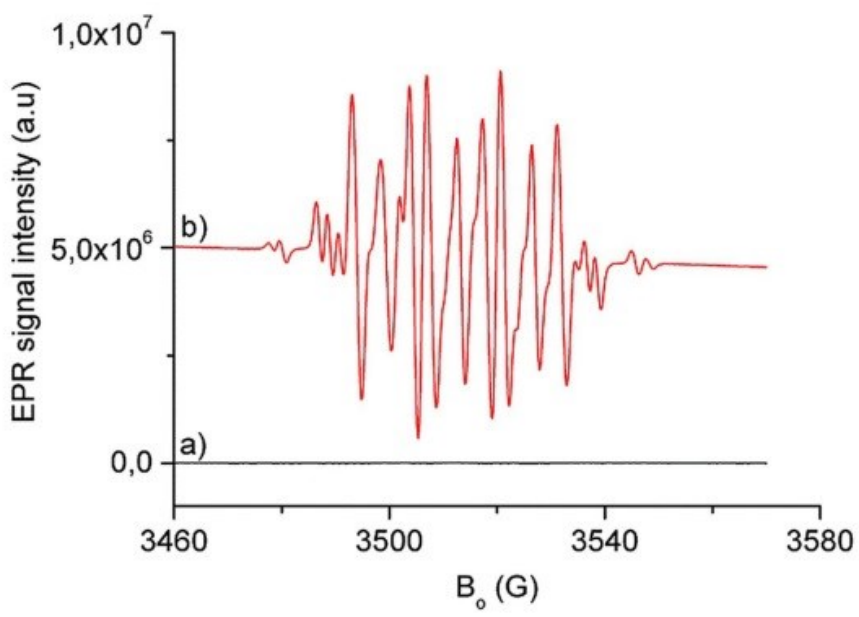

Figure 1. EPR spectra of a) $\mathrm{Mn}_{2}(\mathrm{CO})_{10}$, caprolactam, and butyl iodide in cyclohexane after the catalytic test at $65^{\circ} \mathrm{C}$ and $\mathrm{CO}(2 \mathrm{MPa})$ : a) experiment and b) in the presence of DMPO (5,5-dimethyl-1-pyrroline- $\mathrm{N}$-oxide) as a spin trap.

short life of the radicals. However, EPR measurement of the mixture in the presence of 5,5-dimethyl-1-pyrroline- $\mathrm{N}$-oxide (DMPO) as a spin trap for 10 min showed a complex spectrum because of the superimposition of several radical signals (Figure $1 \mathrm{~b}$ ), which suggested that the catalytic reaction proceeded through a radical pathway. To prove that the catalytic reaction was initiated by the reaction of the alkyl iodide with the thermally generated $\mathrm{Mn}(\mathrm{CO})_{5}$ radical [by thermolysis of the $\mathrm{Mn}_{2}(\mathrm{CO})_{10}$ dimer] to produce an alkyl radical, EPR investigation was performed in the presence of DMPO similar to that mentioned above but in the absence of caprolactam. EPR measurement of the mixture after subtraction of the background signals originating from DMPO (commercial DMPO often has varying amounts of paramagnetic impurities) showed a six-line spectrum at $g=2.007\left(a_{\mathrm{N}}=14.1 \mathrm{G}\right.$ and $a_{\mathrm{H}}=20.2 \mathrm{G}$, Figure 2$)$ as a result of the formation of a spin adduct (DMPO/R). This EPR experiment provided definitive proof for the production of ' $R$.

On the basis of our results, a possible reaction mechanism is proposed in Scheme 5. The catalytic reaction starts with thermally induced thermolysis of the $\mathrm{Mn}-\mathrm{Mn}$ bond in $\mathrm{Mn}_{2}(\mathrm{CO})_{10}$ (A) to generate the $\mathrm{Mn}(\mathrm{CO})_{5}$ (B) radical; ${ }^{[10]}$ radical $\mathrm{B}$ abstracts an iodine atom from alkyl iodide $\mathbf{C}$ to generate alkyl-centered radical $\mathrm{D}$ and to form $\mathrm{I}-\mathrm{Mn}(\mathrm{CO})_{5}(\mathrm{E})$. Alkyl-centered radical $\mathrm{D}$ was detected by the in situ EPR study by using DMPO as a spin trap. Alkyl radical $\mathbf{D}$ undergoes carbonylation by

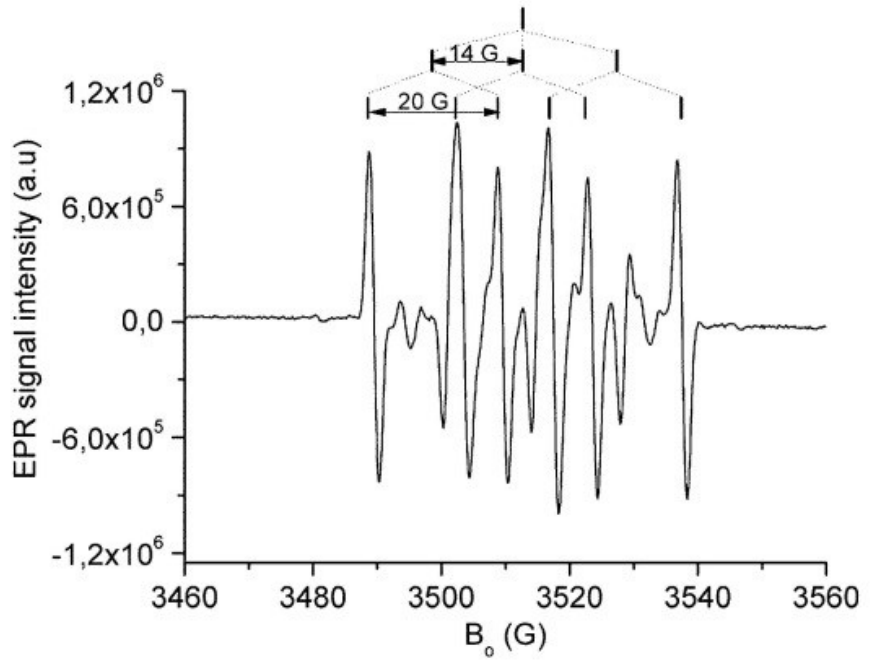

Figure 2. EPR spectrum (measured at $20^{\circ} \mathrm{C}$ ) of the spin adduct formed after adding DMPO (5,5-dimethyl-1-pyrroline- $\mathrm{N}$-oxide) to a mixture of $\mathrm{Mn}_{2}(\mathrm{CO})_{10}$ and butyl iodide in cyclohexane at $65^{\circ} \mathrm{C}$ for $10 \mathrm{~min}$ under $\mathrm{CO}$ pressure ( $2 \mathrm{MPa}$ ). (The background signals originating from the DMPO sample were subtracted, as commercial DMPO often has varying amounts of paramagnetic impurities.)

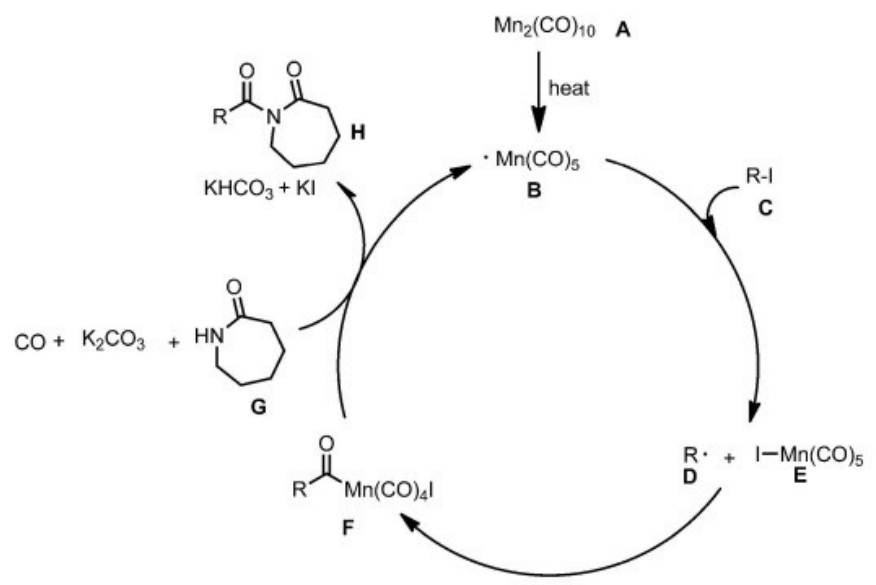

Scheme 5. Proposed reaction mechanism.

reaction with $\mathrm{E}$ to provide acyl manganese $\mathrm{RCOMn}(\mathrm{CO})_{4}-\mathrm{I}$ intermediate $\mathbf{F}^{[11]}$ Then, complex $\mathbf{F}$ reacts with amide $\mathbf{G}$ to produce final carbonylation product $\mathbf{H}$ with regeneration of complex $\mathbf{B}$ under the assistance of base and ready for the next catalytic cycle.

In conclusion, a novel and practical manganese-catalyzed carbonylation reaction of alkyl iodides with amides was developed. Various imides were prepared in moderate to good yields from readily available alkyl halides and amides. Notably, this is the first report on the carbonylative coupling of alkyl halides with amides. Mechanistically, control experiments and EPR spectroscopy studies confirmed the radical nature of this new process. This procedure is expected to complement the current methods for carbonylation reactions in organic synthesis. 


\section{Acknowledgements}

The authors thank the Chinese Scholarship Council for financial support. We also appreciate general support from Professor Matthias Beller in LIKAT. The analytical support of Dr. W. Baumann, Dr. C. Fisher, S. Buchholz, and S. Schareinaare is gratefully acknowledged.

Keywords: alkyl halides - amides - carbonylation - imides manganese

[1] a) M. K. Hargreaves, J. G. Pritchard, H. R. Dave, Chem. Rev. 1970, 70, 439-469; b) Y. Kamitori, M. Hojo, R. Masuda, T. Kimura, T. Yoshida, J. Org. Chem. 1986, 51, 1427-1431; c) A. D. Abell, M. D. Oldham, J. Org. Chem. 1997, 62, 1509-1513; d) P. Y. Reddy, S. Kondo, T. Toru, Y. Ueno, J. Org. Chem. 1997, 62, 2652-2654; e) D. Barker, D. H. S. Lin, J. E. Carland, C.P.Y. Chu, M. Chebib, M. A. Brimble, G.P. Savage, M. D. Mdeod, Bioorg. Med. Chem. 2005, 13, 4565-4575; f) F. A. Luzzio, Scence of Synthesis, Houben-Weyl Methods of Molecular Transformation, Georg Thieme Verlag, Stuttgart, 2005, pp. 229-324; g) R. M. de Figueiredo, M. Voith, R. Fröhlich, M. Christmann, Synlett 2007, 391-394; h) K. Rad-Moghadam, L. Kheyrkhah, Synth. Commun. 2009, 39, 2108-2115; i) J. Kim, S. H. Hong, Org. Lett. 2014, 16, 4404-4407.

[2] a) N. A. McGrath, M. Brichacek, J. T. Njardarson, J. Chem. Educ. 2010, 87, 1348-1349; b) E.-S. Kim, K. Y. Park, J.-M. Heo, B. J. Kim, K. D. Ahn, J.-G. Lee, Ind. Eng. Chem. Res. 2010, 49, 11250-11253; c) The Merck Index, version 12:3, Merck\&Co Inc. Whitehouse Station, NJ. USA, 1999.

[3] a) N. A. Al-Awadi, J. Chem. Soc. Perkin Trans. 2 1990, 2187-2189.

[4] Modern Carbonylation Methods, (ed. L. Kollár), Wiley-VCH, 2008.

[5] For selected recent references on carbonylation, see: a) X.-F. Wu, H. Neumann, M. Beller, Chem. Rev. 2013, 113, 1-35; b) X.F. Wu, H. Neumann, M. Beller, Chem. Soc. Rev. 2011, 40, 4986-5009; c) Q. Liu, H. Zhang, A. Lei, Angew. Chem. Int. Ed. 2011, 50, 10788-10799; Angew. Chem. 2011, 123, 10978-10989; d) X.-F. Wu, H. Neumann, M. Beller, ChemSusChem 2013, 6, 229-241; e) X.-F. Wu, H. Neumann, ChemCatChem 2012, 4, 447-458; f) C. F.J. Barnard, Organometallics 2008, 27 , $5402-5422$; g) B. Gabriele, R. Mancuso, G. Salerno, Eur. J. Org. Chem. 2012, 6825-6839; h) T. Morimoto, K. Kakiuchi, Angew. Chem. Int. Ed. 2004, 43, 5580-5588; Angew. Chem. 2004, 116, 5698-5706; i) L. R. Odell, F. Russo, M. Larhed, Syniett 2012, 685-698; j) H. Konishi, K.
Manabe, Synlett 2014, 1971-1986; k) P. Gautam, B. M. Bhanage, Catal. Sci. Technol. 2015, 5, 4663-4702; I) S. D. Friis, A. T. Lindhardt, T. Skrydstrup, Acc. Chem. Res. 2016, 49, 594-605; m) X.-F. Wu, RSC Adv. 2016, 6, $83831-83837$; n) J.-B. Peng, X. Qi, X.-F. Wu, ChemSusChem 2016, 9, 2279-2283.

[6] For leading reviews on radical carbonylation, see: a) C. H. Schiesser, U. Wille, H. Matsubara, I. Ryu, Acc. Chem. Res. 2007, 40, 303-313; b) S Sumino, A. Fusano, T. Fukuyama, I. Ryu, Acc. Chem. Res. 2014, 47, $1563-$ 1574 ; c) I. Ryu, N. Sonoda, Angew. Chem. Int. Ed. Engl. 1996, 35, $1050-$ 1066; Angew. Chem. 1996, 108, 1140-1157; d) I. Ryu, Chem. Rec. 2002, 2, 249-258; e) I. Ryu, A. Tani, T. Fukuyama, D. Ravelli, M. Fagnoni, A. Albini, Angew. Chem. Int. Ed. 2011, 50, 1869-1872; Angew. Chem. 2011, 123, 1909-1912; f) M. Okada, T. Fukuyama, K. Yamada, I. Ryu, D. Ravelli, M. Fagnoni, Chem. Sci. 2014, 5, 2893-2898.

[7] a) A. Schnyder, A. F. Indolese, J. Org. Chem. 2002, 67, 594-597; b) H. Li, K. Dong, H. Neumann, M. Beller, Angew. Chem. Int. Ed. 2015, 54, 10239 10243; Angew. Chem. 2015, 127, 10377-10381; c) Y. Li, K. Dong, F. Zhu Z. Wang, X.-F. Wu, Angew. Chem. Int. Ed. 2016, 55, 7227-7230; Angew. Chem. 2016, 128, 7343-7346.

[8] a) J. M. Concellón, H. Rodríguez-Solla, V. del Amo, Chem. Eur. J. 2008, 14, 10184-10191; b) A. J. Wu, J. E. Penner-Hahn, V. L. Pecoraro, Chem. Rev. 2004, 104, 903-938; c) B. B. Snider, Chem. Rev. 1996, 96, 339-364; d) E. M. McGarrigle, D. G. Gilheany, Chem. Rev. 2005, 105, 1563-1602 e) C. Wang, Synlett 2013, 1606-1613; f) X. Qi, L. Jiang, X.-F. Wu, Tetrahedron Lett. 2016, 57, 1706-1710; g) S. Elangovan, C. Topf, S. Fischer, H. Jiao, A. Spannenberg, W. Baumann, R. Ludwig, K. Junge, M. Beller, J. Am. Chem. Soc. 2016, 138, 8809-8814; h) S. Elangovan, J. Neumann, J.B. Sortais, K. Junge, C. Darcel, M. Beller, Nat. Commun. 2016, 7, 12641.

[9] a) C. M. McMahon, M. S. Renn, E. J. Alexanian, Org. Lett. 2016, 18, 4148 4150 ; b) T. Kondo, Y. Tsuji, Y. Watanabe, Tetrahedron Lett. 1988, 29, 3833-3836; c) T. Kondo, Y. Sone, Y. Tsuji, Y. Watanabe, J. Organomet. Chem. 1994, 473, 163-173.

[10] a) A. Hudson, M. F. Lappert, B. K. Nicholson, J. Chem. Soc. Dalton Trans. 1977, 551-554; b) T. J. Meyer, J. V. Caspar, Chem. Rev. 1985, 85, $187-$ 218.

[11] T. Fukuyama, S. Nishitani, T. Inouye, K. Morimoto, I. Ryu, Org. Lett. 2006 8, 1383-1386.

Manuscript received: December 29, 2016

Revised: January 11, 2017

Accepted Article published: January 12, 2017

Final Article published: February 23, 2017 
3.6 A copper-catalyzed carbonylative four-component reaction of ethane and aliphatic olefins

Yahui Li, Fengxiang Zhu, Zechao Wang, and Xiao-Feng Wu*

Chem. Commun., 2018, 54, 1984--1987

Author contributions:

Dr. Xiao-Feng Wu and Yahui conceived and developed this project. Dr. Xiao-Feng Wu and Yahui Li wrote the manuscript with revisions provided by Fengxiang Zhu, Zechao Wang. My contribution as co-author of this paper is approximately $85 \%$. 


\section{ChemComm}

\section{D) Check for updates}

Cite this: Chem. Commun., 2018, 54,1984

Received 22nd December 2017,

Accepted 29th January 2018

\section{A copper-catalyzed carbonylative four-component reaction of ethene and aliphatic olefins $\dagger$}

\author{
Yahui Li, Fengxiang Zhu, Zechao Wang and Xiao-Feng Wu (D)*
}

DOI: $10.1039 / \mathrm{c} 7 \mathrm{cc} 09803 \mathrm{k}$

rsc.li/chemcomm

To have a balance between reactivity and selectivity has been a long-standing challenge in multicomponent reactions. In this communication, a carbonylative four-component reaction has been developed. With copper as the catalyst, using ethene including other aliphatic alkenes, alcohols and acetonitrile as the substrates under CO pressure, various desired products were produced in moderate to good yields. The obtained products can be applied in the synthesis of $\delta$-valerolactams. Good functional group tolerance and reaction efficiency can be observed here.

In modern organic synthesis, chemists are working on developing new synthetic procedures which have advantages such as easy manipulation, good efficiency, good functional group tolerance, etc. Among the various possibilities, multicomponent reactions are definitely one good choice. Starting from readily available substrates, through domino transformation sequences, the target products can be prepared effectively. ${ }^{1}$ But challenges still exist in multicomponent reactions, the main one is to find the balance between the reactivity and selectivity in each system. A high reactivity but low selectivity gives a low yield of the target molecule, and a high selectivity but low reactivity means low conversion of the substrates, which will lead to a methodology not applicable in both cases.

On the other hand, transition metal-catalyzed carbonylative coupling reactions are already a real toolbox in organic chemistry. ${ }^{2}$ By the introduction of carbon monoxide as one of the cheapest $\mathrm{C} 1$ sources, value-added chemicals can be easily produced. And some of the processes are even proceeding at industrial scales. However, it is worthy to point out that most of the known procedures are three-component reactions (one electrophile, CO, and one nucleophile). Examples on carbonylative four or even more component reactions are still limited $(\geq 2$ electrophiles and/or nucleophiles). ${ }^{3}$ One explanation is the high reactivity of the in situ generated acyl-metal intermediate.

Leibniz-Institut für Katalyse e. $V$, an der Universität Rostock, Albert-Einstein-Strasse 29a, 18059 Rostock, Germany. E-mail: Xiao-Feng.Wu@catalysis.de

$\dagger$ Electronic supplementary information (ESI) available. See DOI: $10.1039 / \mathrm{c} 7 \mathrm{cc} 09803 \mathrm{k}$
Hence more efforts are needed to further explore this area. Recently, we established some palladium-catalyzed carbonylative multicomponent reaction systems. ${ }^{4}$ With aryl halides as the substrates, quinazolinones and thiochromenones can be produced in an efficient manner. During the process of this project, an idea on the merging of $\mathrm{C}-\mathrm{H}$ bond activation, carbonylation and multicomponent reactions came to our mind. ${ }^{5}$ Such a reaction system can have the advantages from all partners and should be attractive for the synthetic community.

In order to realize this idea, we decided to choose ethene, 3-phenyl-1-propanol and acetonitrile as the model substrates to establish this transformation. Ethene is one of the most important industrial olefin feedstocks (over 150 million tonne production in 2016), and its utilization related with carbonylation mainly focused on polyketone or methyl propanoate production. ${ }^{6}$ And the development of a procedure for transforming ethene into other high-value synthetic intermediates should be interesting. Additionally, acetonitrile is a commonly applied organic solvent, and the $\mathrm{Csp}^{3}-\mathrm{H}$ bond of its methyl group can potentially be activated and then used as a reagent in organic reactions, which will introduce a nitrile group into the parent molecules meanwhile. ${ }^{7}$ And concerning the catalyst, we prefer to take non-expensive and less toxic copper salts. Although copper catalysts have been well explored in oxidation reactions and coupling chemistry, their ability in carbonylation chemistry is still rarely developed. ${ }^{8}$

After extensive and systematic studies, $68 \%$ of the desired 3-phenylpropyl 4-cyanobutanoate can be isolated from the model system with $5 \mathrm{~mol} \%$ of $\mathrm{CuBr}\left(\mathrm{Me}_{2} \mathrm{~S}\right)$ and $10 \mathrm{~mol} \%$ of $4,4^{\prime}, 4^{\prime \prime}$-tritert-butyl-2,2 $2^{\prime}: 6^{\prime}, 2^{\prime \prime}$-terpyridine as the catalytic system together with $\operatorname{BuPAd}_{2}(5 \mathrm{~mol} \%)$ and tert-butyl peroxide (4 equiv.) under CO pressure (Table 1, entry 1). $\$$ Upon variation of the reaction conditions, different yields of the desired product can be obtained (Table 1). Only traces of the desired product could be detected in the absence of the copper catalyst and ligand (Table 1, entry 2). In testing with some other nitrogen ligands, such as $2,2^{\prime}: 6^{\prime}, 2^{\prime \prime}$-terpyridine and 1,10-phenanthroline, the yields of the desired product decreased (Table 1, entries 3 and 4). 
Table 1 Optimization studies of this reaction ${ }^{2}$

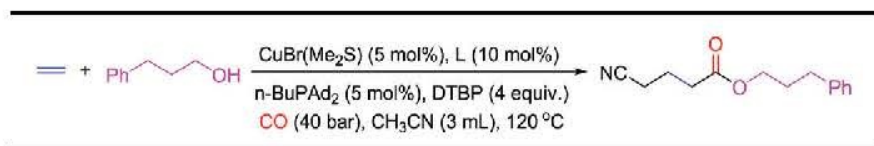

\begin{tabular}{lll}
\hline Entry & Variations from the standard conditions & Yield $(\%)^{b}$ \\
\hline 1 & - & $72\left(68^{\circ}\right)$ \\
2 & Without catalyst and ligand & Trace \\
3 & $2,2^{\prime}: 6^{\prime}, 2^{\prime \prime}$-Terpyridine instead of L & 54 \\
4 & $1,10-\mathrm{Phen}$. instead of L & 31 \\
5 & Without BuPAd & 52 \\
6 & 10 mol\% BuPAd & 60 \\
7 & TBAI instead of BuPAd $_{2}$ & 43 \\
8 & $\left(n-\mathrm{C}_{4} \mathrm{H}_{9}\right)_{4}$ PBr instead of BuPAd & 55 \\
9 & $110^{\circ}{\mathrm{C} \text { instead of } 120^{\circ} \mathrm{C}}$ & 51
\end{tabular}

${ }^{a}$ Ethene (20 bar), 3-phenyl-1-propanol ( $\left.0.5 \mathrm{mmol}\right), \mathrm{CuBr}\left(\mathrm{Me}_{2} \mathrm{~S}\right)(5 \mathrm{~mol} \%)$, $4,4^{\prime}, 4^{\prime \prime}$-tri-tert-butyl-2, $2^{\prime}: 6^{\prime}, 2^{\prime \prime}$-terpyridine ( $\left.10 \mathrm{~mol} \%\right)$, DTBP ( $\left.2 \mathrm{mmol}\right)$, CO (40 bar), acetonitrile ( $3 \mathrm{~mL}$ ), $12 \mathrm{~h} .{ }^{b} \mathrm{GC}$ yields with hexadecane as the internal standard. ${ }^{\circ}$ Isolated yield. 1,10-Phen: 1,10-phenanthroline. TBAI: tetrabutylammonium iodide. $\left(n-\mathrm{C}_{4} \mathrm{H}_{9}\right)_{4} \mathrm{PBr}$ : tetrabutyphosphonium bromide. BuPAd $_{2}$ : di(1-adamanty)-n-butylphosphine (cataCXium $\left.{ }^{\mathbb{B}} \mathrm{A}\right)$.

Furthermore, upon variation of the additives, reaction temperature, gas pressure and reagent loadings, no better yields could be obtained (Table 1, entries 5-9).

Subsequently, several alcohols were tested in this carbonylative multicomponent reaction of ethene under the optimized conditions. Different aliphatic alcohols were tested at the first stage; moderate to good yields of the desired products can be produced in all the cases (Table 2, entries 1-3). In addition to ethanol, cyclopropylmethanol and allyl alcohol can be applied as well. Then some benzyl alcohols were checked, which are more intended to be oxidized under oxidative conditions. To our delight, good yields of the desired products can also be obtained in all the cases (Table 2, entries 4-8). Notably, the bromide functional group in the product is ready for further transformations via crosscoupling reactions. ${ }^{8}$ Here, it is important to mention that the non-carbonylated product (ethers) can always be detected from the reaction mixture, and also the alcohol oxidized by-products.

Remarkably, the products we obtained are ready to be transformed into important $\delta$-valerolactams which show outstanding biological activities and also act as precursors for polyamides in synthetic chemistry. ${ }^{9}$ As shown in Scheme 1, $80 \%$ of $\delta$-valerolactam can be produced from our product.

In order to further illustrate the scope of this method, different alkenes and a variety of substituted aliphatic alcohols were tested under our standard conditions successively (Table 3). The corresponding carbonylative products were produced in synthetically useful yields with excellent regioselectivity. For example, when hexene was used as the substrate, methanol, 1-hexanol and 1-octanol can all give good yields of the desired products $(60-66 \%$, Table $3,3 \mathrm{t}-3 \mathbf{v})$. Interestingly, cyclopropylmethanol can also be used and gave the desired product in $62 \%$ yield (Table $3,3 \mathrm{z}$ ). $70 \%$ yield of the desired product can also be produced by using benzyl alcohol as the nucleophile and other benzyl alcohol derivatives can be applied as well (Table 3, 3i-3s). Additionally, thiophene and phenylthiol substituted alcohols can also give the desired products in moderate yields (Table 3, 3y and 3ab). Moreover, allylic alcohol can be applied
Table 2 Carbonylative multicomponent reaction of ethene ${ }^{2}$

Entry

${ }^{a}$ Ethene (20 bar), alcohol ( $\left.0.5 \mathrm{mmol}\right), \mathrm{CuBr}\left(\mathrm{Me}_{2} \mathrm{~S}\right)(5 \mathrm{~mol} \%)$, L (10 mol\%), BuPAd $_{2}(5 \mathrm{~mol} \%), 2 \mathrm{mmol}$ DTBP, 40 bar CO, acetonitrile $(3 \mathrm{~mL}), 12 \mathrm{~h}$, isolated yields.

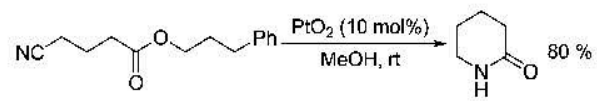

Scheme 1 Synthesis of $\delta$-valerolactam.

as well and gave $55 \%$ yield of the desired product (Table 3, 3aa). Then, different alkenes were tested. Simple short- and longchain aliphatic olefins, such as 1-octene and 1-dodecene, all can give the corresponding products in moderate to good yields. 3,3-Dimethylbut-1-ene can be applied as the substrate with acetonitrile successfully as well. Alkenes bearing benzylic and phenoxy groups were shown to be compatible. Furthermore, allylbenzene can also give the desired products in good yields. However, in the cases of 2-allylisoindoline-1,3-dione, 1-(vinyloxy)butane and styrene, no desired product could be detected.

After proving the compatibility of alkene and alcohols of this methodology, we become interested in some other types of nucleophiles. Compared with alcohols, using amides and sulphonamide as coupling partners in carbonylative coupling reactions is more difficult due to their low nucleophilicity and remains a challenge. To our delight, amides and benzenesulfonamide can also be used in the catalytic protocol, and provide the corresponding products (Table 4). 
Table 3 Carbonylative multicomponent reaction of alkenes ${ }^{2}$

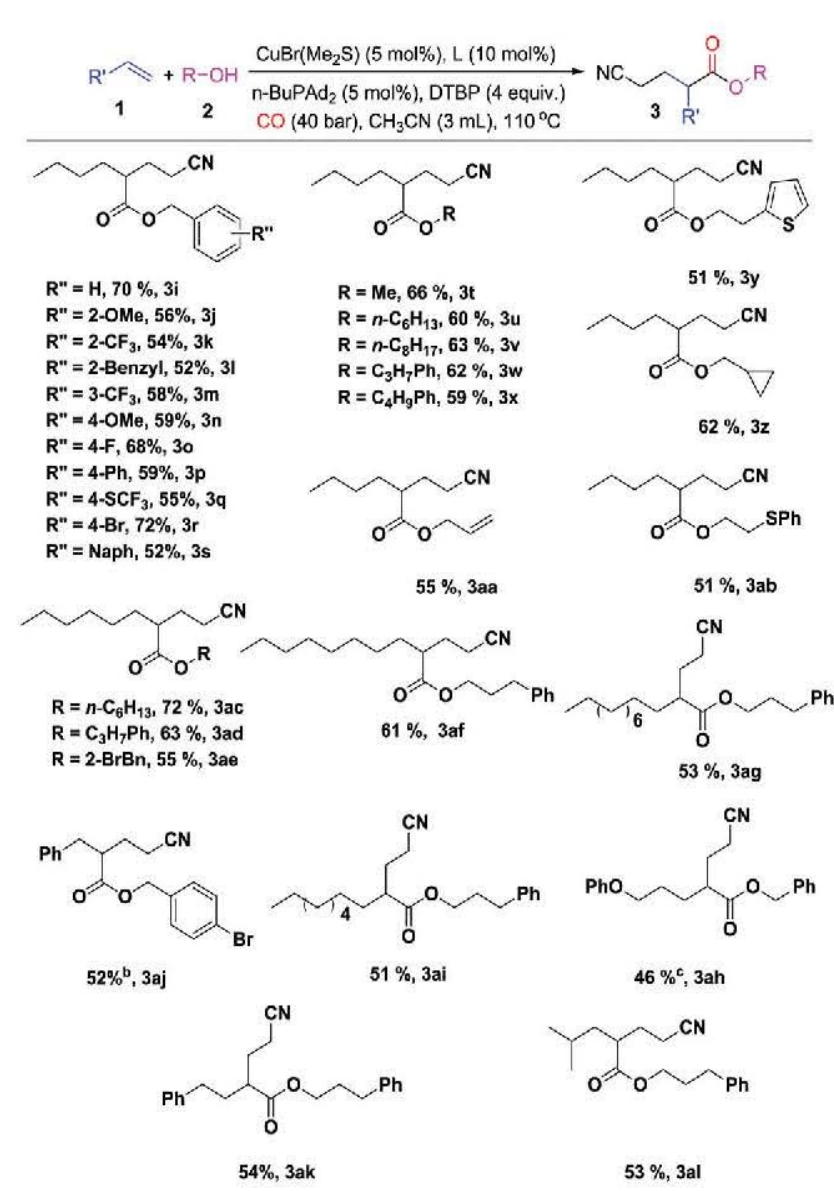

${ }^{a}$ Alkene (2 mmol), alcohol (0.5 mmol), CuBr(Me $\left.2 \mathrm{~S}\right)(5 \mathrm{~mol} \%)$, L (10 mol\%), $\operatorname{BuPAd}_{2}(5 \mathrm{~mol} \%), 2 \mathrm{mmol}$ DTBP, 40 bar CO, acetonitrile $(3 \mathrm{~mL}), 12 \mathrm{~h}$, isolated yields. ${ }^{b} 60$ bar $\mathrm{CO}, 24 \mathrm{~h} .{ }^{c} \mathrm{CuBr}\left(\mathrm{Me}_{2} \mathrm{~S}\right)(20 \mathrm{~mol} \%), \mathrm{L}(40 \mathrm{~mol} \%)$, $\operatorname{BuPAd}_{2}(10 \mathrm{~mol} \%), 60$ bar CO, $24 \mathrm{~h}$.

A control experiment was performed to gain some insight into the reaction mechanism (Scheme 2). With the addition of TEMPO ( 2 equiv.) into our model system, no desired product can be observed and TEMPO trapped acetonitrile radical (TEMPOCH ${ }_{2} \mathrm{CN}$ ) can be detected using GC-MS. Finally, in order to illustrate the synthetic potential of this method, we performed a second carbonylative transformation with estrone and the desired estrone derivative was formed in $52 \%$ yield upon isolation (Scheme 3).

Table 4 Carbonylative multicomponent reaction with different nucleophiles ${ }^{2}$

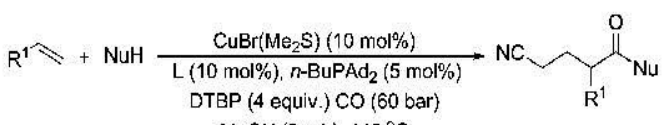

$$
\begin{aligned}
& \operatorname{MeCN}(3 \mathrm{~mL}), 110^{\circ} \mathrm{C}
\end{aligned}
$$

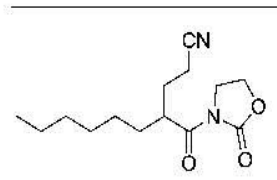

3am, $63 \%$

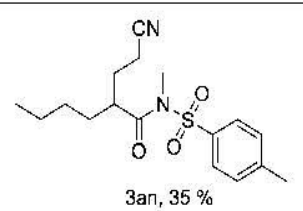

3an, $35 \%$

${ }^{a}$ Alkene ( $2 \mathrm{mmol}$ ), $\mathrm{NuH}(0.5 \mathrm{mmol}), \mathrm{CuBr}\left(\mathrm{Me}_{2} \mathrm{~S}\right)(10 \mathrm{~mol} \%), \mathrm{L}(10 \mathrm{~mol} \%)$, $\operatorname{BuPAd}_{2}(5 \mathrm{~mol} \%), 2 \mathrm{mmol}$ DTBP, 60 bar $\mathrm{CO}$, acetonitrile $(3 \mathrm{~mL}), 24 \mathrm{~h}$, isolated yields.

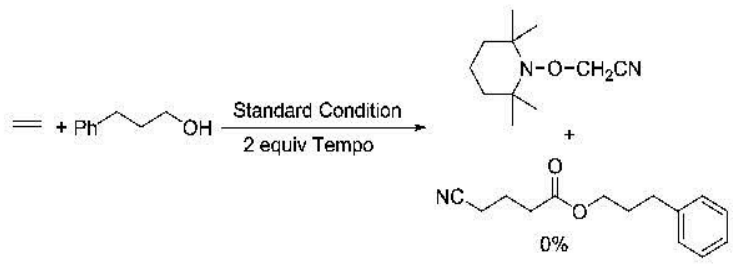

Scheme 2 Control experiment.

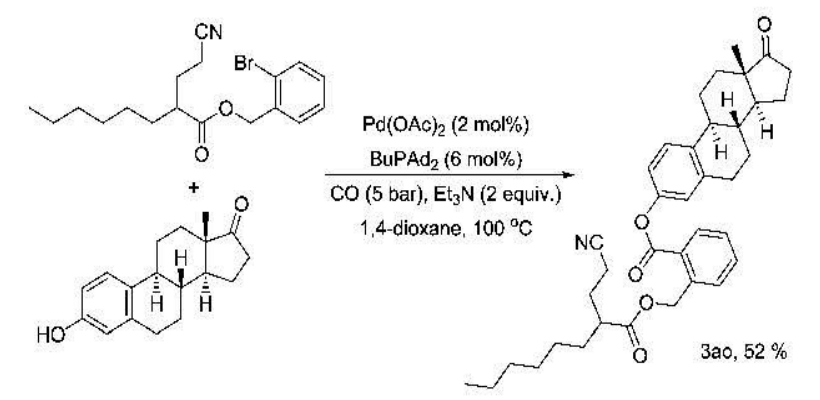

Scheme 3 Further transformation of products.

Based on our results and the literature, ${ }^{7,10}$ a possible reaction mechanism is proposed (Scheme 4). Initially, acetonitrile will be activated under the co-effect from the copper catalyst and DTBP, and the corresponding $\cdot \mathrm{CH}_{2} \mathrm{CN}$ radical $\mathrm{B}$ will be generated, which was proven by our TEMPO experiment. Then the radical $\mathbf{B}$ will undergo the addition reaction with alkenes to give the intermediate radical $\mathrm{C}$. Meanwhile, the copper pre-catalyst will be activated by ${ }^{t} \mathrm{BuOO}{ }^{t} \mathrm{Bu}$ to give the intermediate $\mathrm{F}^{10}$ The key intermediate complex $\mathbf{G}$ will be formed after the reaction between complex $\mathbf{F}$ and radical C. Subsequent coordination and insertion of $\mathrm{CO}$ forms the acylcopper intermediate $\mathrm{H}$ or $\mathrm{H}^{\prime}$, which then affords the final carbonylation product after reductive elimination, with the generation of active CuI species for the next catalytic cycle.

In conclusion, an interesting carbonylative multicomponent reaction of bulk industrial olefins with different nucleophiles has been developed. With copper salts as the catalyst, an excellent balance between the reactivity and selectivity can be

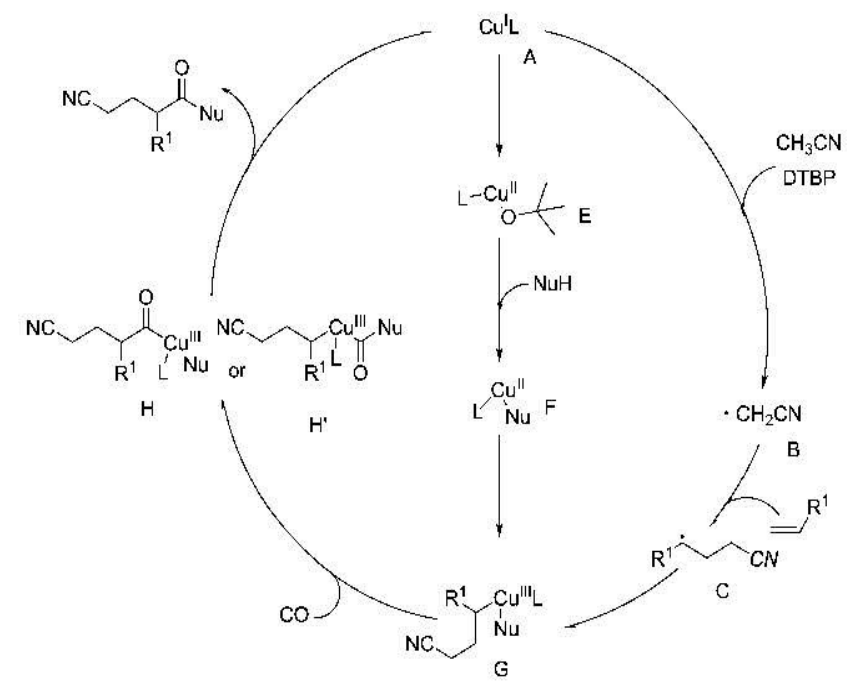

Scheme 4 Proposed reaction mechanism. 
achieved. The reaction proceeds with high selectivity and gave the desired products in moderate to good yields. The use of our products as the precursor for estrone ester and $\delta$-valerolactam synthesis has been performed as well.

The authors thank the Chinese Scholarship Council for financial support. The analytical support of Dr W. Baumann, Dr C. Fisher, S. Buchholz, and S. Schareina is gratefully acknowledged. We also appreciate the general support from Professors Matthias Beller and Armin Börner in LIKAT.

\section{Conflicts of interest}

There are no conflicts to declare.

\section{References}

\$ General procedure: A $4 \mathrm{~mL}$ screw-cap vial was charged with $\mathrm{CuBr}\left(\mathrm{Me}_{2} \mathrm{~S}\right)$

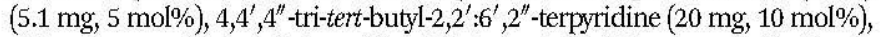
di(1-adamantyl)-n-butylphosphine ( $8.96 \mathrm{mg}, 5 \mathrm{~mol} \%)$, acetonitrile $(3 \mathrm{~mL})$ and an oven-dried stirring bar. The vial was closed by a Teflon septum equipped with a phenolic cap and connected with the atmosphere with a needle. After 3-phenyl-1-propanol $(0.5 \mathrm{mmol})$ and DTBP $(2 \mathrm{mmol})$ were injected using a syringe, the vial was fixed in an alloy plate and put into a Parr 4560 series autoclave $(300 \mathrm{~mL})$ under an argon atmosphere. At room temperature, the autoclave was charged with 20 bar of ethene and 40 bar of carbon monoxide. The autoclave was placed on a heating plate equipped with a magnetic stirrer and an aluminum block. The reaction was heated at $120^{\circ} \mathrm{C}$ for 12 hours. Afterwards, the autoclave is cooled to room temperature and the pressure was carefully released. After the removal of the solvent under reduced pressure, the pure product was obtained using column chromatography on silica gel (eluent: pentane/ethyl acetate $=50-10: 1$ ).

1 For selected reviews, see: (a) Multicomponent Reactions, ed. J. Zhu and H. Bienayme, Wiley-VCH, Weinheim, 2005; (b) L. F. Tietze, G. Brasche and K. Gericke, Domino Reactions in Organic Synthesis, Wiley-VCH, Weinheim, 2006; (c) L. F. Tietze, Chem. Rev., 1996, 96, 115-136; (d) E. Ruijter, R. Scheffelaar and R. V. A. Orru, Angew. Chem, Int. Ed., 2011, 50, 6234-6246; (e) A. Dcmling and I. Ugi, Angew. Chem. Int. Ed., 2000, 39, 3168-3210; $(f)$ D. M. D'Souza and T. J. J. Müller, Chem. Soc. Rev., 2007, 36, 1095-1108; $(g)$ B. Willy and T. J. J. Müller, Curr. Org. Chem, 2009, 13, 1777-1790; (h) J. Zhu, Q. Wang and M.-X. Wang, Multicomponent Reactions in Organic Synthesis, Wiely-VCH, Weinheim, 2014; (i) L. F. Tietze and A. Modi, Med. Res. Rev., 2000, 20, 304-322.

2 For selected reviews on carbonylation, see: (a) L. Kollär, Modern Carbonylation Methods, Wiley-VCH, Weinheim, 2008; (b) C. F. J. Barnard, Organometallics, 2008, 27, 5402-5422; (c) A. Brennfhrer, H. Neumann and M. Beller, Angew. Chem, Int. Ed., 2009, 48, 4114-4133 (Angew. Chem, 2009, 121, 4176-4196); (d) B. Gabriele, R. Mancuso and G. Salerno, Eur. J. Org. Chem, 2012, 6825-6839; (e) L. R. Odell, F. Russo and M. Larhed, Synlett, 2012, 685-698; (f) B. Sam, B. Breit and M. J. Krische, Angew. Chem., Int. Ed., 2015, 54, 3267-3274; (g) R. Grigg and S. P. Mutton, Tetrahedron, 2010, 66, 5515-5548; $(h)$ S. D. Friis, A. T. Lindhardt and T. Skrydstrup, Acc. Chem. Res., 2016, 49, 594-605; (i) S. Sumino, A. Fusano, T. Fukuyama and I. Ryu, Acc. Chem. Res., 2014, 47, 1563-1574.

3 C. Shen and X.-F. Wu, Chem. - Eur. J., 2017, 23, 2973-2987 and references cited therein.

4 (a) L. He, H. Li, H. Neumann, M. Beller and X.-F. Wu, Angew. Chem., Int. Ed., 2014, 53, 1420-1424; (b) K. Natte, H. Neumann and X.-F. Wu, Catal. Sci. Technol., 2015, 5, 4474-4480; (c) C. Shen, A. Spannenberg and X.-F. Wu, Angew. Chem., Int. Ed̂., 2016, 55, $5067-5070$; (d) C. Shen, A. Spannenberg, M. Auer and X.-F. Wu, Adv. Synth. Catal., 2017, 359, 941-946.

5 Selected examples on carbonylative $\mathrm{C}-\mathrm{H}$ activations, see: (a) X. Li, X. Li and N. Jiao, J. Am. Chem. Soc., 2015, 137, 9246-9249; (b) Z.H. Guan, M. Chen and Z.-H. Ren, J. Am. Chem. Soc., 2012, 134, 17490-17493; (c) W. Li, C. Liu, H. Zhang, K. Ye, G. Zhang, W. Zhang, Z. Duan, S. You and A. Lei, Angew. Chem., Int. Ed., 2014, 53, 2443-2446; (d) X. Wu, Y. Zhao and H. Ge, J. Am Chem Soc., 2015, 137, 4924-4927; (e) K Orito, A. Horibata, T. Nakamura, H. Ushito, H. Nagasaki, M. Yuguchi, S. Yamashita and M. Tokuda, J. Am Chem Soc, 2004, 126, 14342-14343; $(f)$ B. Haffemayer, M. Gulias and M. J. Gaunt, Chem. Sci, 2011, 2, 312-315; (g) P. Xie, Y. Xie, B. Qian, H. Zhou, C. Xia and H. Huang, J. Am Chem. Soc., 2012, 134, 9902-9905; (h) H. Liu, G. Laurenczy, N. Yan and P. J. Dyson, Chem Commun, 2014, 50, 341-343; (i) I. Ryu, A. Tani, T. Fukuyama, D. Ravelli, M. Fagnoni and A. Albini, Angew. Chem., Int. Ed, 2011, 50, 1869-1872; (j) M. Okada, T. Fukuyama, K. Yamada, I. Ryu, D. Ravelli and M. Fagnoni, Chem Sci., 2014, 5, 2893-2898.

6 "The Ethylene Technology Report 2016 - Research and Markets". www.researchandmarkets.com. Retrieved 19 June 2016.

7 (a) C. Chatalova-Sazepin, Q. Wang, G. M. Sammis and J. Zhu, Angew. Chem., Int. Ed., 2015, 54, 5443-5446; (b) A. Bunescu, Q. Wang and J. Zhu, Chem. - Eur. J., 2014, 20, 14633-14636; (c) T. M. Ha, C. Chatalova-Sazepin, Q. Wang and J. Zhu, Angew. Chem. Int. Ed., 2016, 55, 9249-9252; (d) X.-Q. Chu, X.-P. Xu, H. Meng and S.-J. Ji, RSC Adv., 2015, 5, 67829-67832; (e) H. Su, L. Wang, H. Rao and H. Xu, Org. Lett., 2017, 19, 2226-2229; (f) Z. Li, Y. Xiao and Z.-Q. Liu, Chem. Commun., 2015, 51, 9969-9971; (g) X.-Q. Chu, Z.-H. Xing, H. Meng, X.-P. Xu and S.-J. Ji, Org. Chem. Front., 2016, 3, 165-169; (h) X. Wu, J. Riedel and V. M. Dong, Angew. Chem., Int. Ed., 2017, 56, 11589-11593; (i) A. Bunescu, T. M. Ha, Q. Wang and J. Zhu, Angew. Chem., Int. Ed., 2017, 56, 10555-10558.

8 (a) S. E. Allen, R R. Walvoord, R. Padilla-Salinas and M. C. Kozlowski, Chem. Rev., 2013, 113, 6234-6458; (b) S. V. Ley and A. W. Thomas, Angew. Chem. Int. Ed., 2003, 42, 5400-5449; (c) G. Evano, N. Blanchard and M. Toumi, Chem. Rev., 2008, 108, 3054-3131; (d) Copper-Mediated Cross-Coupling Reactions, ed. G. Evano and N. Blanchard, Wiley-VCH, Weinheim, 2013.

9 L. Lebreton, E. Jost, B. Carboni, J. Annat, M. Vaultier, P. Dutartre and P. Renaut, J. Med. Chem., 1999, 42, 4749-4763.

10 (a) T. K. Salvador, C. H. Arnett, S. Kundu, N. G. Sapiezynski, J. A. Bertke, M. R. Boroujeni and T. H. Warren, J. Am. Chem Soc., 2016, 138, 16580-16583; (b) L.-J. Cheng and N. P. Mankad, J. Am. Chem. Soc., 2017, 139, 10200-10203. 


\section{References}

[1] a) M. Beller, Catalytic Carbonylation Reactions; Springer: Berlin, 2006; b) L. Kollär, Modern Carbonylation Methods; Wiley-VCH: Weinheim, 2008; c) B. Gabriele, R. Mancuso, G. Salerno, Eur. J. Org. Chem. 2012, 6825-6839; d) X.-F. Wu, H. Neumann, M. Beller, Chem. Soc. Rev., 2011, 40, 4986-5009; e) X.-F. Wu, H. Neumann, M. Beller, Chem. Rev., 2012, 113, 1-35; f) X.-F. Wu, X. Fang, L. Wu, R. Jackstell, H. Neumann, M. Beller, Acc. Chem. Res., 2014, 47, 1041-1053; g) B. Sam, B. Breit, M. J. Krische, Angew. Chem., Int. Ed., 2015, 54, 3267-3274; h) R. Franke, D. Selent, A. Börner, Chem. Rev., 2012, 112, 5675-5732; i) C. F. J. Barnard, Organometallics 2008, 27, 5402-5422; j) Q. Liu, H. Zhang, A. Lei, Angew. Chem. Int. Ed. 2011, 50, 10788-10799; k) T. Morimoto, K. Kakiuchi, Angew. Chem. Int. Ed. 2004, 43, 5580-5588; I) L. R. Odell, F. Russo, M. Larhed, Synlett 2012, 685-698; m) H. Konishi, K. Manabe, Synlett 2014, 1971-1986; n) P. Gautam, B. M. Bhanage, Catal. Sci. Technol. 2015, 5, 4663-4702; o) S. D. Friis, A. T. Lindhardt, T. Skrydstrup, Acc. Chem. Res. 2016, 49, 594-605; p) X.-F. Wu, RSC Adv. 2016, 6, 83831-83837; q) J.-B. Peng, X. Qi, X.-F. Wu, ChemSusChem 2016, 9, 2279-2283; r) J.-B. Peng, X. Qi, X.-F. Wu, Synlett 2017, 28, 175-194.

[2] For selected reviews on industrial applications, see: a) C. Torborg, M. Beller, Adv. Synth. Catal., 2009, 351, 3027-3043; b) C. A. Busacca, D. R. Fandrick, J. J. Song, C. H. Senanayaka, Adv. Synth. Catal., 2011, 353, 1815-1864.

[3] a) C. H. Schiesser, U. Wille, H. Matsubara, I. Ryu, Acc. Chem. Res., 2007, 40, 303-313; b) S. Sumino, A. Fusano, T. Fukuyama, I. Ryu, Acc. Chem. Res., 2014, 47, 1563-1574; c) I. Ryu, N. Sonoda, Angew. Chem. Int. Ed. Engl., 1996, 35, 1050-1066; d) I. Ryu, Chem. Rec., 2002, 2 , 249-258.

[4] a) R. Skoda-Földes, L. Kollár, Curr. Org. Chem., 2002, 6, 1097-1119; b) B. Gabriele, G. Salerno, M. Costa, G. P. Chiusoli, Curr. Org. Chem., 2004, 8, 919-946.

[5] X.-F. Wu, H. Neumann, ChemCatChem 2012, 4, 447-458.

[6] For selected examples on iridium-catalysed carbonylation reactions, see: a) A. Haynes, P. M. Maitlis, G. E. Morris, G. J. Sunley, H. Adams, P. W. Badger, C. M. Bowers, D. B. Cook, P. I. P. Elliott, T. Ghaffar, H. Green, T. R. Griffin, M. Payne, J. M. Pearson, M. J. Taylor, P. W. Vickers, R. J. Watt, J. Am. Chem. Soc., 2004, 126, 2847-2861; b) V. J. Garza, M. J. Krische, J. Am. Chem. Soc., 2016, 138, 3655-3658; c) F. Zhu, Y. Li, Z. Wang, X.-F. Wu, Angew. Chem., Int. Ed., 2016, 55, 14151-14154; d) F. Zhu, Z. Wang, Y. Li, X.-F. Wu, Chem. Eur. J., 2017, 23, 3276-3279.

[7] For selected reviews on non-noble metal catalysed reactions see: a) C.-L. Sun, B.-J. Li, Z.-J. Shi, Chem. Rev., 2011, 111, 1293-1314; b) Fürstner, A. Angew. Chem. Int. Ed., 2009, 48, 1364-1370; c) A. Correa, O. Garcia Mancheno, C. Bolm, Chem. Soc. Rev., 2008, 37, 1108-1117; d) S. E. Allen, R. R. Walvoord, R. Padilla-Salinas, M. C. Kozlowski, Chem. Rev., 2013, 113, 6234-6458; e) A. E. Wendlandt, A. M. Suess, S. S. Stahl, Angew. Chem. Int. Ed., 2011, 50, 11062-11087; f) X.-X. Guo, D.-W. Gu, Z. Wu, W. Zhang, Chem. Rev., 2015, 115, 1622-1651.

[8] a) W. Liu, L. Ackermann, ACS Catal., 2016, 6, 3743-3752; b) C. Wang, Synlett 2013, 24, 1606-1613; c) F. Calderazzo, Inorg. Chem., 1965, 4, 293-296.

[9] a) T. Kondo, Y. Tsuji, Y. Watanabe, Tetrahedron Lett. 1988, 29, 3833-3836; b) T. Kondo, Y. Sone, Y. Tsuji, Y. Watanabe, J. Organomet. Chem. 1994, 473, 163-173. 
[10] S.-K. Kang, W.-Y. Kim, Y.-T. Lee, S.-K. Ahn, J.-C. Kim, Tetrahedron Lett. 1998, 39, 2131-2132.

[11] C. M. McMahon, M. S. Renn, E. J. Alexanian, Org. Lett., 2016, 18, 4148-4150.

[12] a) A. Devasagayaraj, M. Periasamy, Transition Met. Chem., 1991, 16, 503-504; b) J. J. Brunet, R. Chauvin, D. Neibecker, Syn. Commun., 1997, 27, 1433-1437.

[13] J. P. Collman, Acc. Chem. Res., 1975, 8, 342-347.

[14] J. P. Collman, S. R. Winter, R. G. Komoto, J. Am. Chem. Soc., 1973, 95, 249-250.

[15] J. P. Collman, S. R. Winter, D. R. Clark, J. Am. Chem. Soc., 1972, 94, 1788-1789.

[16] J. P. Collman, N. W. Hoffman, J. Am. Chem. Soc., 1973, 95, 2689-2691.

[17] M. P. Cooke, J. Am. Chem. Soc., 1970, 92, 6080-6082.

[18] H. Alper, K. E. Hashem, J. Am. Chem. Soc., 1981, 103, 6514-6515.

[19] B. E. Eaton, B. Rollman, J. A. Kaduk, J. Am. Chem. Soc., 1992, 114, 6245-6246.

[20] a) M. S. Sigman, C. E. Kerr, B. E. Eaton, J. Am. Chem. Soc., 1993, 115, 7545-7546; b) M. S. Sigman, B. E. Eaton, J. Org. Chem., 1994, 59, 7488-7491.

[21] a) K. Rueck-Braun, Angew. Chem. Int. Ed. 1997, 36, 509-511; b) K. Rueck-Braun, T. Martin, M. Mikulas, Chem. Eur. J. 1999, 5, 1028-1037; c) K. Rueck-Braun, C. Moeller, Chem. Eur. J. 1999, 5, 1038-1044; d) P. Amrhein, D. Schollmeyer, K. Rueck-Braun, Organometallics 2000, 19, 3527-3534; e) C. Moeller, M. Mikulas, F. Wierschem, K. Rueck-Braun, Synlett 2000, 182-184.

[22] J. J. Brunet, M. Taillefer, J. Organomet. Chem., 1988, 361, C1-C4.

[23] J. J. Brunet, M. Taillefer, J. Organomet. Chem., 1990, 384, 193-197.

[24] A. Devasagayaraj, M. L. N. Rao, M. Periasamy, J. Organomet. Chem., 1991, 421, 147-150.

[25] a) A. Devasagayaraj and M. Periasamy, Tetrahedron Lett., 1992, 33, 1227-1228; b) $M$, Periasamy, A. Devasagayaraj, U. Radhakrishnan, Organometallics, 1993, 12, 1424-1428.

[26] M. Periasamy, U. Radhakrishnan, J. J. Brunet, R. Chauvin, A. W. El Zaizi, Chem. Commun., 1996, 1499-1500.

[27] M. Periasamy, M. Beesu, D. S. Raj, J. Organomet. Chem., 2008, 693, 2843-2846.

[28] M. Periasamy, C. Rameshkumar, U. Radhakrishnan, Tetrahedron Lett., 1997, 38, 7229-7232.

[29] C. Rameshkumar and M. Periasamy, Tetrahedron Lett., 2000, 2719-2722.

[30] M. Periasamy, A. Mukkanti, D. S. Raj, Organometallics 2004, 23, 6323-6326.

[31] M. Beesu, M. Periasamy, J. Org. Chem., 2011, 76, 543-549.

[32] K. M. Driller, H. Klein, R. Jackstell, M. Beller, Angew. Chem. Int. Ed., 2009, 48, 6041-6044.

[33] S. Prateeptongkum, K. M. Driller, R. Jackstell, A. Spannenberg, M. Beller, Chem. Eur. J., 2010, 16, 9606-9615.

[34] S. Prateeptongkum, K. M. Driller, R. Jackstell, M. Beller, Chem. Asian J., 2010, 5, 2173-2176.

[35] a) K. M. Driller, S. Prateeptongkum, R. Jackstell, M.Beller, Angew. Chem. Int. Ed., 2011, 50, 537-541; b) M. Pizzetti, A. Russo, E. Petricci, Chem. Eur. J. 2011, 17, 4523-4528.

[36] P. Mathur, R. K. Joshi, D. K. Rai, B. Jha, S. M. Mobin, Dalton Trans., 2012, 41, 5045-5054.

[37] a) N. Iranpoor, H. Firouzabadi, A. Riazi, K. Pedrood, J. Organomet. Chem., 2016, 822, 67-73; b) P. Mathur, R. K. Joshi, B. Jha, A. K. Singh, S. M. Mobin, J. Organomet. Chem. 2010, 695, 2687-2694.

[38] Y. Zhong, W. Han, Chem. Commun., 2014, 50, 3874-3877.

[39] S.-K. Kang, T. Yamaguchi, T.-H. Kim, P.-S. Ho, J. Org. Chem., 1996, 61, 9082-9083.

[40] Y. Fujiwara, K. Tabaki, Y. Taniguchi, Synlett 1996, 591-599.

[41] V. Raab, M. Merz, J. Sundermeyer, J. Mol. Catal. A: Chem., 2001, 175, 51-63.

[42] M. Casiello, A. Monopoli, P. Cotugno, A. Milella, M. M. Dell'Anna, F. Ciminale, A. Nacci, J. Mol. 
Catal. A: Chem., 2014, 381, 99-106.

[43] C. Wang, S. Lei, H. Cao, S. Qiu, J. Liu, H. Deng, C. Yan, J. Org. Chem., 2015, 80, 12725-12732.

[44] S. Lei, Y. Mai, C. Yan, J. Mao, H. Cao, Org. Lett., 2016, 18, 3582-3585.

[45] J-J Wu, Y. Li, H.-Y. Zhou, A-H Wen, C-C Lun, S-Y Yao, Z. Ke, B-H Ye, ACS Catal., 2016, 6, 1263-1267.

[46] G. Shen, L. Zhao, Y. Wang, T. Zhang, RSC Adv., 2016, 6, 78307-78310.

[47] M. Usman, Z-H. Ren, Y-Y. Wang, Z-H. Guan, RSC Adv., 2016, 6, 107542-107546.

[48] C-M. Yu, J-H. Kweon, P-S. Ho, S-C. Kang, G. Y. Lee, Synlett 2005, 2631-2634.

[49] X. Wu, J. Miao, Y. Li, G. Li, H. Ge, Chem. Sci., 2016, 7, 5260-5264. 56 H. Alper, H. des Abbayes, J. Organomet. Chem., 1977, 134, C11-C14.

[50] H. Alper, H. des Abbayes, J. Organomet. Chem., 1977, 134, C11-C14.

[51] H. des Abbayes, A. Buloup, J. Chem. Soc., Chem. Comm., 1978, 1090-1091.

[52] T. Imamoto, T. Kusumoto, M. Yokoyama, Bull. Chem. Soc. Jpn., 1982, 55, 643-644.

[53] F. Francalanci, M. Foa, J. Organomet. Chem., 1982, 232, 59-70.

[54] F. Francalanci, G. Gardano, L. Abis, T. Fiorani, M. Foa, J. Organomet. Chem., 1983, 243, 87-94.

[55] H. Alper, H. Arzoumanian, J. F. Petrignani, M. S. Maldonadob, J. Chem. Soc., Chem. Commun., 1985, 340-341.

[56] R. W. Wegman, D. C. Busby, J. Chem. Soc., Chem. Commun., 1986, 332-333.

[57] T. Kashimura, K. Kudo, S. Mori, N. Sugita, Chem. Lett., 1986, 483-486.

[58] M. Foa, F. Francalanci, E. Bencini, A. Gardano, J. Organomet. Chem., 1985, 285, 293-303.

[59] F. Francalanci, E. Bencini, A. Gardano, M. Vincenti, M. Foa, J. Organomet. Chem., 1986, 301, C27-C30.

[60] H. Alper, S. Calet, Tetrahedron Lett., 1988, 29, 1763-1766.

[61] D. Roberto, H. Alper, J. Am. Chem. Soc., 1989, 111, 7539-7543.

[62] Y. Tsuji, M. Kobayashi, F. Okuda, Y. Watanabe, J. Chem. Soc., Chem. Commun., 1989, 1253-1254.

[63] H. Alper, A. Eisenstat, N. Satyanarayana, J. Am. Chem. Soc., 1990, 112, 7061-7063.

[64] Y. Amino, S. Nishi, K. Izawa, Bull. Chem. Soc. Jpn., 1991, 64, 620-623.

[65] V. V. Grushin, H. Alper, Tetrahedron Lett., 1991, 32, 3349-3352.

[66] H. Urata, D. Goto, T. Fuchikami, Tetrahedron Lett., 1991, 32, 3091-3094.

[67] M. D. Wang, H. Alper, J. Am. Chem. Soc., 1992, 114, 7018-7024.

[68] E. Bolzacchini, S. Meinardi, M. Orlandi, B. Rindone, J. Mol. Catal. A: Chem., 1996, 111, 281-287.

[69] M. E. Piotti, H. Alper, J. Am. Chem. Soc., 1996, 118, 111-116.

[70] C. Zucchi, G. Palyi, V. Galamb, E. Sampar-Szerencses, L. Marko, P. Li, H. Alper, Organometallics 1996, 15, 3222-3231.

[71] J. Lin, J. F. Knifton, Catal. Lett., 1997, 45, 139-141.

[72] J. T. Lee, P. J. Thomas, H. Alper, J. Org. Chem., 2001, 66, 5424-5426.

[73] V. Dragojlovic, D. B. Gao, Y. L. Chow, J. Mol. Catal. A: Chem., 2001, 171, 43-51.

[74] S. N. Goodman, E. N. Jacobsen, Angew. Chem. Int. Ed., 2002, 41, 4703-4705.

[75] H. Xu, L. Jia, Org. Lett., 2003, 5, 1575-1577.

[76] H. Xu, L. Jia, Org. Lett., 2003, 5, 3955-3957.

[77] H. Xu, J. A. Gladding, L. Jia, Inorg. Chim. Acta., 2004, 357, 4024-4028.

[78] G. Liu, L. Jia, J. Am. Chem. Soc., 2004, 126. 14716-14717. 
[79] G. Liu, L. Jia, Angew. Chem. Int. Ed., 2006, 118, 135-137.

[80] J. Chai, G. Liu, K. Chaicharoen, C. Wesdemiotis, L. Jia, Macromolecules 2008, 41, 8980-8985.

[81] J. K. Funk, H. Yennawar, A. Sen, Helv. Chim. Acta., 2006, 89, 1687-1695.

[82] L. J. Chen, J. Bao, F. M. Mei, G. X. Li, Catal. Commun., 2008, 9, 658-663.

[83] Y. P. Jia, Y. N. Cui, J. M. Yin, G. Y. Zhou, S. M. Li, D. B. Gao, X. S. Wang, Chin. Chem. Lett., 2010, 21, 1033-1036.

[84] P. Ganji, D. J. Doyle, H. Ibrahim, Org. Lett., 2011, 13, 3142-3145.

[85] Y. Higuchi, S. Atobe, M. Tanaka, I. Kamiya, T. Yamamoto, A. Nomoto, M. Sonoda, A. Ogawa, Organometallics 2011, 30, 4539-4543.

[86] Y. Higuchi, S. Higashimae, T. Tamai, A. Ogawa, Tetrahedron 2013, 69, 11197-11202.

[87] F. Saliu, B. Putomatti, B. Rindone, Tetrahedron Lett., 2012, 53, 3590-3593.

[88] M. She, D. Xiao, B. Yin, Z. Yang, P. Liu, J. Li, Z. Shi, Tetrahedron 2013, 69, 7264-7268.

[89] Y. Zhang, J. Ji, X. Zhang, S. Lin, Q. Pan, L. Jia, Org. Lett. 2014, 16, 2130-2133.

[90] L. Grigorjeva, O. Daugulis, Org. Lett., 2014, 16, 4688-4690.

[91] J. Ni, J. Li, Z. Fan, A. Zhang, Org. Lett., 2016, 18, 5960-5963.

[92] P. Williamson, A. Galvan, M. J. Gaunt, Chem. Sci., 2017, 8, 2588-2591.

[93] N. Barsu, S. K. Bolli, B. Sundararaju, Chem. Sci., 2017, 8, 2431-2435.

[94] E. J. Corey, L. S. Hegedus, J. Am. Chem. Soc., 1969, 91, 1233-1234.

[95] M. F. Semmelhack, S. J. Brickner, J. Org. Chem., 1981, 46, 1723-1726.

[96] H. Alper, I. Amer, G. Vasapollo, Tetrahedron Lett., 1989, 30, 2615-2616.

[97] H. Alper, G. Vasapollo, Tetrahedron Lett., 1989, 30, 2617-2618.

[98] J. F. Gong, Q. H. Fan, D. Z. Jiang, J. Mol. Catal. A: Chem., 1999, 147, 113-124.

[99] W. R. Moser, B. J. Marshik-Guerts, S. J. Okrasinski, J. Mol. Catal. A: Chem., 1999, 143, 57-69.

[100] W. R. Moser, B. J. Marshik-Guerts, S. J. Okrasinski, J. Mol. Catal. A: Chem., 1999, 143, 71-83.

[101] M. P. Kapoor, Y. Matsumura, Catal. Today, 2004, 93-95, 287-291.

[102] D. del Moral, J. M. Moreto, E. Molins, S. Ricart, Tetrahedron Lett. 2008, 49, 6947-6950.

[103] Q. Wang, C. Chen, Tetrahedron Lett., 2008, 49, 2916-2921.

[104] S. Ogoshi, T. Arai, M. Ohashi, H. Karosawa, Chem. Commun., 2008, 1347-1349.

[105] Y. Jo, J. Ju, J. Choe, K. H. Song, S. Lee, J. Org. Chem., 2009, 74, 6358-6361.

[106] a) D. del Moral, A. M. Banet Osuna, A. Cordoba, J. M. Moreto, J. Veciana, S. Ricart, N. Ventosa, Chem. Commun., 2009, 4723-4725. b) D. del Moral, S. Ricart, J. M. Moreto, Chem. Eur. J., 2010, 16, 9193-9203.

[107] Y. Hoshimoto, T. Ohata, Y. Sasaoka, M. Ohashi, S. Ogoshi, J. Am. Chem. Soc., 2014, 136, 15877-15880.

[108] J. Tjutrins, J. L. Shao, V. Yempally, A. A. Bengali, B. A. Arndtsen, Organometallics 2015, 34, 1802-1805.

[109] J. Hou, M. L. Yuan, J. H. Xie, Q. L. Zhou, Green Chem., 2016, 18, 2981-2984.

[110] M. C. Fu, R. Shang, W. M. Cheng, Y. Fu, ACS Catal., 2016, 6, 2501-2505.

[111] H. Yu, B. Gao, B. Hu, H. Huang, Org. Lett. 2017, 19, 3520-3523 


\section{Curriculum Vitae}

\section{Yahui Li}

Leibniz Institute for Catalysis at the University of Rostock (LIKAT)

Room 2.222, Albert-Einstein-Str. 29a, 18059 Rostock, Germany

Phone: +49(381)1281-187,

Email: Yahui.Li@catalysis.de

\section{- Personals:}

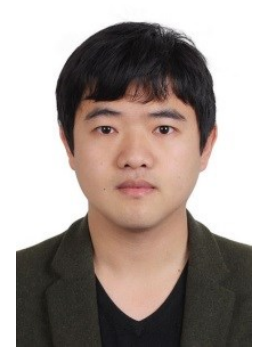

Date of birth: 20. May, 1989

Place of birth: Anhui

Nationality: Chinese

\section{- Education:}

-09/2008-06/2012

Bachelor, Department of Chemistry, Huaibei Normal University, China

09/2012-03/2015

Master, Department of Chemistry, Tongji University, China

10/2015 - present Ph.D. candidate, Leibniz Institute for Catalysis at the University of Rostock, Germany

Supervisor: Prof. Matthias Beller

\section{- Awards:}

- Scholarship from China Scholarship Council (2015)

- Graduate National Scholarship (2014)

- Outstanding Student awarded by Huaibei Normal University (2012)

- National inspirational scholarship (2011)

\section{- $\underline{\text { Relevant Skills: }}$}

- Organic synthesis, Proficient with high-pressure equipment, Skilled in operation of analytical instruments and data analysis

- Skilled in MS Office, Chemdraw, Sci-Finder, Reaxys and NMR analysis

\section{- Publications(Selected):}

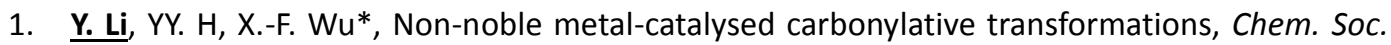
Rev , 2018, 47, 172-194.

2. Y. Li, K. Dong, F. Zhu, Z. Wang, X.-F. Wu*, Copper-Catalysed Carbonylative Coupling of 
Cycloalkanes and Amides, Angew. Chem. Int. Ed. 2016, 55, 7227-7230.

3. Y. Li, F. Zhu, Z. Wang, X.-F. Wu*, Copper-Catalysed Carbonylative Synthesis of Aliphatic Amides from Alkanes and Primary Amines via $\mathrm{C}\left({ }_{\text {sp } 3}\right)-\mathrm{H}$ Bond Activation, ACS Catal. 2016, 5561-5564.

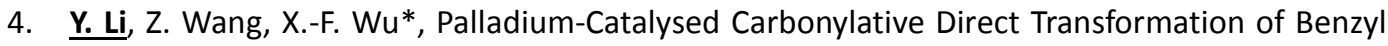
Amines under Additive-Free Conditions, ACS Catal. 2018, 738-741.

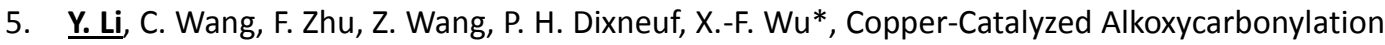
of Alkanes with Alcohols, ChemSusChem 2017, 10, 1341-1345.

6. Y. Li, C. Wang, F. Zhu, Z. Wang, J. Francois Soule, P. H. Dixneuf, X.-F. Wu*, An unexpected copper-catalysed carbonylative acetylation of amines, Chem. Commun. 2017, 53, 142-144.

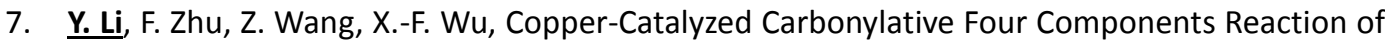
Ethene and Aliphatic Olefins, Chem. Commun. 2018, 54, 1984-1987.

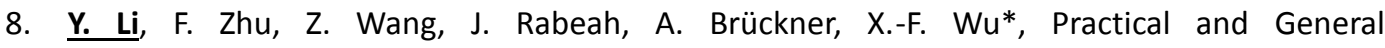
Manganese-Catalysed Carbonylative Coupling of Alkyl lodides with Amides. ChemCatChem, 2017, 9, 915-919.

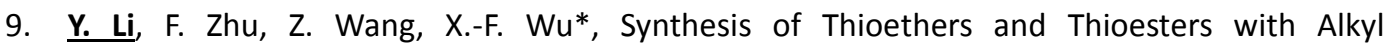
Arylsulfinates as the Sulfenylation Agent under Metal-Free Conditions. Chem. Asian J. 2016, 11,3503-3507.

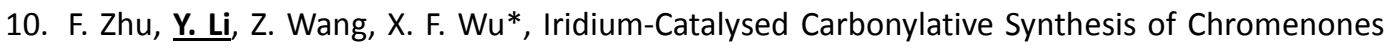
from Simple Phenols and Internal Alkynes at Atmospheric Pressure. Angew. Chem. Int. Ed. 2016, 55, 14151-14154.

11. Z. Wang, Y. Li, F. Zhu, X. F. Wu, Palladium-Catalysed Oxidative Carbonylation of Aromatic C-H Bonds with Alcohols using Molybdenum Hexacarbonyl as the Carbon Monoxide Source. Adv. Synth. Catal. 2016, 358, 2855-2859.

12. F. Zhu, Y. Li, Z. Wang, X. F. Wu, Iridium-Catalysed Carbonylative Synthesis of Halogen-Containing Quinolin-2(1H)-ones from Internal Alkynes and Simple Anilines, Adv. Synth. Catal. 2016, 358, 3350-3354. 


\section{Selbstständigkeitserklärung}


Doktorandinnen/Doktoranden-Erklärung gemäß $§ 4$ Absatz 1 Buchstaben g und $h$ der Promotionsordnung der Mathematisch-Naturwissenschaftlichen Fakultät der Universität Rostock

Name

Li, Yahui

(Name, Vorname)

Anschrift

Albert-Einstein-Str. 29, 18059, Rostock

(Straße, PLZ, Wohnort)

Ich habe eine Dissertation zum Thema

Non-Noble Metal-Catalysed Carbonylative Transformations

an der Mathematisch-Naturwissenschaftlichen Fakultät der Universität Rostock angefertigt. Dabei wurde ich von Frau/Herrn

Prof. Dr. Matthias Beller

betreut.

Ich gebe folgende Erklärung ab:

1. Die Gelegenheit zum vorliegenden Promotionsvorhaben ist mir nicht kommerziell vermittelt worden. Insbesondere habe ich keine Organisation eingeschaltet, die gegen Entgelt Betreuerinnen/Betreuer für die Anfertigung von Dissertationen sucht oder die mir obliegenden Pflichten hinsichtlich der Prüfungsleistungen für mich ganz oder teilweise erledigt.

2. Ich versichere hiermit an Eides statt, dass ich die vorliegende Arbeit selbstständig angefertigt und ohne fremde Hilfe verfasst habe. Dazu habe ich keine außer den von mir angegebenen Hilfsmitteln und Quellen verwendet und die den benutzten Werken inhaltlich und wörtlich entnommenen Stellen habe ich als solche kenntlich gemacht.

Rostock, den 